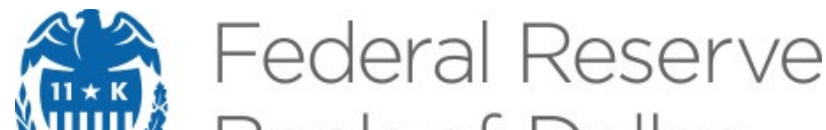 Bank of Dallas
}

\section{Quantifying Risks to Sovereign Market Access: Methods and Challenges}

Diana Zigraiova, Aitor Erce and Xu Jiang

\section{Globalization Institute Working Paper 377}

Research Department

https://doi.org/10.24149/gwp377

Working papers from the Federal Reserve Bank of Dallas are preliminary drafts circulated for professional comment. The views in this paper are those of the authors and do not necessarily reflect the views of the Federal Reserve Bank of Dallas or the Federal Reserve System. Any errors or omissions are the responsibility of the authors. 


\title{
Quantifying Risks to Sovereign Market Access: Methods and Challenges ${ }^{*}$
}

\author{
Diana Zigraiova ${ }^{\dagger}$, Aitor Erce $^{\ddagger}$ and Xu Jiang ${ }^{\S}$
}

January 2020

\begin{abstract}
In this paper we use data from the euro area to study episodes when sovereigns lose market access. We construct a detailed dataset with potential indicators of market access tensions, and evaluate their ability to forecast episodes when market access is lost, using various econometric approaches. We find that factors associated with high market access tensions are not limited to financial markets, but also encompass developments in global demand, macroeconomic conditions and the fiscal stance. Using the top-performing indicators, we construct a number of market tension indices and use them as single predictors of market access tensions. While such indices are helpful in capturing worsening conditions, they do not yield satisfactory out-of-sample results. On the other hand, using the same top-performing indicators in various multivariate models generates good forecasts of upcoming difficulties in accessing sovereign bond markets. Our results thus point to a trade-off between communicability and accuracy that policymakers face in the search for tools to evaluate risks to market access.
\end{abstract}

Keywords: Euro area sovereign bond market; forecasting; sovereign debt crises; sovereign market access; variable selection

JEL codes: C53, G01, G15

\footnotetext{
*We thank Jaroslav Baran, Anastasia Guscina, Carlos Martins, Jacques Netzer, Stephanie Pamies, Markus Rodlauer, Rolf Strauch, Sheetal Tewari and seminar participants at the IMF workshop on "Fiscal Policies in a Challenging World" and the European Stability Mechanism for their suggestions. We are grateful to the European Stability Mechanism's Investment and Funding teams, who provided us with two separate detailed lists of market indicators to be tracked. Disclaimer: This paper does not develop an operational methodology for determining market access for evaluating eligibility for precautionary financing by the European Stability Mechanism. All the views presented in this paper are the authors' and not those of the institutions the authors are affiliated with, the Federal Reserve Bank of Dallas or the Federal Reserve System.

${ }^{\dagger}$ Corresponding author: Diana Zigraiova, European Stability Mechanism and Charles University, d.zigraiova@esm.europa.eu.

${ }^{\ddagger}$ Aitor Erce, European Investment Bank and European University Institute.

$\S$ Xu Jiang, European Stability Mechanism.
} 


\section{Introduction}

The lack of a central bank explicitly playing the role of lender-of-last-resort for governments, combined with the magnitude of public debt stocks, had two negative consequences that exacerbated the euro area crisis. First, markets for government bonds lacked a stabilizing tool against the ongoing liquidity runs, and this triggered a recessionary tightening of financing conditions. Second, domestic banks were induced to become lenders of last resort, setting the stage for destabilising doom-loops that reinforced the effect of the worsening financing conditions. Such extreme tensions in deep and highly liquid public bond markets caught most by surprise (Casalinho et al. 2016). ${ }^{1}$

While the theoretical literature is large, there is just a handful of papers that have focused on understanding empirically what drives tensions in euro area public bond markets. A consequence of this is that, as recently acknowledged by the International Monetary Fund in its 2018 Review of Conditionality (ROC, 2018), existing policy tools for detecting sovereign debt crises and risks to market access were designed for countries with critically different public debt markets than those in more advanced economies - where markets are deeper, more liquid, and debt is mostly denominated in the local currency. In fact, while Greece has become the poster child for the potentially devastating effects of losing the confidence of market creditors, there is still a lack of analytical understanding on how to predict an episode of a sovereign losing access to its domestic bond market. ${ }^{2}$ This paper contributes to filling this analytical gap.

De Broeck \& Guscina (2011) study the effect of the global crisis on issuance strategies of advanced economy sovereigns. They document a deviation away from plain-vanilla bond issuance, especially in countries with high deficits and high debt levels. Bassanetti, Cottarelli \& Presbitero (2016) study the role of debt flows for understanding market access. Fisher (2012) discusses the importance of understanding the drivers of demand for public debt. Casalinho et al. (2016) review the experience of Ireland, Portugal, Cyprus and Spain in re-accessing the market after their official programs ended. Schalck (2017) estimates reaction functions to identify shifts in the behaviour of public debt managers, and shows that, following the crisis, France's funding strategy shifted towards cost minimisation. Guscina, Malik \& Papaioannou (2017) provide an operational definition of loss of market access (LMA) and examine the predictive capacity of potential leading indicators of LMA. ${ }^{3}$ One lesson from the literature and from our discussions with bond traders is that market access depends on a host of factors and, depending on the information available, can be assessed in a variety of ways.

In this paper we contribute to this literature in at least two fronts. First, using a selected set of indicators chosen by two teams of financial market participants (experts on primary and secondary markets) and a thorough reading of the academic literature, we construct an extensive and detailed dataset of potential leading indicators of market access tensions. Second, we evaluate these selected indicators systematically, using a variety of univariate and multivariate econometric frameworks. We use univariate analysis to select the best indicators from our rich dataset. While forward rate difference from the best performer emerged as the most important predictor of market access tensions, we find that factors associated with high market access tensions are not limited to financial markets, but also encompass developments in global demand, macroeconomic factors and the fiscal stance.

\footnotetext{
${ }^{1}$ The ample literature studying public debt auctions in advanced economies does not consider LMA episodes (Sigaux 2018 or Belton et al. 2018). Sovereign loss of market access has traditionally been focused on emerging countries (Gelos et al. 2004).

2 The IMF is revising its debt sustainability analysis for countries with market access after its failure to predict the euro area crisis.

${ }^{3}$ For analyses of euro area public bond markets not considering market access risks see Eidam (2017) or Beetsma et al. (2018).
} 
We propose an easy-to-construct and transparent index summarising the set of best indicators of market access tensions, and use it to understand the driving forces of past episodes of market access tensions. We also use a variety of econometric methods to predict future tensions to market access. We show that multivariate methods perform better than the univariate index. We also show that models allowing for endogenous selection of explanatory variables perform better in terms of detecting increased market access tensions, although that may come at the cost of more false alarms.

The rest of this paper is organized as follows: Section 2 provides our definition of episodes when sovereigns lose market access. Section 3 lists those primary market, secondary market and demand and supply side indicators that can be useful in capturing high market access tensions. Section 4 summarizes our data collection and variable transformations, yielding an extensive set of potentially useful indicators of market access tensions. Section 5 applies a univariate evaluation and identifies those indicators that are the most useful for signalling upcoming loss of market access (LMA) episodes. Section 6 builds our market access tensions indices. Section 7 presents the methodology, evaluates the performance of different econometric approaches and compares their performance out of sample. Section 8 analyses usefulness of our framework for policymakers with asymmetric preferences and Section 9 checks robustness of our baseline results.

\section{Defining episodes of high sovereign bond market tensions}

When countries effectively lose market access, they either default or ask for official support. Thus, one straightforward way to determine whether a country suffered a loss of market access (LMA) is to check whether the country announced a debt restructuring or requested concessional support from official lenders (Gelos et al. 2004). Things get more complicated when one wants to determine episodes in which market access conditions became more difficult. In this case, countries may have continued to access bond markets for financing, but the conditions on which they did so were hard to sustain in the long run. According to Guscina, Malik and Papaioannou (2017) an assessment of whether a sovereign continues to have market access would be based on whether the sovereign can tap bond markets on a sustained basis, across a range of maturities (in both local and foreign currencies) at interest rates compatible with reasonable medium-term growth rates and an achievable primary fiscal position. More precisely, Guscina, Malik and Papaioannou (2017) employ a decision rule according to which they identify periods associated with default or restructuring as LMA. They further identify as suspect LMA episodes periods in which issuance deviates from its established pattern. ${ }^{4}$ Aloong these lines, we define periods of high sovereign bond market tensions using the union of the following three definitions of loss of market access:

I. ESM/IMF program dates

II. Periods identified by Guscina, Malik \& Papaioannou (2017)

III. Periods when 10 -year spread to Germany is above the $90^{\text {th }}$ percentile of the spread distribution for the full sample, which corresponds approximately to 350 basis points ${ }^{5}$

\footnotetext{
${ }^{4}$ To confirm whether the identified suspect LMA cases are indeed LMA, they further investigate explanations for lack of issuance such as lack of funding needs and prefunding.

${ }^{5}$ The chosen level threshold corresponds to 92.7 percentile of the spread distribution, which indicates spread levels beyond 350 basis points fall into extreme values of the distribution and could be understood as market tensions. We also tried with a country specific approach, as in Baldacci et al. (2011). We used two standard deviations above a country's historical rolling average of the spread as our definition. In Figure A5 in the appendix, we show that this approach delivers distress episodes even for countries which clearly did not experience any, such as Austria or Netherlands.
} 
We mark the start of a LMA event in our dataset by whichever event from the three definitions materialized first. For Greece and Ireland, all three definitions materialized simultaneously in 2010. According to the above definitions, since 2000 Q1 there have been LMA episodes in 9 euro area countries. Starting dates by definition are shown in Table $1 .{ }^{6}$

Given our interest in forecasting sovereign bond market tensions up to one year ahead, we transform our LMA variable into a pre-LMA dummy the following way. We create a dummy to which we assign a " 1 " in the four quarters preceding LMA episodes and we assign a value 0 in the remaining periods. In addition, we exclude high market access tension periods and four quarters following these periods from our analysis to avoid post-crisis bias (Bussiere \& Fratzscher, 2006). In a robustness exercise, we also perform the analysis excluding episodes identified using the spread level.

Table 1: Start of LMA episodes

\begin{tabular}{|c|c|c|c|}
\hline COUNTRY & ESM/IMF PROGRAM & GUSCINA ET AL. (2017) & SPREAD LEVEL \\
\hline \multicolumn{4}{|l|}{ AUSTRIA } \\
\hline \multicolumn{4}{|l|}{ BELGIUM } \\
\hline CYPRUS & 2012 Q2 & 2013 Q2 & 2016 Q1 \\
\hline \multicolumn{4}{|l|}{ GERMANY } \\
\hline \multicolumn{4}{|l|}{ ESTONIA } \\
\hline SPAIN & 2012 Q3 & & 2011 Q4 \\
\hline \multicolumn{4}{|l|}{ FINLAND } \\
\hline \multicolumn{4}{|l|}{ FRANCE } \\
\hline GREECE & 2010 Q2 & 2010 Q2; 2014 Q4 & 2010 Q2 \\
\hline IRELAND & 2010 Q4 & 2010 Q4 & 2010 Q4 \\
\hline ITALY & & & $2011 Q 4 ; 2012 Q^{37}$ \\
\hline LITHUANIA & & & 2008 Q4 \\
\hline \multicolumn{4}{|l|}{ LUXEMBOURG } \\
\hline LATVIA & 2008 Q4 & 2008 Q4 & \\
\hline \multicolumn{4}{|l|}{ MALTA } \\
\hline \multicolumn{4}{|l|}{ NETHERLANDS } \\
\hline PORTUGAL & 2011 Q2 & 2011 Q2 & 2010 Q4; 2017 Q1 \\
\hline SLOVENIA & & & 2013 Q1 \\
\hline SLOVAKIA & & & \\
\hline
\end{tabular}

\section{Universe of sovereign bond market tension indicators}

For a sovereign to lose market access, it must be the case that it finds no adequate demand for its debt supply. For that reason, the framework places a lot of weight into understanding future demand and future supply. We categorize information into buckets reflecting both the different potential sources of information and the need to identify supply and demand drivers.

Given the relevance of bond markets for sovereign financing, the use of market data is critical. One block of information focuses on primary markets data, and another block on secondary markets data. Market data provides information about countries' fundamental and liquidity risks in the timeliest

\footnotetext{
${ }^{6}$ Figure $A 3$ in the Appendix provides an overview of LMA episodes by country and definition.

${ }^{7}$ An additional metric could be the presence of extensive support from the Central Bank. Using such logic, for Italy we can define start of an LMA episode the quarter of Draghi's "Whatever it takes" speech. In robustness checks we remove this event.
} 
manner, and is available with high frequency. To further enhance the framework's ability to understand future demand and supply dynamics, the third block collects potential demand and supply drivers through the use of other macroeconomic, global and geopolitical variables.

\subsection{Preferred primary market indicators}

Maturity at issuance: generally, a decline in the average maturity at issuance in a short period of time may signal the increasing difficulty to fund in the sovereign markets. The maturity at issuance is a result of an intertemporal trade-off between the lower costs of holding short-term debt against the likelihood of a debt roll-over crisis, owing to an unexpected surge in repayment risks (Broner et al, 2013). The cost-risk trade-off usually translates into issuance across the maturity spectrum (Abbas, et al, 2014). Therefore, excessive reliance on short-term debt may expose the government to volatile and potentially increasing debt costs if financial market conditions tighten quickly.

Share of bill financing: a sudden shift to bill issuance may signal that the treasury finds it increasingly difficult to finance through medium- and long-term bonds given the size of gross financing needs. During the European debt crisis, the share of bill issuance temporarily increased in larger issuers, such as Germany, France and Italy, and was the only instrument issued by most countries that entered an EFSF/ESM financial assistance programme.

Issuance patterns: shifting away from the standard funding practices - competitive auctions of debt instruments with a fixed coupon, long maturities, and local currency denomination may reflect changes in macroeconomic conditions and investor sentiment (De Broeck \& Guscina 2011), such as a manifestation of structural shifts in fiscal policy imperatives and sovereign borrowing needs, currency regimes, financial market architecture, and financial market conditions (Abbas, et al, 2014). Nevertheless, bonds with various currencies and coupon features can be helpful to expand and maintain the investor base and diversify funding sources. ${ }^{8}$

Distribution methods (syndications and private placements): the aim of syndications is to issue new benchmarks and/or raise relatively larger amounts. Their use may reflect the quality of market access of the issuers. De Broeck \& Guscina (2011) documented that the 2007-2008 financial crisis led to an increasing use of syndications as a distribution method in a number of euro area countries, such as Greece, Cyprus, Belgium, Finland, and so on. In an ideal situation, an analysis of the investor base in these transactions and of the new issue premium the treasuries pay would help to evaluate the quality of market access. Private placements can be tailor-made to meet the needs of specific types of investors and to maintain the investor base. This distribution method is only occasionally used in some small issuers (such as Cyprus and Ireland) and not utilized in countries with solid market access (Germany).

Pace of issuance relative to targets: a slower-than-usual issuance pace may reflect the increased difficulty of placing bonds in the prevailing market conditions.

Auction frequency: treasuries usually have a pre-determined funding schedule. Changes in auction frequency may be used to meet structural/temporary variations in funding needs. A marked deviation from the usual pattern, either an increase or decrease of the number of auctions, may hint at weakened market access. De Broeck \& Guscina (2011) documented an increased number of auctions in almost all

\footnotetext{
8 Portugal is an example of increased use of floating coupon bonds in the run-up to LMA in 2010 Q4. In November 2010 Portugal issued 10-year floating coupon bonds at more than $6 \%$ despite the total size was small - below $€ 500$ million. Shortly after, in February 2011, the issuance of a fixed coupon bond at $6.4 \%$ was deemed an unsustainable funding cost, triggering the formal request for an official program.
} 
euro area countries during the European debt crisis compared to pre-crisis periods as a result of elevated gross financing needs.

Auction volume: treasuries usually come to markets with a pre-determined schedule for their bond auctions. A deviation from the usual pattern, either an increase or decrease of the accepted volume of auctions, can be a warning sign.

Auction tail: it is the difference between the accepted average and minimum prices, or the difference between average and maximum accepted yields. A large auction tail in general is not a good sign, as the marginal buyer is only willing to pay a lower price than the average for additional allotment. ${ }^{9}$ But this measure can be noisy (auction tails can be large because of a few aggressive bidders).

Auction overbidding: it is the difference between the average price at which a bond is sold at an auction and the market price of that bond at the auction bidding deadline. If the auctioned price is higher than the prevailing market price at bidding deadline, there is overbidding; in the opposite case, there is underbidding. In general, the higher the overbidding vs prior auctions, the stronger an auction is deemed to be.

New issue premium: this measures the difference between primary accepted prices and secondary fair prices. Generally, higher new issue premium means the treasuries will need to pay more given a desirable amount of new issues. But the estimation of fair value is model specific and it is hard to compile historical data on it across countries based on public information.

Auction cycle/Concession: Secondary market yields rise preceding auctions and decline afterwards. This affects the cost of the auctions in the primary market and they may provide an indication of the potential roll-over risk associated with the public debt (Beetsma et al., 2018). Typically, a rise in secondary yields before an auction signals good demand for that auction.

Auction cancellation/delay: auction cancellation can be a result of a pre-funding (e.g. end of year cancellations) and an auction can be delayed in order to avoid heightened market volatilities.

Bid-to-cover ratio: this measures over-subscription from investors (demand) relative to supply. Generally, the higher it is, the better the auction. Beetsma et al. (2018) find that more successful auctions of euro area public debt, as captured by higher bid-to-cover ratios, lead to lower secondarymarket yields following the auctions. However, the reliability of this indicator is debatable: (1) bid-tocover ratios can be inflated due to market design (the way auctions are organized); (2) when a treasury issue several bonds in a day, it can play with the allotment, making individual bid-to-cover less reliable.

Auction allotment relative to indicative targets: this compares actual allotment to targeted size or range. Treasuries face a trade-off between announcing a high target, which increases the chance that a given auction fails and yields are driven up, and announcing a low target, which forces them to more frequently organize auctions, and incur the associated costs and risks (Beetsma et al., 2018). If the issuer does not receive enough bids to cover the desirable allotment, it is a sign of weak demand. If the increase in size results in weaker pricing, it is likely the issuer is attempting to 'stuff' the market.

Ratio of non-competitive allotment to total accepted amount: generally, a certain percentage of competitive allotment is made available for (selected) primary dealers to submit non-competitive bids within a short time window, such as one day or two. Presumably, the higher the ratio is, the stronger

\footnotetext{
${ }^{9}$ Some auctions are run as "Dutch auctions" in which uniform price is applied, and therefore no auction tails are observed.
} 
the investor demand, as primary dealers could not buy sufficiently either in the auctions and/or from the prevailing secondary markets.

\subsection{Preferred secondary market indicators}

Yield curve: Using yields of short- and long-term maturities, we can construct the yield curve of interest rates. A rapid increase in the short-term rates relative to long-term ones, resulting in a flat or an inverted curve, generally signals elevated near-term risks. Estrella \& Mishkin (1998), Bordo \& Haubrich (2008) and Gerlach \& Stuart (2018), among others, show that slope of the yield curve has predictive power for US growth ${ }^{10}$. The yield curve also affects the maturity of debt a government will choose to supply. In times of rising short-term rates, a country will likely issue debt over longer maturities and vice versa (Broner \& Lorenzoni).

Spreads of sovereign bond yields: sovereign spreads are the most widely used measures in the academia and markets, and are typically monitored to evaluate the overall risk premium emerging from credit, liquidity and political uncertainties (Guscina, Malik \& Papaioannou, 2017). Typically, a sharp increase in sovereign yield levels and spreads indicates an increased sovereign stress as investors demand extra premium to hold such securities. This will lead to the shortening of debt maturity issued by the sovereign (Arellano \& Ramanarayanan, 2012).

Bid-ask spreads: the bid-ask spread measures the costs of hypothetically carrying out small round trip trades. Basically, it informs the market participant how much one needs to pay to buy one security and immediately sell it back (in the secondary market). Generally, a higher level of bid-ask spreads indicates a relatively high degree of illiquidity. Bid-ask spreads capture a price dimension, rather than a quantity dimension, of market liquidity. ${ }^{11}$

CDS prices: a sovereign CDS contract provides protection against the default of the underlying sovereign. A sharp increase in CDS prices generally signals the increased risk of sovereign default (Guscina, Malik \& Papaioannou, 2017). 5-year Senior USD CDS is arguably the most liquid and mostly traded CDS instrument in the markets. ${ }^{12}$

Trading volume: the level of trading volume in a security or its turnover (volume divided by the outstanding amount of that security) is used as an indicator of market liquidity of a sovereign bond. Trading volume tends to increase when new information reaches the market, typically a time of higher market volatility and concomitantly wide bid-ask spreads. Therefore, turnover can be high when trading costs increase (i.e. if there is turmoil around political elections).

Bond forwards: periods of high expected yield represent increased costs for future government debt issuance. In order to optimize costs, a country will likely increase its debt supply in immediate future and as such prefund for the upcoming periods of increased costs. To capture this effect, one can collect forward rates of the 10-year bonds in three months' time and calculate forward premium/discount as the difference between the forward rate and current ten-year yield, as well as difference between this forward rate and the benchmark rate, which during our sample period is the best performer's ten-year forward rate.

\footnotetext{
10 Estrella \& Hardouvelis (1991) argue that the slope of the yield curve has extra predictive power over the index of leading indicators, real short-term interest rates, lagged growth in economic activity, and lagged rates of inflation.

11 The size of bid-ask spreads is structurally different among countries, reflecting variations in the depth and market design.

12 The spread between USD and euro-denominated CDS prices and different vintages of CDS contracts, if data are available, can potentially be used as a measure of redenomination risk.
} 
Investor base: monitoring investor holdings by residence and sector helps to assess sovereign market access from a complementary angle. Evidence shows that the changing dynamics in sectoral investor base is associated with sovereign yield dynamics (Arslanalp \& Poghosyan 2014, Hauner \& Kumar 2006, Jaramillo \& Zhang 2013). A rapid sell-off by foreign investors is often an underlying driver of sharp pickup in yields and spreads, which can quickly jeopardize a sovereign's market access.

\subsection{Other demand and supply factors}

Growth outlook: We aim to capture this using GDP growth and growth expectations. Alesina et al. 1992) and Bernoth et al., (2004) argued that sovereign debt becomes riskier during periods of economic slowdown. Therefore, an increase (reduction) in growth performance is assumed to improve (deteriorate) creditworthiness.

Risk aversion: We approximate investor risk aversion by means of the VIX index and its European equivalent, the V2X index. Since these indices capture expected future market volatility, they can be used as a proxy for appetite of investors for safe assets, i.e. sovereign bonds, given the flight to quality phenomenon (Baur and Lucey, 2009). We additionally include the MOVE index, the US Treasury option implied volatility index produced by Merrill Lynch. The MOVE index can thus serve as a proxy for investor appetite for other safe assets, such as non-US government bonds.

Sentiment and uncertainty: To account for investor sentiment and uncertainty perceptions vis-à-vis a country's economic policy, we use the European Commission' sentiment index ${ }^{13}$ (Gelper and Croux, 2009) as well as the Economic Policy Uncertainty index (Baker et al, 2016).

Expected financing needs: In principle, countries with larger financing needs will be more dependent on bond markets. Beyond a certain level, the larger this future supply, the more jittery markets become. In order to operationalize this concept, we put together information regarding expected deficits and refinancing needs. ${ }^{14}$ This flow measure should provide more information, compared to the stock measure, on a sovereign's likelihood of distress (Gabriele et al, 2017).

Future redemptions profile: Countries with large amounts of maturing debt have greater funding needs and potentially are at risk of not meeting them via debt issuance. This will probably lead to heightened roll-over risks, which are higher when the maturity profile is concentrated on or around a particular maturity and when the maturity profile is short with large individual redemptions (Jonasson and Papaioannou, 2018). We capture amounts of maturing debt over the following three years as share of total maturing debt over the next ten years, as well as debt maturing in the medium term (four to six years) and in the long term (eight to ten years).

Bank CDS and public bailouts (contingent liabilities): this captures implicit liabilities materializing in adverse scenarios. Following bank crises, contingent liabilities from the banking sector could be a significant determinant of sovereign risk (Arslanalp and Liao, 2014). We collect data on bank bailouts by governments and CDS prices of banks active within a country. These indicators capture government costs related to domestic banks' distress and represent an additional funding need for a country.

\footnotetext{
${ }^{13}$ Available at: https://ec.europa.eu/info/business-economy-euro/indicators-statistics/economic-databases/business-andconsumer-surveys en

${ }^{14}$ We approximate a country's expected financing needs over the next year as the sum of the expected deficit for that year (we assume it is the same as the current year's deficit) and future debt redemptions over the same year.
} 
Banking sector index: a country-level index measuring the performance of average banking equity prices weighted by market capitalization on the same day. Generally, increases in the index indicate positive investor sentiment towards that country's banking sector. Sovereign and banking distress feed into each other, with balance sheet interconnections, credit dynamics, financial openness and economic growth being important ((Erce and Balteanu 2017, Del'Ariccia et al. 2018).

Stock market index: the performance of the stock market informs about investor sentiment on the state of the economy. Generally, increases in stock market indices signal positive investor sentiment. Also, volatilities in stock markets can be related to variations in the underlying macroeconomic factors, such as GDP growth, inflation and short-term interest rates (Engel and Rangel, 2007).

Cash position: indicative of a sovereign's need for financing through debt markets. Large cash or liquidity reserves lower the need for a government to issue debt. Sovereign debt managers view a liquidity buffer as an effective tool to address re-financing risk and liquidity risk that may arise for reasons such as unexpected increases in borrowing needs, short-term mismatches in fiscal cash flows or the temporary loss of market access (OECD, 2018).

Fiscal outlook: Indicators capturing fiscal position, debt/GDP and deficit/GDP, provide a picture of how much a country will need to raise to finance its position. Projections of key fiscal variables should help to inform the fiscal sustainability risks associated with a government's possible inability to roll over its outstanding stock of debts (Baldacci et al. 2011).

Shocks to foreign investors: Negative shocks to a government's bondholders adversely affect their demand for government bonds. We proxy these shocks using GDP growth in large countries. Therefore we assume that if there is a negative output shock, their shares of debt holdings will increase.

\section{Collecting and transforming the data}

We collected 48 raw underlying indicators, listed in Table 2, from primary and secondary markets, capturing global demand and government supply, for 19 euro area countries. We generated transformations of these indicators to capture proportions on debt issuance, share of GDP, moving averages over one and two years, differences to these moving averages, standard deviation and skewness of selected indicators over moving one-year horizon, as well as per current period, year-onyear differences, and differences compared to Germany and the best performing country. The transformations yielded 242 variables altogether.

Several indicators such as bid-to-cover ratios, PMI, Italian futures rate, the forecast of fiscal balance as share of GDP, and forecast of general government structural balance as a percent of potential GDP suffer from serious data limitations in the form of either short time series or restricted availability across countries. Thus, we exclude them from further analysis. We also exclude yield spreads to Germany on 6-month T-bills, 2-year, 5-year and 10-year sovereign bonds since these overlap with our definition of LMA episodes. We also eliminate Cyprus, Estonia, Malta, Lithuania and Luxembourg due to significant data limitations across indicators from primary and secondary markets, global demand and government supply side. All the indicators and their transformations were lagged by one quarter to account for data publication lags. 
Table 2. Underlying data and sources

1. Bid-to-cover on 6-month government bills

Bloomberg

2. Bid-to-cover on 10-year government bonds

Bloomberg

3. Syndicated issuance

Dealogic

4. Foreign currency issuance

Dealogic

5. Floating coupon issuance

Dealogic

6. Inflation-linked issuance

Dealogic

7. Volume issued

Dealogic

8. Number of issuances

Dealogic

9. Yield to maturity

Dealogic

10. Years to maturity

Dealogic

11. Bills issued

12. Domestic long-term fixed-coupon issuance

ECB SDW, Bloomberg, Own

calculations

Dealogic

13. Slope of the yield curve

14. 10-year forward rate in 3 months' time

15. Bid-ask spread on 2-, 5- and 10-year bonds and 6-month T-bills

16. Spread to Germany on 6-month bills, 2-, 5- and 10-year bonds

17. CDS rate

18. Foreign debt holdings

19. Economic sentiment index

20. GDP

21. GDP of US and China

22. VIX

23. $V 2 X$

24. MOVE

25. PMI-Purchasing managers' index

26. German, Italian futures rate

27. European economic policy uncertainty index

28. GDP year-on-year change, forecast

29. Interest expense as percent of GDP, forecast

30. Gross debt as percent of GDP, forecast

31. Primary balance as percent of GDP, forecast

32. Deficit as percent of GDP, forecast

33. General government structural balance as percent of potential GDP, forecast

34. Fiscal balance as share of GDP, forecast 1-year ahead

35. Systemic crisis dummy

36. Deficit

37. Debt

38. Government expenditure

Bloomberg and Haver Bloomberg

Bloomberg, Own calculations

Bloomberg, Own calculations

Bloomberg and Datastream IMF, Bruegel, and Haver

Haver

Haver

Bloomberg

Bloomberg

Bloomberg

Bloomberg

Bloomberg

Bloomberg

Haver

WEO, Own calculations

AMECO EC, Own calculations

AMECO EC. Own calculations AMECO EC. Own calculations

AMECO EC, Own calculations

WEO

Haver, Own calculations Lo Duca et al. (2017)

ECB SDW

Haver

Haver

39. Cash balances

Eurostat

40. Primary balance

Haver 
43. Bank equity index weighted by market capitalization

44. Stock market index calculations

45. Bank bailouts

Adding normalized transformations. To increase the ability of our indicators to predict market distress, we also built transformations comparing indicator dynamics to either country-specific history or against-peers at a point in time. We also add normalized forms of the indicators and their transformations both within and across countries. We based the normalization of individual indicators on comments from ESM Funding and Investment teams, reading of the relevant literature and the indicators' dynamics. ${ }^{15}$

After extending the set of indicators and their transformations with their normalized transformations both by country and across countries, the final dataset comprises 657 indicators altogether.

\section{Univariate (signalling) analysis of indicators}

To identify indicators most suitable for signalling increased sovereign bond market tensions, we evaluate the usefulness of all the collected indicators individually. For this purpose we employ signalling analysis as well as calculate area under receiver operating characteristic curve (AUROC) on data until 2011 Q2. The data after this point we reserve for out-of-sample testing.

In the signalling approach, a warning signal is issued when an indicator exceeds a threshold, which we define by a particular percentile of an indicator's own cross-country distribution. This approach assumes an extreme non-linear relationship between the indicator and the event to be predicted. Each quarter for each indicator falls into one of the four quadrants of the matrix below.

Table 3: Classification matrix

\begin{tabular}{|c|c|c|}
\hline & Loss of market access & No loss of market access \\
\hline Signal issued & True positive & False positive (False alarm) \\
\hline No signal issued & False negative (Missed event) & True negative \\
\hline
\end{tabular}

Missed events rate (Type I) error can be obtained by dividing the number of missed events by the number of periods in which sovereign bond market tensions were high:

$$
\text { Type } I=\frac{\sum \text { False negative }}{\sum \text { False negative }+\sum \text { True positive }}
$$

\footnotetext{
15 Normalization results in loss of observations for some indicators where we choose to stress country-specific dynamics. Floating coupon issuance share and foreign currency issuance share are examples of such indicators. These indicators manifest zero variance until 2011 Q2. To preserve as many observations as possible, we do not normalize indicators with zero variance.
} 
False alarm rate (Type II error) can be calculated by dividing the number of false alarms by the number of periods in which there were no high sovereign bond market tensions:

$$
\text { Type II }=\frac{\sum \text { False positive }}{\sum \text { False positive }+\sum \text { True negative }}
$$

Following Alessi and Detken (2011) we calculate the overall utility of each indicator using the function:

$$
\begin{gathered}
\mathrm{U}=\min (\theta ; 1-\theta)-\theta \frac{F N}{(F N+T P)}+(1-\theta) \frac{F P}{(F P+T N)^{\prime}}, \text { where } \\
L=\theta \frac{F N}{(F N+T P)}+(1-\theta) \frac{F P}{(F P+T N)^{\prime}}
\end{gathered}
$$

where FN, FP, TP and TN stand for false negative, false positive, true positive and true negative, respectively. $L$ stands for loss function of the policymaker, which combines both error types as well as her relative risk aversion between Type I and Type II errors. A $\theta$ lower than 0.5 shows that the policymaker is less averse towards missing a signal for high sovereign market tensions than towards receiving a false alarm. A policymaker can always realize a loss of $\min (\theta ; 1-\theta)$ by not accounting for an indicator. If $\theta$ is smaller than 0.5 , the benchmark is obtained by ignoring the indicator, which means there will be no signal issued so that TP $=F P=0$. The resulting loss according to the utility function is $\theta$. If $\theta$ exceeds 0.5 , the benchmark is assuming there are costly sovereign bond market tensions developing, i.e. assuming a signal is always issued so that $\mathrm{FN}=\mathrm{TN}=0$. The resulting loss is $1-\theta$. An indicator is then useful to the extent that it produces a loss lower than $\min (\theta ; 1-\theta)$ for a given $\theta$.

We search for the value threshold of each indicator which maximizes the utility function (3), given that we assume neutral policymaker preferences between both error types (i.e. $\theta=0.5$ ).

In addition to the signalling analysis of individual indicators, we calculate for each indicator the area under the ROC curve (AUROC) whose use is advocated in the context of evaluating the performance of early warning models by e.g. Candelon et al. (2012). The ROC curve plots a false positive rate (number of false positives over the number of all negative sample periods) against a true positive rate (number of true positives over the number of all positive sample periods) for individual threshold values of an indicator. The best possible prediction would yield a point in the upper left corner (point $(0,1)$ ) of the ROC space, which indicates a $100 \%$ true positive rate and a $0 \%$ false positive rate. This point is called the perfect classification point. A random guess would give a point along a diagonal line (line of nodiscrimination) from the left bottom to the top right corner. The diagonal divides the ROC space as follows: points above the diagonal represent good classification results (better than random); points below the line represent bad results (worse than random). The area under the diagonal equals 0.5 , thus AUROC greater than 0.5 shows an indicator is useful, i.e. it gives better than random results.

The AUROC is greater than 0.5 for 468 indicators (out of 657), indicating better than random performance for predicting high bond market tensions over the 4-quarter forecasting horizon:

- Among primary market indicators, the difference in country-specific normalization of changes in an 8-quarter moving average of the number of issuances is the most useful indicator over the 4-quarter forecast horizon, with the highest AUROC of 0.82 and maximum utility of 0.29 .

- From among secondary market variables, the most useful predictor is the cross-country normalization of difference of 10-year forward rate from the best performing country in the given year-quarter, with AUROC of 0.916 and maximum utility of 0.386 . The second most useful indicator is the cross-country normalization of the forward premium (difference between long- 
term forward rate and the spot yield on bonds of the same maturity), which yields AUROC of 0.85 and maximum utility of 0.30 .

- From our demand indicators, year-on-year difference in forecast of interest expense two years ahead (as a share on GDP) is most useful. Its AUROC is 0.78 and maximum utility is 0.30 .

- Finally, among supply side indicators, the country-specific normalization of ratio of government expenditure over GDP is the best-performing indicator with $A U R O C$ of 0.85 and utility of 0.35 .

To check for consistency of the useful indicators over time, we also conduct a signalling analysis on all the original and normalized indicators over the whole sample, i.e. until 2018 Q4. Overall, the best performing indicators remain broadly unchanged. Using primary markets data, cross-country normalization of changes in an 8-quarter moving average of the number of issuances is the best predictor with AUROC of 0.732 but a quite high Type II error rate of 0.4 . Using secondary markets data, cross-country normalization of difference of the 10-year forward rate from the best performing country remains the most useful indicator, with AUROC of 0.936 and utility of 0.397 . Within demand and supply side indicators, year-on-year growth in the inverse of a 4-quarter moving average of the banking sector index is the most useful indicator with utility of 0.301 and AUROC of 0.846. The second most useful indicator is cross-country normalization of the year-on-year difference in debt-to-GDP ratio with AUROC of 0.83 and utility of 0.25 .

\subsection{Selection of the indicators to be monitored}

Following the results of the signalling analysis, we proceed to identify and pre-select the most useful indicators on a univariate basis for further use within a multivariate framework. For this purpose, we use the area under the ROC curve and Type I and Type II error rates calculated for each indicator in a univariate analysis on the sample ending in 2011 Q2.

First, we discard indicators whose AUROC, a global measure of usefulness to predict periods leading to high sovereign bond market tensions, does not exceed 0.5 ; the number corresponding to an indicator yielding random results. Next, we discard those indicators for which either Type I or Type II error equals or exceeds 0.4. That is we exclude indicators that either fail to issue a signal or emit false alarms in 40 percent and more quarters of high tension episodes or tranquil periods, respectively. Subsequently, we select the best performing transformation of the underlying indicator that meets both of the above criteria: AUROC above 0.5 and Type I and Type II error below 0.4. These conditions leave us with substantially reduced sets of useful univariate indicators, especially from the primary markets. For this reason, we also consider such transformations of the primary market indicators that do not strictly meet the error type condition, but have AUROC and usefulness sufficiently high and which outperform other primary market indicators. Similarly, we retain the best performing transformations of the V2X index and US GDP growth in order to control for global demand factors. On the supply side, best performing transformations of GDP growth forecast and gross financing needs were retained to ensure comprehensiveness. Table 4 presents the set of the best-performing indicators.

The set of the most useful indicators contains the following transformations of the raw indicators:

- Primary market: country-specific normalization of difference in moving average of number of issuances over 8 quarters, country-specific normalization of ratio of bills issuance to GDP, crosscountry normalization of difference in moving average of share of floating coupon issuance 
over 8 quarters, cross-country normalization of difference in moving average of share of syndicated issuance over 8 quarters.

- Secondary market: cross-country normalization of bid-ask spread on 2-year bonds, crosscountry normalization of standard deviation of bid-ask spread on 5-year bonds, cross-country normalization of bid-ask spread on 10-year bonds, cross-country normalization of difference in foreign-held debt share on total debt, cross-country normalization of difference of 10-year forward rate from the best-performing country, cross-country normalization of forward premium, cross-country normalization of year-on-year difference in CDS rate.

- Supply and global demand indicators: year-on-year difference in forecast of interest expense share on GDP in two years, cross-country normalization of European economic uncertainty index, cross-country normalization of US GDP growth, cross-country normalization of V2X index, cross-country normalization of year-on-year difference in stock market index, crosscountry normalization of difference in GDP growth forecast in three years, cross-country normalization of difference in gross debt over GDP forecast in a year, country-specific normalization of government expenditure over GDP, cross-country normalization of year-onyear difference in debt-to-GDP ratio, cross-country normalization of difference in interest payable to GDP, cross-country normalization of rate of change in banking sector index (weighted average of bank equity prices by market capitalization), cross-country normalization of difference in 4-quarter moving average of gross financing needs over GDP, cross-country normalization of difference in bailouts to GDP.

Table 4: Identified top indicators for the forecast horizons of 4 quarters

\begin{tabular}{|c|c|c|c|c|c|c|}
\hline Variable & Usefulness & Threshold & $\begin{array}{l}\text { Threshold } \\
\text { (percentile) }\end{array}$ & $A \cup C$ & Type I & Type /I \\
\hline \multicolumn{7}{|l|}{ Primary market } \\
\hline No. of issuances & 0.291 & -0.064 & 0.555 & 0.819 & 0.000 & 0.418 \\
\hline Bills issued & 0.205 & 1.338 & 0.897 & 0.708 & 0.500 & 0.089 \\
\hline Floating coupon issuance & 0.218 & 0.136 & 0.843 & 0.609 & 0.417 & 0.147 \\
\hline Syndicated issuance & 0.110 & 0.592 & 0.793 & 0.562 & 0.583 & 0.197 \\
\hline \multicolumn{7}{|l|}{ Secondary market } \\
\hline Bid-ask $2 Y$ & 0.273 & -0.045 & 0.663 & 0.781 & 0.143 & 0.310 \\
\hline Bid-ask $5 Y$ & 0.254 & -0.151 & 0.596 & 0.729 & 0.111 & 0.380 \\
\hline Bid-ask $10 Y$ & 0.220 & -0.015 & 0.782 & 0.719 & 0.368 & 0.191 \\
\hline Foreign debt & 0.199 & 0.288 & 0.661 & 0.673 & 0.292 & 0.310 \\
\hline Forward rate & 0.386 & 0.015 & 0.751 & 0.916 & 0.042 & 0.186 \\
\hline Forward premium & 0.302 & 0.187 & 0.734 & 0.848 & 0.158 & 0.237 \\
\hline \multicolumn{7}{|l|}{ Global demand and supply } \\
\hline CDS & 0.262 & 0.311 & 0.842 & 0.797 & 0.391 & 0.084 \\
\hline Interest forecast & 0.297 & 0.400 & 0.873 & 0.781 & 0.333 & 0.073 \\
\hline Economic policy uncertainty & 0.215 & 0.175 & 0.645 & 0.727 & 0.250 & 0.319 \\
\hline US GDP & 0.180 & -0.488 & 0.334 & 0.679 & 0.000 & 0.640 \\
\hline$V 2 X$ & 0.187 & -0.334 & 0.423 & 0.613 & 0.083 & 0.543 \\
\hline Stock market & 0.143 & -0.076 & 0.643 & 0.591 & 0.375 & 0.339 \\
\hline GDP forecast & 0.237 & 0.969 & 0.874 & 0.697 & 0.417 & 0.109 \\
\hline Debt forecast & 0.254 & 0.049 & 0.709 & 0.775 & 0.250 & 0.241 \\
\hline
\end{tabular}




\begin{tabular}{c|llllll} 
Government expenditure & 0.347 & 0.172 & 0.650 & 0.852 & 0.000 & 0.306 \\
Debt & 0.280 & 0.790 & 0.843 & 0.832 & 0.333 & 0.107 \\
Interest payable & 0.213 & 0.233 & 0.758 & 0.709 & 0.375 & 0.200 \\
Bank index & 0.198 & 0.100 & 0.593 & 0.695 & 0.222 & 0.382 \\
Gross financing needs & 0.204 & 0.784 & 0.827 & 0.691 & 0.458 & 0.134 \\
Bailouts & 0.252 & -0.204 & 0.834 & 0.610 & 0.375 & 0.121
\end{tabular}

Notes: AUC stands for area under receiver's operating characteristics curve (ROC).

\subsection{Dynamics of the identified top indicators}

This subsection investigates the dynamics of the top indicators identified using univariate analysis. Figure A1 in the appendix shows the median dynamics of each indicator in the four quarters prior to the start of the loss of market access episodes, as well as in the four quarters following the loss of market access incidence. The dashed red line represents the median behaviour around LMA episodes and the shaded area highlights interquartile range or the difference between the $75^{\text {th }}$ and the $25^{\text {th }}$ percentile of the indicator distribution around LMA episodes. The green line shows the median of the indicator before the Global Financial Crisis, i.e. in the period from 2003 Q4 until 2005 Q4. The black line indicates an indicator-specific threshold for issuing signals. Overall, given their observed dynamics, most selected indicators would issue a signal either during full four quarters leading to the LMA episode or at least at some point in this four-quarter window. However, four indicators do not show good ability to correctly signal high stress periods leading to an LMA event: the ratio of bills issuance-to-GDP, changes in the 8-quarter moving average of syndicated issuance share, year-on-year difference in 3years ahead GDP growth forecast, and year-on-year change in 4-quarter moving average of gross financing needs to GDP. The median dynamics of these indicators during high-tensions pre-LMA periods are quite close in direction and magnitude to those during tranquil times, and as such, fail to exceed their indicator-specific thresholds. Consequently, we infer that median dynamics of these indicators cannot be relied upon to provide a good early warning signal of sovereign market access tensions. This unsatisfactory performance can be attributed to a relatively large Type I error rate of these four indicators, i.e. exceeding 0.4 , and in the case of the ratio of bills issuance-to-GDP and the changes in the 8-quarter moving average of syndicated issuance share even exceeding 0.5. Table 5 presents a detailed list of those quarters in the year preceding the start of LMA episodes per country that were successfully identified by our selected indicators of market tensions.

Table 5: Identified periods of up to 4 quarters prior to LMA by top indicators

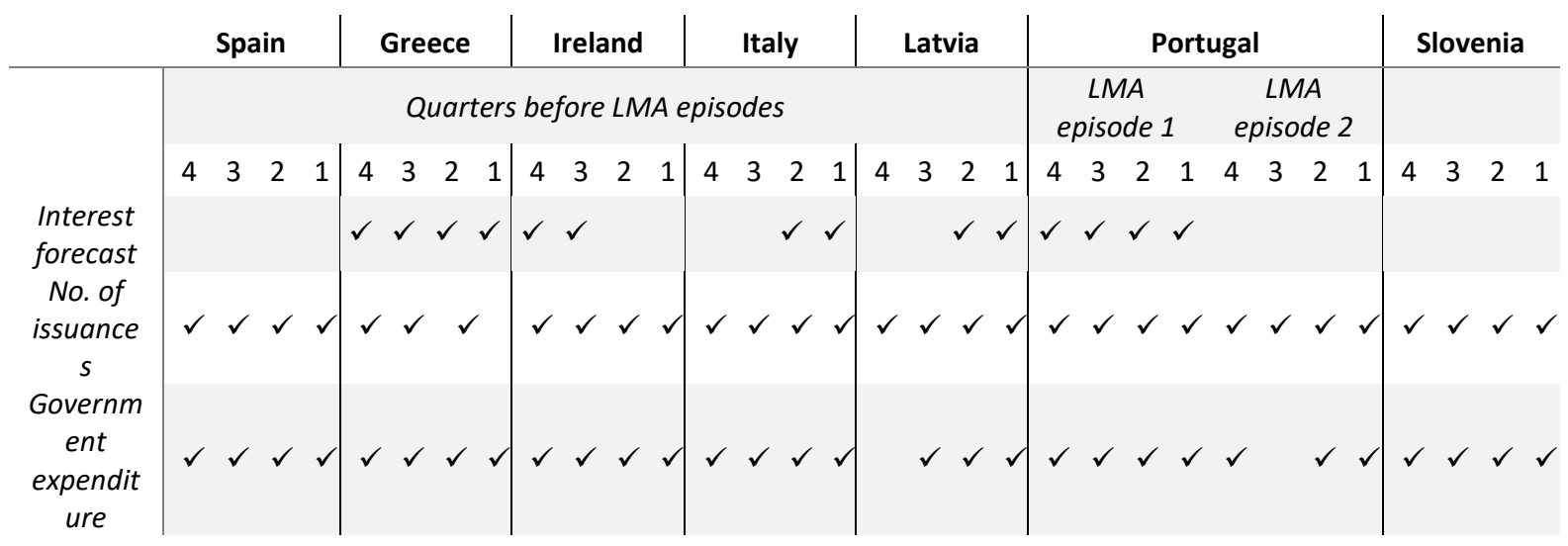




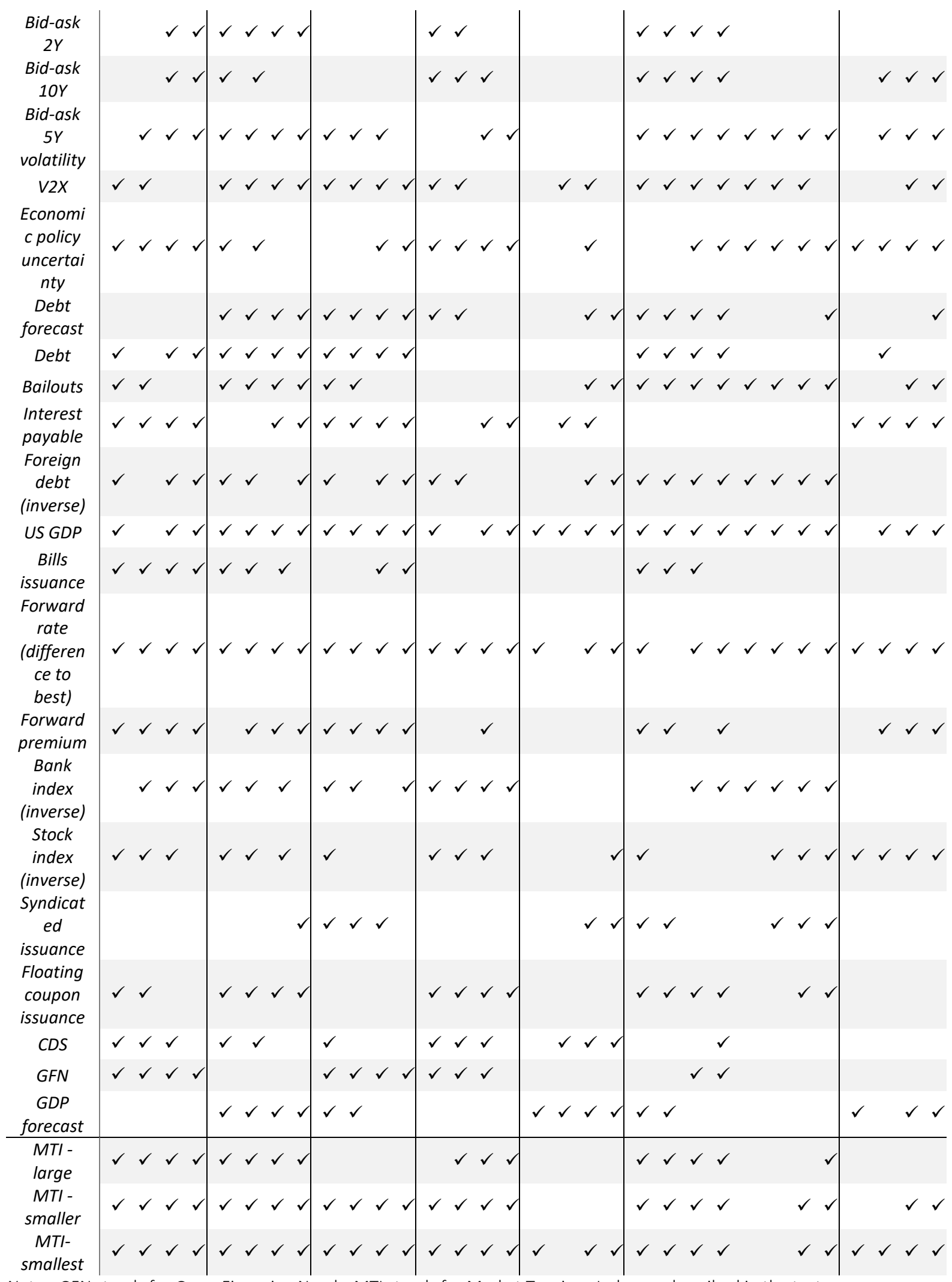

Notes: GFN stands for Gross Financing Needs. MTI stands for Market Tensions Index, as described in the text.

16 


\subsection{Presenting results of the univariate analysis}

We build on the identified individual thresholds to depict developments in our selected indicators over the four-quarter forecast horizon for the period from 2008 Q1 to 2018 Q4.

Figure A2 in the Appendix depicts indicator dynamics by comparing their current level to their identified thresholds from 2008 Q1 to 2018 Q4 for each EA 14 country in our sample. The red colour shows yearquarters in which the threshold was exceeded for an indicator, while blue colour marks year-quarters in which an indicator remained below the threshold, thus not emitting signals for the potential high bond market tensions. The darker the colour, the further away from its threshold an indicator is; dark blue therefore shows that an indicator is far below its threshold, while dark red points to an indicator that has far exceeded its threshold, thus marking very high likelihood of bond market tensions. The vertical lines mark the first quarters of identified LMA episodes based on our definition.

In line with what one would expect, for Ireland, Portugal and Greece, various indicators started to deteriorate as the countries were in the run-up to their corresponding official assistance programs. In contrast, for Germany and Netherlands, the figure shows a (blue) sea of smooth market access.

\section{Market access tensions index}

This section builds on the univariate identification of the most useful predictors of sovereign bond market tensions conducted in the previous section. We construct a composite index that aggregates the most useful predictors. For this purpose, we apply to bond market tensions the methodology outlined in Lang et al. (2019), who construct a composite index of financial stress. We follow this approach to ensure the transparency, interpretability and tractability of the results for policy use.

First, we calculate each indicator's difference from the optimal threshold we identified in the univariate analysis. ${ }^{16}$ Second, we normalize this difference from threshold on a cross-country basis, by subtracting the sample mean of the difference from threshold and dividing it by its standard error. Third, to ensure the resulting index is parsimonious, i.e. does not incorporate highly correlated indicators, we evaluate pairwise correlations between the normalized top indicators' differences from threshold and eliminate highly correlated ones. Consequently, we eliminate cross-country normalization of year-on-year difference in debt-to-GDP ratio and cross-country normalization of US GDP growth due to their high correlations with the debt-to-GDP forecast and interest forecast, which we consider important from the forward-looking perspective. We also exclude cross-country normalization of banking sector index rate of change due to very low correlation with our dependent, cross-country normalization of yearon-year difference in CDS rate due to data limitations for the countries in the sample, cross-country normalization of bid-ask spread on 10-year bonds due to its high correlation with bid-ask indicators for 2-year and 5-year bonds, cross-country normalization of V2X index and cross-country normalization of year-on-year difference in stock index due to their high correlations with banking sector index.

Fourth, we aim to aggregate individual component indicators into the index based on their optimal indicator weights. We obtain the optimal weights by running a univariate linear regression of our LMA dummy dependent on the normalized difference of an indicator from its threshold and by using the

\footnotetext{
${ }^{16}$ To construct our composite market tensions measure, we need to ensure all the identified top indicators presented in Table 4 are related to our loss of market access dummy in a positive way. Since foreign-held debt ratio, US GDP growth, rate of change of a country's banking sector index and difference in a country's stock index are typically negatively related to loss of market access episodes, we invert their sign by multiplying them by minus one.
} 
estimated coefficient as weight. The weights are constrained to sum to 1 by dividing each indicator's estimated coefficient by the sum of all the estimated coefficients from univariate regressions. We proceed to construct the market access tensions index as follows:

$$
\text { Market access tensions index }=\sum_{j=1}^{J} \omega^{j} \cdot \widetilde{\Delta x}_{i, t}^{j}
$$

$\widetilde{\Delta x} x_{i, t}^{j}=\left(\Delta x_{i, t}^{j}-\Delta x_{\text {Mean }}^{j}\right) / \Delta x_{S D}^{j}$ denotes the normalized difference of sub-indicator from its threshold, $i$ indicates a country, $t$ a year-quarter and $j$ an individual sub-component. As observed by Lang et al. (2019), optimal country-specific weights are difficult to estimate due to the scarcity of loss of market access episodes. By using cross-country normalisation and applying constant weights across countries and time we assume a common patterns across market access tension episodes in individual countries and at different points in time. Applying the cross-country aggregation also mitigates overfitting for individual LMA events. Furthermore, constraining the sum of weights of individual subcomponents to 1 allows us to decompose the market access tensions index (MTI) into its drivers at any quarter in our sample. Figure A4 in the Appendix shows the MTI decomposition for EA 14 countries.

Out of the best performing indicators in Table 4, based on their subpar median dynamics over the start of loss of market access episodes (see Figure $\mathrm{A} 1$ in the Appendix), we exclude from the composite index the following indicators: ratio of bills issuance-to-GDP, difference in moving average of syndicated issuance share over the last 2 years, year-on-year difference in GDP growth forecast in 3 years, and year-on-year difference in moving average of gross financing needs to GDP over previous 4 quarters. ${ }^{17}$

Due to data constraints, we construct an alternative (smaller) market access tensions index comprising fewer indicators. Due to data limitations for Ireland, Latvia and Slovenia, we eliminate the two bid-ask indicators (spread on 2-year bond and volatility of spread on 5-year bond). We then exclude the forward premium, which is missing for Latvia and Slovenia, and calculate the "smallest" market tensions index, comprising 10 indicators from Table 4. The calculated optimal weights for individual indicators are shown in Table 6. Figure 1 compares the dynamics of the "largest" market tensions index (comprising 13 sub-components) with the "smallest" index. While the indices co-move strongly, in most countries the largest index appears shifted downwards compared to the more parsimonious version. For illustrative purposes in Figure 1 the resulting indices are rescaled between 0 and 1.

17 These indicators behave similarly around LMA events and tranquil times, failing to issue signals of elevated market tensions. 
Figure 1. Sovereign bond market tensions index
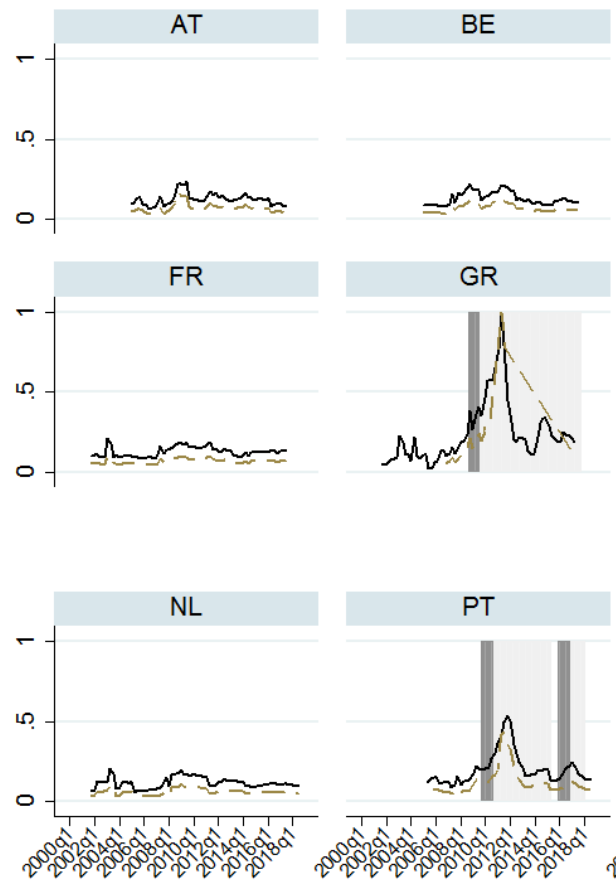

pre-LMA

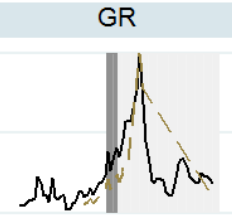

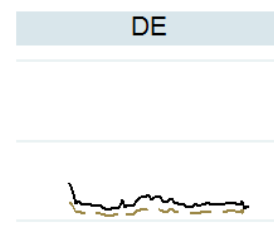

IE

Market tensions index (smallest)

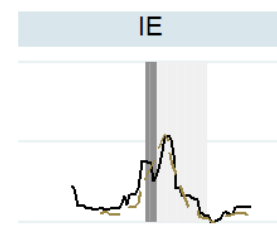

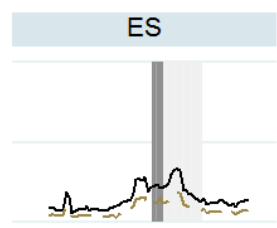
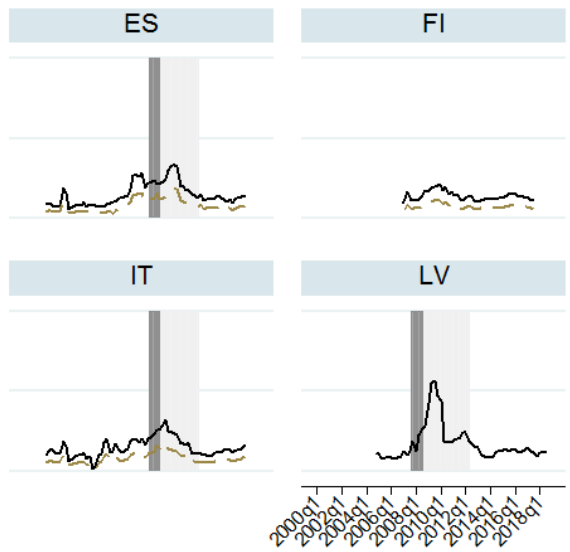

SK

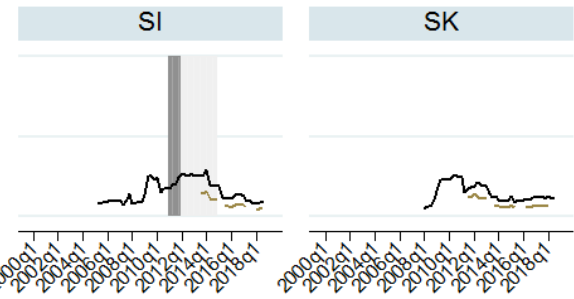

LMA

Notes: The vertical axis measures the probability of losing market access within up to 4 quarters. LMA shows periods of identified high market access tensions while pre-LMA identifies periods of up to 4 quarters prior to LMA. Country name abbreviations are as follows: $\mathrm{AT}=$ Austria, $\mathrm{BE}=$ Belgium, $\mathrm{DE}=$ Germany, $\mathrm{ES}=\mathrm{Sp}$ ain, FI=Finland, FR=France, GR=Greece, IE=Ireland, IT=Italy, LV=Latvia, NL=Netherlands, PT=Portugal, SI=Slovenia, SK=Slovakia.

Table 6: Optimal weights for sub-components of market access tension indices

\begin{tabular}{|c|c|c|c|}
\hline Sub-component & $\begin{array}{l}\text { Largest } \\
\text { Index }\end{array}$ & $\begin{array}{c}\text { Smaller } \\
\text { index }\end{array}$ & $\begin{array}{c}\text { Smallest } \\
\text { index }\end{array}$ \\
\hline \multicolumn{4}{|c|}{ Weight } \\
\hline Primary market & & & \\
\hline No. of issuances & 0.05 & 0.07 & 0.07 \\
\hline Bills issued & - & - & - \\
\hline Floating coupon issuance & 0.04 & 0.06 & 0.06 \\
\hline Syndicated issuance & - & - & - \\
\hline \multicolumn{4}{|l|}{ Secondary market } \\
\hline Bid-ask $2 Y$ & 0.13 & - & - \\
\hline Bid-ask $5 Y$ & 0.15 & - & - \\
\hline Bid-ask 10Y & - & - & - \\
\hline Foreign debt & 0.03 & 0.04 & 0.04 \\
\hline Forward rate & 0.27 & 0.37 & 0.40 \\
\hline Forward premium & 0.02 & 0.03 & - \\
\hline \multicolumn{4}{|l|}{ Global demand and supply } \\
\hline CDS & - & - & - \\
\hline Interest forecast & 0.13 & 0.18 & 0.18 \\
\hline Economic policy uncertainty & 0.02 & 0.03 & 0.03 \\
\hline
\end{tabular}




\begin{tabular}{c|ccc} 
US GDP & - & - & - \\
V2X & - & - & - \\
Stock market & - & - & - \\
GDP forecast & - & - & - \\
Debt forecast & 0.04 & 0.06 & 0.06 \\
Government expenditure & 0.04 & 0.06 & 0.06 \\
Debt & - & - & - \\
Interest payable & 0.04 & 0.05 & 0.05 \\
Bank index & - & - & - \\
Gross financing needs & - & - & - \\
Bailouts & 0.04 & 0.05 & 0.05
\end{tabular}

To evaluate how successful these indices are in capturing tensions in sovereign bond markets, we compare year-on-year changes in the indices during the four quarters leading to LMA episodes with those in tranquil periods. We conduct difference-in-means testing to assess if on average the composite indices succeed in capturing increases in market tensions for individual countries. Figure 3 shows the results. In all countries that experienced an LMA episode, all three constructed indices of market access tensions capture increases in market tensions in pre-LMA times. Average increases in market tensions in pre-LMA times are more positive and statistically significantly different from those in tranquil times at least at $5 \%$ significance level ${ }^{18}$

\section{Figure 3: Average difference in market tensions: pre-LMA vs. tranquil times (All countries)}

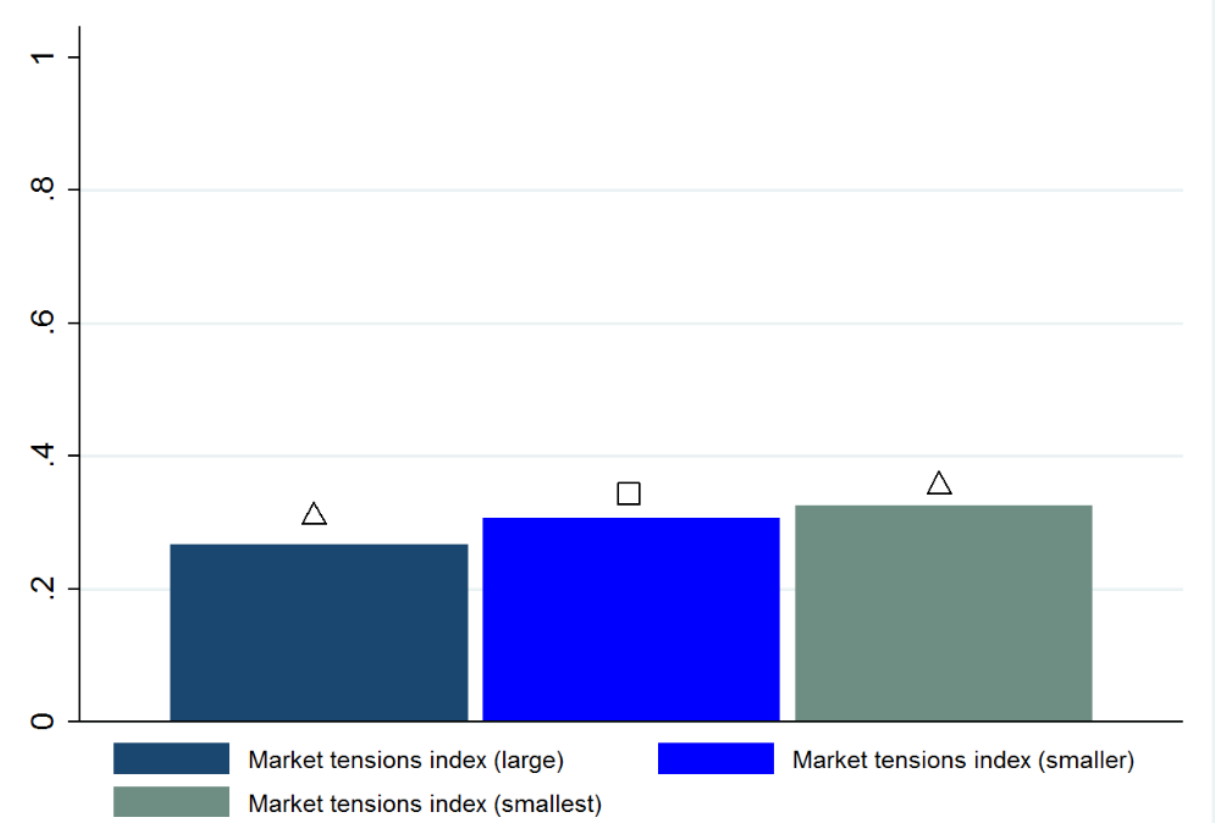

Notes: Average difference between pre-LMA and tranquil periods as captured by market tensions indices. A circle denotes statistically significant difference at $10 \%$ level, a square at $5 \%$ level and a triangle at $1 \%$ level.

${ }^{18}$ Statistical significance is depicted by a hollow shape above bars; a circle for significance at $10 \%$ level, a square at $5 \%$ and a triangle for significance at $1 \%$ level. 


\subsection{Dynamics of market tensions index around identified loss of market access episodes}

Figure 4 compares the median dynamics (red line) of individual market tensions indices around LMAepisodes with median values in tranquil times (green line). The horizontal black line shows the calculated optimal threshold for the index using data until 2011 Q2 and the full data ending in 2018 Q4, respectively. The median index is above its threshold four quarters before as well as after the start of LMA episodes, thus providing a good early warning signal of rising market tensions.

Figure 4. Market tensions index dynamics around LMA episodes

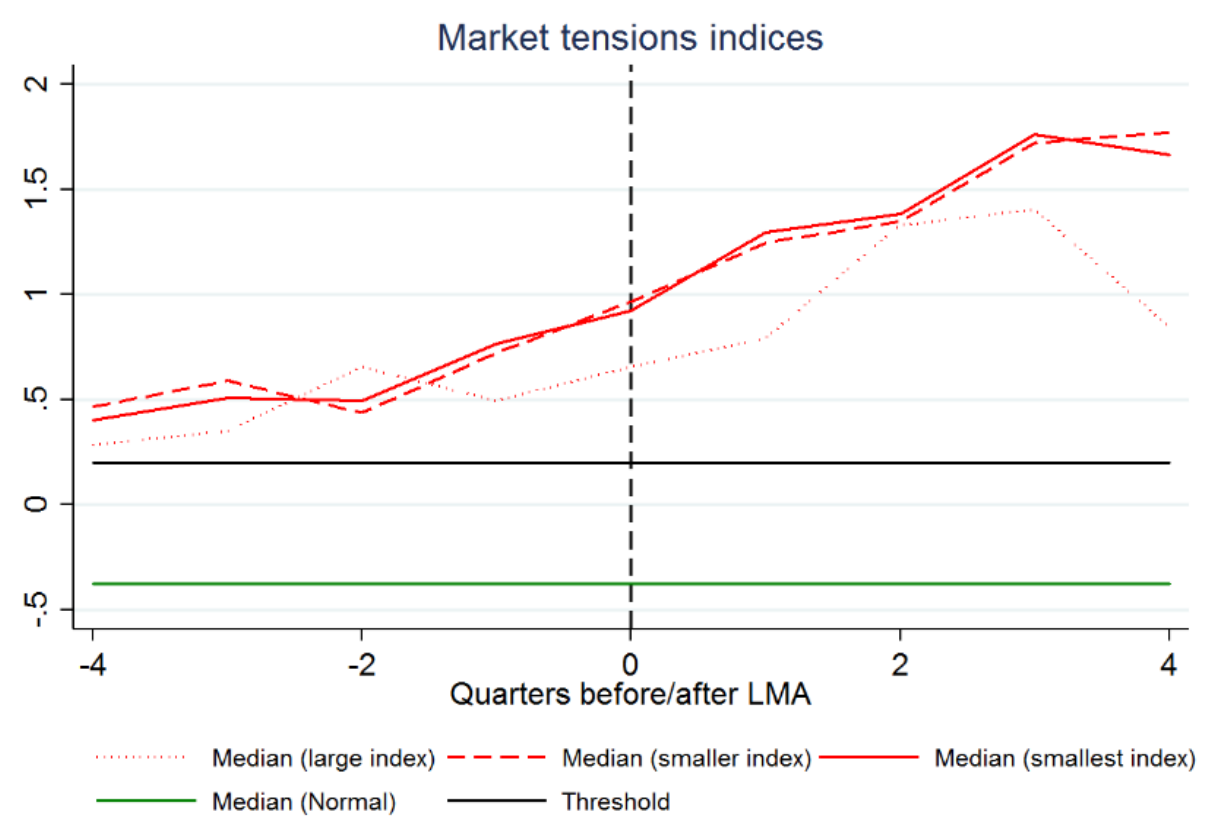

Furthermore, we perform univariate testing of the composite market tensions indices on data until 2011 Q2 (upper panel of Table 7) to ensure comparability with individual indicators. The top performing indicator in our dataset is cross-country normalization of difference of 10-year forward rate from the best performing country, with usefulness of 0.386, AUROC of 0.916 and Type I and Type II error rate of 0.042 and 0.186 , respectively. The composite market tensions indices outperform the 10-year forward rate, while the smallest index has only marginally better performance with AUROC of 0.931 on data until 2011 Q2. However, using the full data until 2018 Q4 (bottom panel of Table 7) marginal performance of the smallest market tensions index improves over the best performing single indicator; AUROC increases to 0.943 and utility rises to 0.4 .

Table 7: Univariate assessment of composite market tensions indices

\begin{tabular}{c|cccccc} 
& Usefulness & Threshold & $\begin{array}{c}\text { Threshold } \\
\text { (percentile) }\end{array}$ & AUC & Type I & Type II \\
\hline $\begin{array}{c}\text { Market tensions index } \\
\text { (largest) }\end{array}$ & 0.462 & 0.234 & 0.860 & 0.969 & 0.000 & 0.075 \\
$\begin{array}{c}\text { Market tensions index } \\
\text { (smaller) }\end{array}$ & 0.440 & 0.357 & 0.804 & 0.957 & 0.000 & 0.121 \\
$\begin{array}{c}\text { Market tensions index } \\
\text { (smallest) }\end{array}$ & 0.385 & 0.198 & 0.730 & 0.931 & 0.042 & 0.188 \\
\hline $\begin{array}{c}\text { Market tensions index } \\
\text { (largest) }\end{array}$ & 0.420 & 0.234 & 0.859 & 0.960 & 0.100 & 0.059
\end{tabular}




\begin{tabular}{c|cccccc}
$\begin{array}{c}\text { Market tensions index } \\
\text { (smaller) }\end{array}$ & 0.427 & 0.357 & 0.826 & 0.959 & 0.074 & 0.072 \\
$\begin{array}{c}\text { Market tensions index } \\
\text { (smallest) }\end{array}$ & 0.400 & 0.181 & 0.731 & 0.943 & 0.063 & 0.138 \\
\hline Notes: AUC stands for the area under receiver's operating characteristics curve (ROC) & &
\end{tabular}

\section{Multivariate analysis and out-of-sample forecasting}

After evaluating the indicators using data until 2011 Q2 on a univariate basis, and identifying those most useful for forecasting episodes of market tensions over a four-quarter horizon, we are left with 24 best performing indicators. However, these are still too numerous to be meaningfully used within a multivariate model that generalizes well out of sample. Furthermore, in our analysis we face the problem of perfect separation of 1 and 0 outcomes when all 24 indicators are included in the logistic regression, which is demonstrated by failure of logistic regression maximum likelihood estimation to converge. As a result, traditional maximum likelihood coefficient estimates do not exist. We tackle this issue by relying on statistical techniques to resolve model uncertainty, i.e. which variables should be included in the final model.

Classic techniques for model building and variable selection, for instance generalized linear models with stepwise selection, are known to be unreliable and often biased (Koop, 2003). The main problem with these techniques is that in applying (one-at-a-time or) sequential variable elimination (backward selection), useful variables may be excluded each time the test is performed (i.e. the model is reestimated on the new subset of variables). Moreover, while the removal of less significant predictors can increase the significance of the remaining variables, it may also lead to overstating their importance. Finally, stepwise variable selection tends to pick models that are smaller than desirable for prediction purposes (Roecker, 1991).

Recent advancements in statistics have focused on the development of algorithms for model building and variable selection (Hastie et al. 2009). In particular, a variety of statistical techniques to select the most informative variables out of a large set of predictor variables have been developed during the past years (e.g. Hastie et al. 2009). To properly address the above concerns, we consider the following approaches for dealing with model uncertainty.

\subsection{Modelling approaches}

\subsubsection{Logistic regression with backward sequential variable selection}

To ascertain the relationship between our dependent variable capturing periods of up to four quarters prior to identified loss of market access episodes and the identified most useful indicators of high market access tensions, a logistic regression is first applied. Logit model is specified as follows:

$$
P(Y=1)=\frac{e^{x \beta}}{1+e^{x \beta}}
$$

Where $P(Y=1)$ is probability of an episode of high market access tensions arising within four quarters, $X$ is the set of useful predictors for high market access tensions. The model is estimated using maximum likelihood estimation, which yields coefficients that are consistent and asymptotically efficient.

Estimating the model with all 24 indicators is, however, not desirable nor is it in our case feasible. For the model containing all the identified useful indicators, maximum likelihood estimation does not 
converge, i.e. the model suffers from separation which indicates that the outcome can be perfectly predicted using a linear combination of explanatory variables. ${ }^{19}$. This issue can be typically remedied by excluding the problematic indicators from the model until estimation is achieved. However, this elimination of indicators can inadvertently exclude the strongest predictors.

Despite the downsides of sequential variable selection, we apply sequential elimination of indicators based on their relative usefulness. For this exercise, we apply Recursive Feature Elimination function with logistic regression in Python.

\subsubsection{Generalized regression models via penalized maximum likelihood}

These models aim is to solve the following function:

$$
\min _{\beta_{0}, \beta} \frac{1}{N} \sum_{i=1}^{N} w_{i} l\left(y_{i}, \beta_{0}+\beta^{T} x_{i}\right)+\lambda\left[\frac{(1-\alpha)}{2}\|\beta\|_{2}^{2}+\alpha\|\beta\|_{1}\right]
$$

over a grid of values of $\lambda$, where $l(y, \eta)$ is the negative log-likelihood contribution of observation $i$. The elastic net penalty is controlled by $\alpha$ and bridges the gap between lasso $(\alpha=1)$ and ridge $(\alpha=0)$. Parameter $\lambda$ controls the overall strength of the penalty. The ridge penalty shrinks coefficients of correlated predictors towards each other while lasso tends to pick one of them and discard the others. The elastic net penalty mixes the two - if predictors are correlated in groups, values of $\alpha$ close to $\alpha=$ 0.5 tend to select the groups in or out together. Parameters are selected by optimizing a loss function (mean squared error for Gaussian models, misclassification error or AUROC for two-class logistic regressions as in our case) using k-fold cross-validation. In our analysis, we have applied 10-fold crossvalidation over our training dataset, i.e. data until 2011 Q2, to select optimal (objective functionminimizing) value of $\lambda$ in the logistic model with lasso penalty. ${ }^{20}$

However, despite its variable selection capacity, penalized estimation is characterized by reducing the variance of estimators by introducing substantial bias. For this reason, the bias of each estimator is a major component of its mean squared error (variance constitutes only a small part). As a result, in most applications it is not feasible to obtain a sufficiently precise estimate of the bias for penalized regressions. Reporting a standard error of penalized regression estimates can thus lead to erroneous conclusions, since these would ignore inaccuracy caused by the bias. Friedman et al. (2008) provide more details on this technique.

\subsubsection{Model-based boosting}

Model-based boosting is a machine learning method for optimizing prediction accuracy and for obtaining statistical model estimates via gradient descent techniques. An important feature of the method is that it carries out variable selection during the fitting process (Buhlmann \&Yu, 2003, Buhlmann, 2006) without relying on heuristic techniques such as stepwise variable selection.

The approach models the relationship between the dependent $y$ and a set of predictors $x$ by minimizing a loss function $\rho(y, f) \in \mathbb{R}$ over a prediction function $f$ depending on $x$. For generalized linear models the loss function is typically the negative log-likelihood function of the outcome distribution. For the binary dependent in our analysis $f$ is a logistic function of $x$ and $\rho$ corresponds to misclassification error

\footnotetext{
19 In this case, estimated coefficients are infinite and the optimization process tries to solve this iteratively. As a consequence, in each step of the estimation process the estimated coefficient is marginally increased ad infinity.

${ }^{20} \mathrm{R}$ implementation of this technique in the gImnet package uses cyclical coordinate descent which optimizes the objective function over each parameter with other parameters fixed and cycles until convergence is reached.
} 
or (inverse) AUROC. In the gradient-boosting approach the aim is to estimate optimal prediction function $f^{*}$ defined by

$$
f^{*}=\operatorname{argmin}_{f} \mathrm{E}_{Y, X}\left[\rho\left(y, f\left(x^{T}\right)\right)\right]
$$

where the loss function $\rho$ is assumed to be differentiable with respect to $f$. In practice, the expectation in (8) is not known and only the realization of $\left(y, x^{T}\right)$ is observed. Therefore, instead of minimizing the expected value in (8), boosting algorithms minimize the observed mean, called the empirical risk $\sum_{i=1}^{n} \rho\left(y_{i}, f\left(x^{T}\right)\right)$. The algorithm adds an estimate of the true negative gradient of empirical risk to the current estimate of $f^{*}$ in each iteration. The component-wise boosting algorithm descends along the gradient of the empirical risk. The empirical risk is thus minimized in a stage-wise fashion, and a structural (regression) relationship between $y$ and $x$ is established. The algorithm also carries out variable selection and model choice. ${ }^{21}$

\subsubsection{Bayesian model averaging}

Another method to deal with model uncertainty in the parametric model space is by averaging over different models sampled from variables in covariate space, which also enables Bayesian variable selection. Bayesian model averaging (BMA) estimates a number of models that use subsets of all explanatory variables on the right-hand side. For a large number of variables, all the possible models are not enumerated but they are sampled from the model space using an algorithm. In most applications, Markov Chain Monte Carlo (MCMC) sampler is used. This sampler only goes through the most important part of the model space (there are $2^{k}$ possible models in total, where $k$ is the number of covariates). Each estimated coefficient (posterior mean) is the average coefficient of all the models weighted by the posterior model probability, which is akin to adjusted R-squared in frequentist econometrics. Another important concept, posterior inclusion probability, is the sum of all posterior model probabilities of the model in which a particular variable is included and reports how likely it is the variable is included in the true model. The posterior standard deviation is analogous to the standard error and follows the distribution of a coefficient from all estimated models. ${ }^{22}$

\subsection{Results of Multivariate Approaches}

\subsubsection{Logistic regression with the market tensions index}

After verifying that the composite indices built in section 6 capture well the build-up of tensions in sovereign bond markets, we now investigate their predictive performance both in sample and out of sample. We run panel logistic regression with random effects using only the composite market tensions index as an explanatory variable and the binary indicator capturing periods of up to four quarters prior to identified loss of market access as the dependent. Table 8 presents the results for univariate logistic regressions using each of the three constructed market tensions indices.

${ }^{21}$ The detailed steps of the algorithm that minimizes the observed mean over $f$ are provided in Hofner et al. (2014).

22 For more information on the technique and on its R implementation see Clyde et al. (2018). 
Table 8: Estimated coefficients from univariate logit with market tensions index

\begin{tabular}{r|ccc}
\multicolumn{5}{c}{ Univariate Logit } \\
\hline Market tensions index (large) & $\begin{array}{c}7.660 * * * \\
(2.071)\end{array}$ & $4.823^{* * *}$ \\
Market tensions index (smaller) & & $(0.986)$ & \\
& & & $4.651^{* * *}$ \\
Market tensions index (smallest) & & $0.837)$ \\
& & $-4.712^{* * *}$ & $-4.553^{* * *}$ \\
Intercept & $-6.044^{* * *}$ & $(0.837)$ & $(0.785)$ \\
\hline Number of countries. & $(1.845)$ & 326 & 397 \\
Notes: Standard errors are in parentheses. & $29 * *$ indicate $1 \%, * * 5 \%$ and * $10 \%$ significance level.
\end{tabular}

As expected due to the construction of the index, the estimated coefficients for the market tensions index are positive and highly significant. Moreover, with a decreasing number of sub-indicators included in the composite index, the estimated slope coefficient decreases while the number of observations and countries included in the regression increases. Figure 5 presents the predicted probabilities from univariate panel logistic regressions with random effects using only the market tensions index as an explanatory variable both in sample and out of sample. The logit model using the market tensions index adequately captures the build-up of vulnerabilities in periods leading to high market access tensions episodes.

Out of sample, the MTI predicts well elevated probabilities of high market tensions after the outbreak of a market loss episode. However, the predicted probabilities tend to be relatively low in the four quarters preceding loss of market access episodes and decrease relatively rapidly to tranquil levels following a few quarters after the identified start of market loss episodes. For Portugal, the second identified episode of high market tensions was not identified by the univariate logit model even though there was a small increase in probability in the four quarters preceding the episode. 
Figure 5: Predicted probability using the market access tensions index
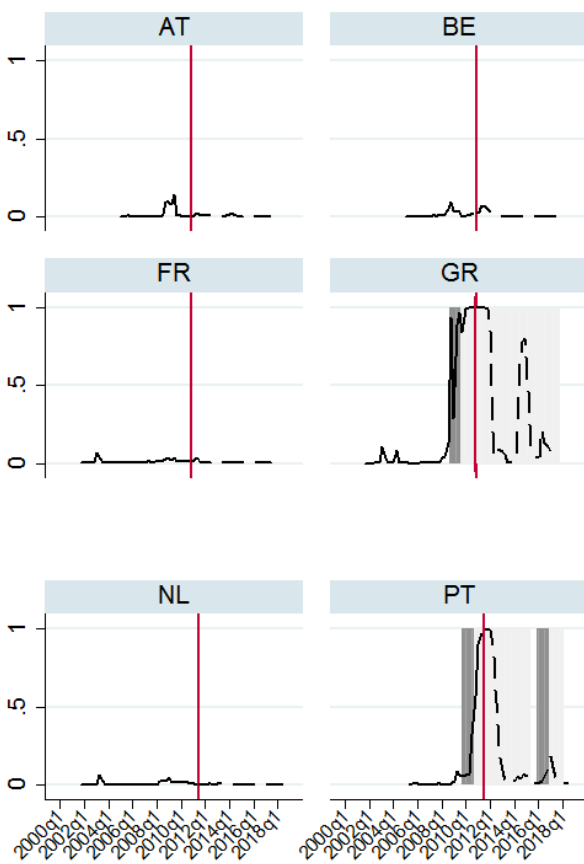

pre-LMA
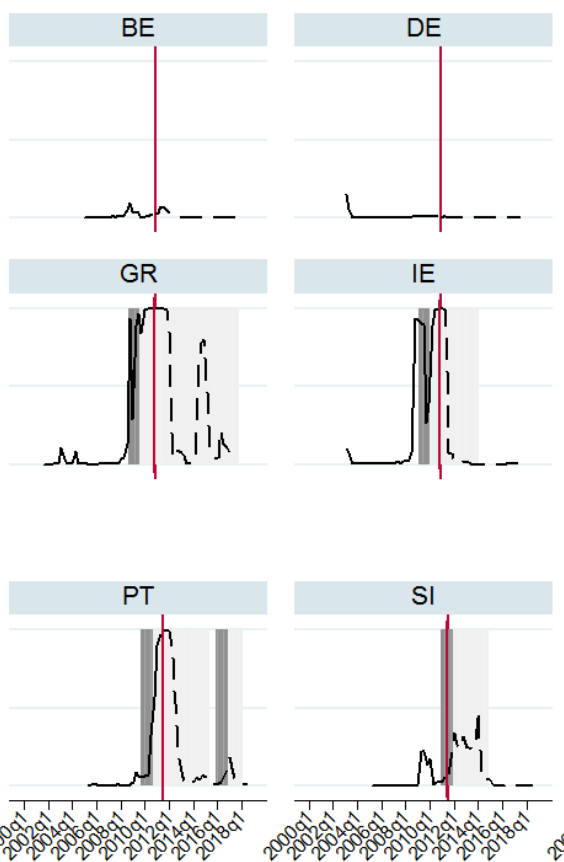

LMA
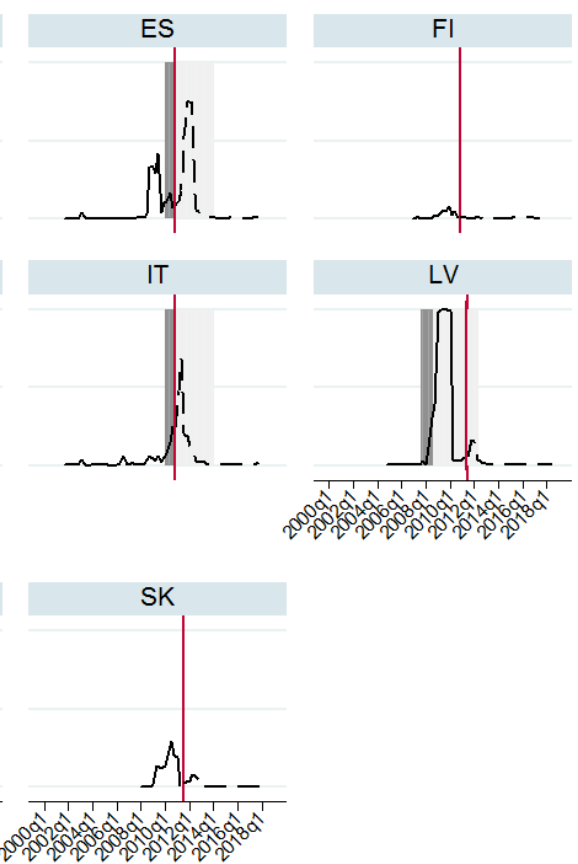

Probability (smallest index)

Notes: Probability of market access tensions from logistic regression using the smallest market tensions index. The vertical axis measures the probability of losing market access within up to 4 quarters. LMA shows periods of identified high market access tensions while pre-LMA identifies periods of up to 4 quarters prior to LMA. The red vertical line indicates start of out-of-sample forecast and the dashed line shows out-of-sample forecast probabilities of market access tensions. Country name abbreviations are as follows: $\mathrm{AT}=$ Austria, $\mathrm{BE}=\mathrm{Belgium}, \mathrm{DE}=$ Germany, $\mathrm{ES}=\mathrm{Sp}$ ain, $\mathrm{FI}=$ Finland, $\mathrm{FR}=\mathrm{France}, \mathrm{GR}=\mathrm{Greece}$, IE=Ireland, IT=Italy, LV=Latvia, NL=Netherlands, PT=Portugal, SI=Slovenia, SK=Slovakia.

\subsubsection{Logistic regression with backward sequential variable selection}

Despite the shortcomings of stepwise variable selection approaches mentioned above, we nevertheless apply a sequential backward variable selection within logistic regression in Python as a first step to evaluating market access conditions using a multivariate framework. Following the pre-selection of the most useful market tensions indicators on data until 2011 Q2, we estimate out of sample probabilities using logistic regression containing only these selected indicators. The selected indicators from logistic regression with backward sequential variable selection are presented in Table 9 together with their coefficients and the corresponding 95\% confidence interval. 
Figure 6: Predicted probability from logistic regression with backward sequential variable selection
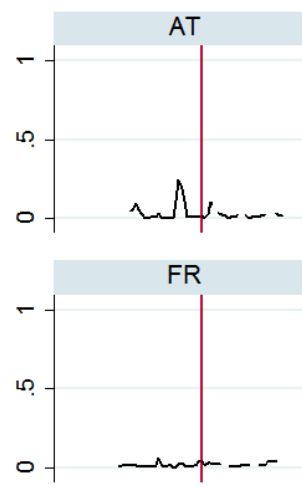

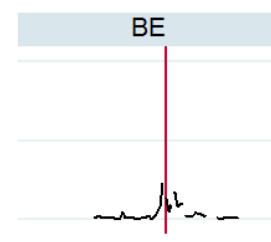

GR

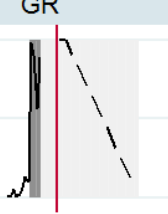

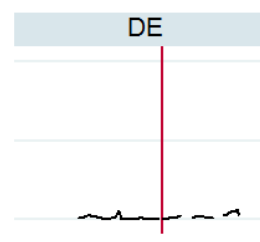

IE

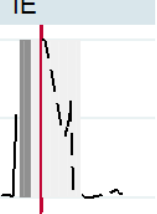

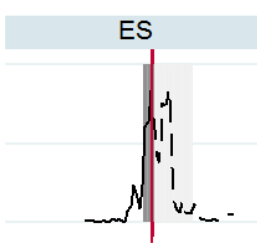

IT

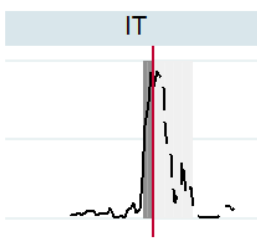

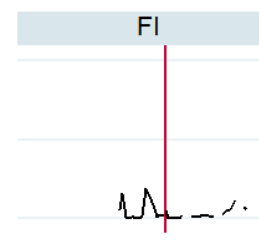

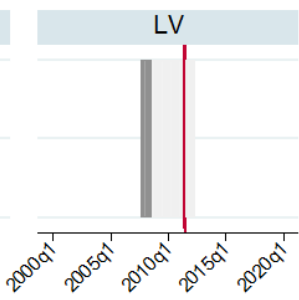

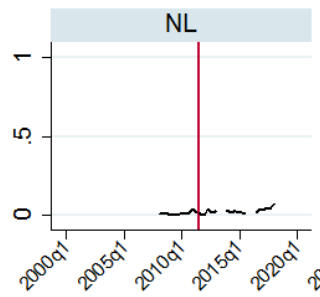
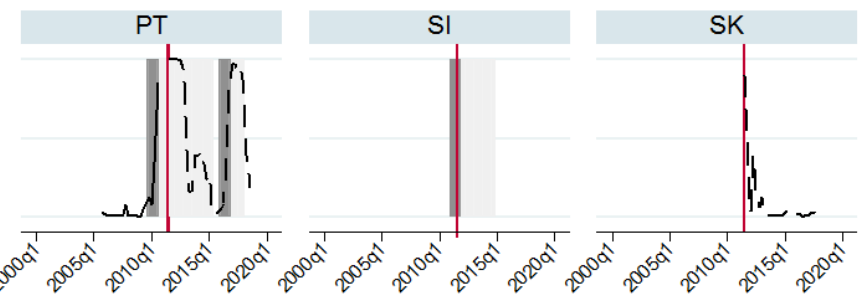

pre-LMA

LMA

\section{Probability}

Notes: Probability of market access tensions from logistic regression using backward sequential variable selection. The vertical axis measures the probability of losing market access within up to 4 quarters. LMA shows periods of identified high market access tensions while pre-LMA identifies periods of up to 4 quarters prior to LMA. The red vertical line indicates start of outof-sample forecast and the dashed line shows out-of-sample forecast probabilities of market access tensions. Country name abbreviations are as follows: $\mathrm{AT}=$ Austria, $\mathrm{BE}=\mathrm{Belgium}, \mathrm{DE}=$ Germany, $\mathrm{ES}=\mathrm{Sp}$ ain, $\mathrm{FI}=$ Finland, $\mathrm{FR}=$ France, $\mathrm{GR}=\mathrm{Greece}, \mathrm{IE}=\mathrm{Ireland}$, $\mathrm{IT}=$ Italy, LV=Latvia, NL=Netherlands, PT=Portugal, SI=Slovenia, SK=Slovakia.

\subsubsection{Penalized and boosted logistic regression}

Table 9 shows the results of running the logistic regression with backward sequential variable selection, with lasso penalty and with the component-wise boosting on the 24 pre-selected indicators. Most indicators selected by the algorithms use secondary and primary markets data, and indicators reflecting global demand and government supply side. Coefficient estimates are overall positive since the selected indicators were adjusted to be positively related to high sovereign bond market tensions.

Overall, both methods result in similar out-of-sample predicted probabilities of high sovereign bond market tensions. The predicted elevated probabilities coincide with actual LMA episodes, with estimated probabilities at least increasing in the four quarters leading to the LMA episode. Only one false alarm would be issued by the models for Slovakia, at the end of 2011, when the estimated probability exceeds 0.5 but no LMA was identified using our definition. 
Figure 7: Predicted probability from penalized logistic regression
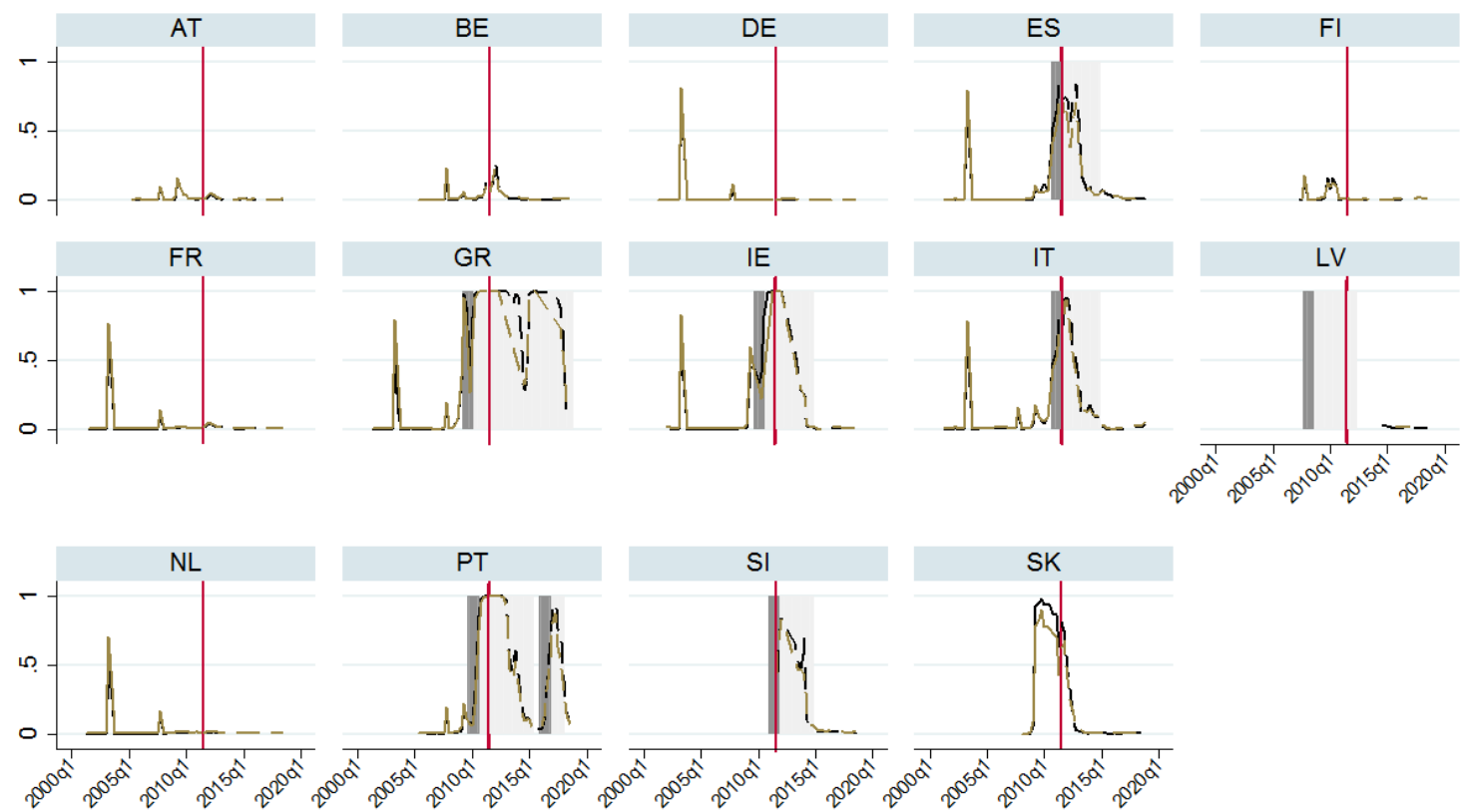

pre-LMA

LMA

Probability (optimal lambda)

Probability (1se lambda)

Notes: Probability of market access tensions from penalized logistic regression with loss-minimizing lambda (black line) and lambda, for which model error is within one standard error of the minimum (brown line). The vertical axis measures the probability of losing market access within up to 4 quarters. LMA shows periods of identified high market access tensions while pre-LMA identifies periods of up to 4 quarters prior to LMA. The red vertical line indicates start of out-of-sample forecast and the dashed line shows out-of-sample forecast probabilities of market access tensions. Country name abbreviations are as follows: $\mathrm{AT}=$ Austria, $\mathrm{BE}=$ Belgium, $\mathrm{DE}=$ Germany, $\mathrm{ES}=\mathrm{Sp}$ ain, $\mathrm{FI}=$ Finland, $\mathrm{FR}=$ France, $\mathrm{GR}=$ Greece, $\mathrm{IE}=\mid$ reland, $\mathrm{IT}=\mid \mathrm{Italy}, \mathrm{LV}=\mathrm{Latvia}$, $\mathrm{NL}=$ Netherlands, $\mathrm{PT}=$ Portugal, SI=Slovenia, SK=Slovakia. 
Figure 8: Predicted probability from boosted logistic regression
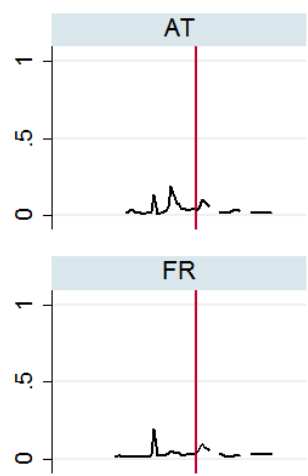
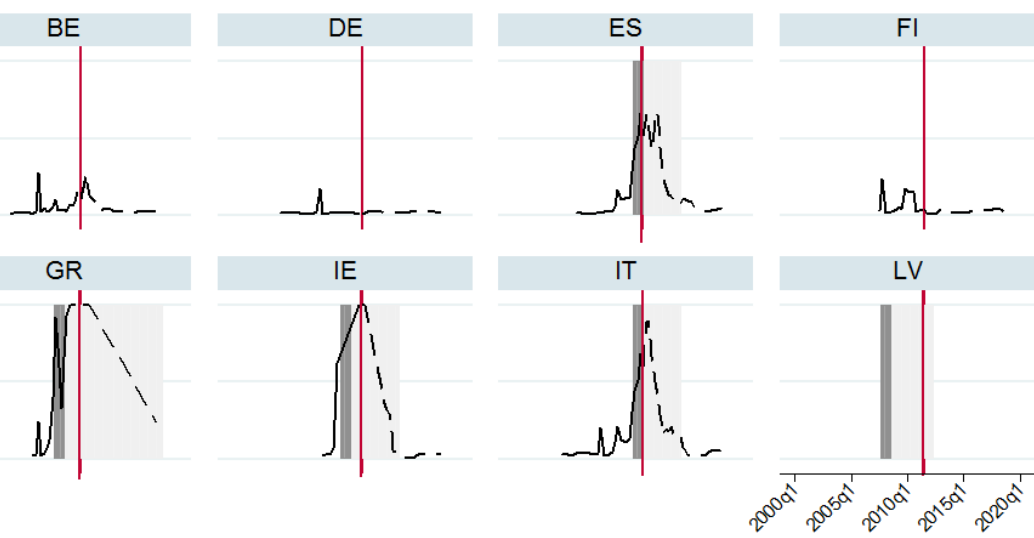
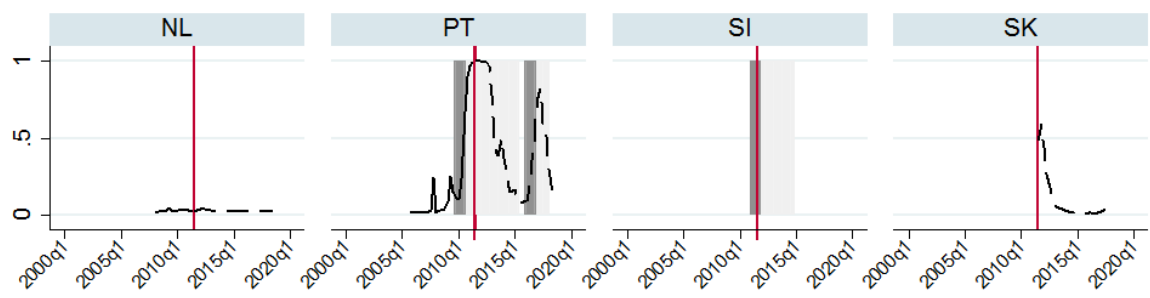

pre-LMA

LMA

Probability

Notes: Probability of market access tensions from boosted logistic regression. The vertical axis measures the probability of losing market access within up to 4 quarters. LMA shows periods of identified high market access tensions while pre-LMA identifies periods of up to 4 quarters prior to LMA. The red vertical line indicates start of out-of-sample forecast and the dashed line shows out-of-sample forecast probabilities of market access tensions. Country name abbreviations are as follows: $A T=$ Austria, $B E=$ Belgium, $D E=$ Germany, $E S=S p a i n, \quad F I=$ Finland, $F R=F r a n c e, ~ G R=G r e e c e, I E=I r e l a n d, I T=I t a l y, L V=L a t v i a$, $\mathrm{NL}=$ Netherlands, $\mathrm{PT}=$ Portugal, SI=Slovenia, SK=Slovakia. 
Table 9: Selected Indicators and their coefficient estimates

\begin{tabular}{|c|c|c|c|c|c|c|c|c|}
\hline & \multicolumn{3}{|c|}{ Logit with Sequential Selection } & \multicolumn{2}{|c|}{ Penalized Logit } & \multicolumn{3}{|c|}{ Boosted Logit } \\
\hline \multirow{2}{*}{$\begin{array}{c}\text { Indicator } \\
\text { Primary market } \\
\text { No. of issuances }\end{array}$} & Coefficient & \multicolumn{2}{|c|}{ 95\% confidence interval } & \multirow{2}{*}{$\begin{array}{c}\text { Coefficient (lambda min) } \\
-\end{array}$} & \multirow{2}{*}{$\begin{array}{c}\text { Coefficient (lambda 1SE) } \\
-\end{array}$} & \multirow{2}{*}{$\begin{array}{c}\text { Coefficient } \\
\text { - }\end{array}$} & \multicolumn{2}{|c|}{ 95\% confidence interval } \\
\hline & - & - & - & & & & - & - \\
\hline Bills issued & 3.126 & -1.066 & 7.319 & 0.24 & 0.063 & 0.02 & 0 & 0.319 \\
\hline $\begin{array}{l}\text { Floating coupon } \\
\text { issuance }\end{array}$ & 3.288 & -0.288 & 6.864 & 0.652 & 0.542 & 0.436 & 0 & 0.811 \\
\hline Syndicated issuance & - & - & - & - & - & - & - & - \\
\hline \multicolumn{9}{|l|}{ Secondary market } \\
\hline Bid-ask $2 Y$ & - & - & - & - & - & - & - & - \\
\hline Bid-ask $5 Y$ & & & & - & 0.019 & 0.086 & 0 & 0.649 \\
\hline Bid-ask $10 Y$ & 10.927 & -3.548 & 25.403 & 0.937 & 0.579 & 0.317 & 0 & 1.038 \\
\hline Foreign debt & 6.058 & -2.253 & 14.368 & 0.521 & 0.235 & 0.217 & 0 & 0.438 \\
\hline Forward rate & 14.33 & -2.529 & 31.19 & 2.942 & 2.61 & 2.053 & 0.757 & 2.574 \\
\hline Forward premium & - & - & - & - & - & - & - & - \\
\hline \multicolumn{9}{|l|}{$\begin{array}{c}\text { Global demand and } \\
\text { supply }\end{array}$} \\
\hline CDS & -3.812 & -11.214 & 3.59 & - & - & - & - & - \\
\hline Interest forecast & 2.103 & -1.346 & 5.55 & 0.453 & 0.297 & 0.306 & 0 & 1.103 \\
\hline $\begin{array}{c}\text { Economic policy } \\
\text { uncertainty }\end{array}$ & - & - & - & - & - & - & - & - \\
\hline US GDP & - & - & - & - & - & - & - & - \\
\hline$V 2 X$ & -5.047 & -11.234 & 1.14 & -0.272 & - & - & - & - \\
\hline Stock market & - & - & - & - & - & - & - & - \\
\hline GDP forecast & - & - & - & - & - & - & - & - \\
\hline Debt forecast & - & - & - & - & - & - & - & - \\
\hline $\begin{array}{l}\text { Government } \\
\text { expenditure }\end{array}$ & - & - & - & 0.132 & - & - & - & - \\
\hline Debt & - & - & - & - & - & - & - & - \\
\hline Interest payable & - & - & - & - & - & - & - & - \\
\hline Bank index & - & - & - & - & - & - & - & - \\
\hline Gross financing needs & - & - & - & - & - & - & - & - \\
\hline Bailouts & - & - & - & - & - & - & - & - \\
\hline Intercept & -7.142 & -16.174 & 1.889 & -3.12 & -3.134 & -2.509 & -3.219 & -1.921 \\
\hline
\end{tabular}




\subsubsection{Bayesian Model Averaging}

Figure 10 shows out-of-sample predicted probabilities of high market tensions based on top 5000 sampled models from Bayesian model averaging (BMA). Due to the nature of our binary dependent, we are fitting logistic regressions using uninformative beta-binomial priors for distribution across models and robust distribution for coefficient estimates. Due to a large number of potential models (there are $2^{24}$ since there are 24 potentially useful predictors) we use Monte Carlo Markov Chain (MCMC) sampler with Bayesian Adaptive Sampling (BAS) that samples models without replacement, i.e. models that have been already sampled by the algorithm are excluded from further sampling. Clyde et al. (2018) provide more details on the sampling technique.

Figure 9 summarizes the top 20 models, by model fit, from the model space, visited by the sampling MCMC algorithm with BAS sampling method. Rows correspond to top indicators while columns represent individual models. The models are ranked by their posterior model probability from the best on the left to worst on the right. Top $x$-axis shows the models' rank. In each model, missing are in black, while included variables are coloured. The colour corresponds to the log of the posterior probability of that model. These posterior probabilities are scaled so that the worst model in the top 20 models is assigned 0 . The values on the lower $\mathrm{x}$-axis correspond to log Bayes factors to allow for model comparison to the lowest probability model in the top 20 models. Models with the same colours have similar log Bayes factors, i.e. the difference in their Bayes factors is not worth a mention.

\section{Figure 9: Top 20 models from Bayesian Model Averaging}

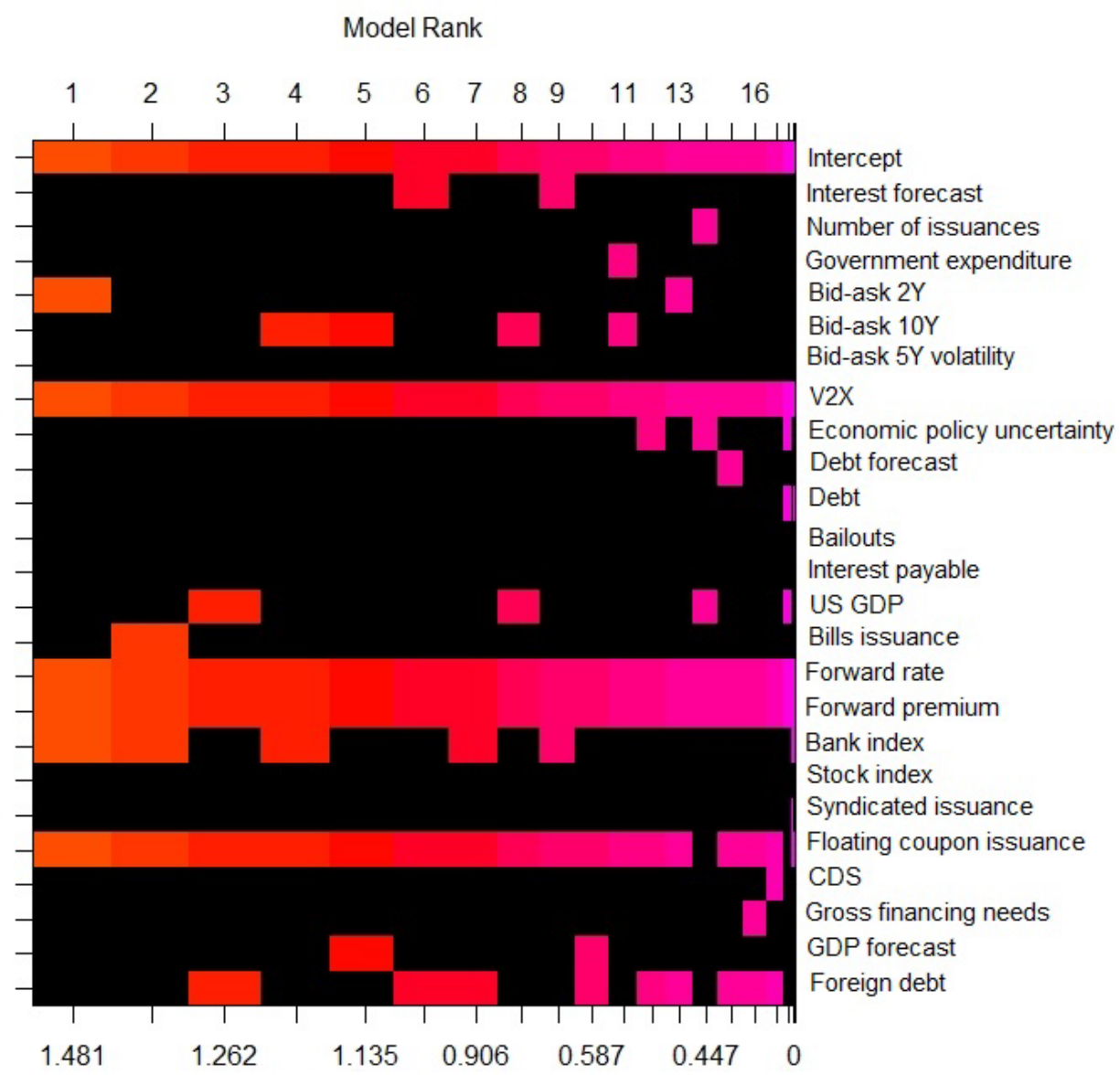

Log Posterior Odds 
Figure 10: Predicted probability of market tensions from Bayesian Model Averaging
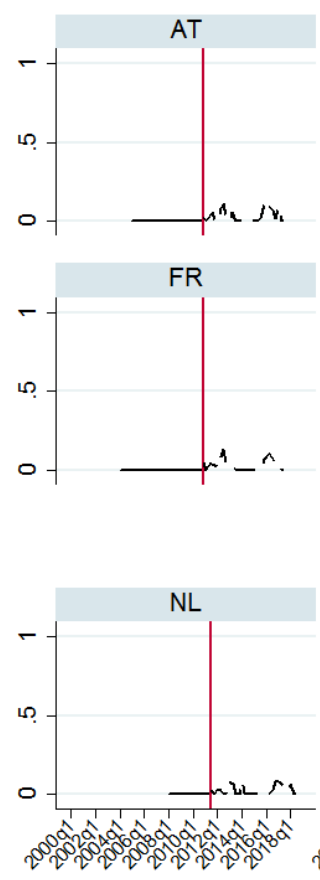
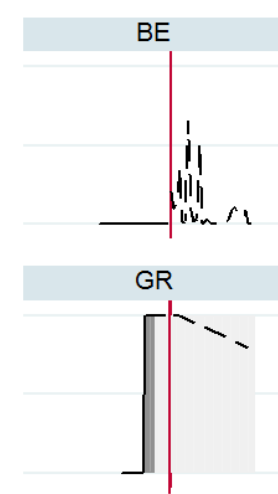

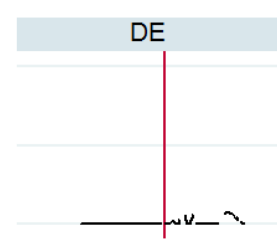

IE
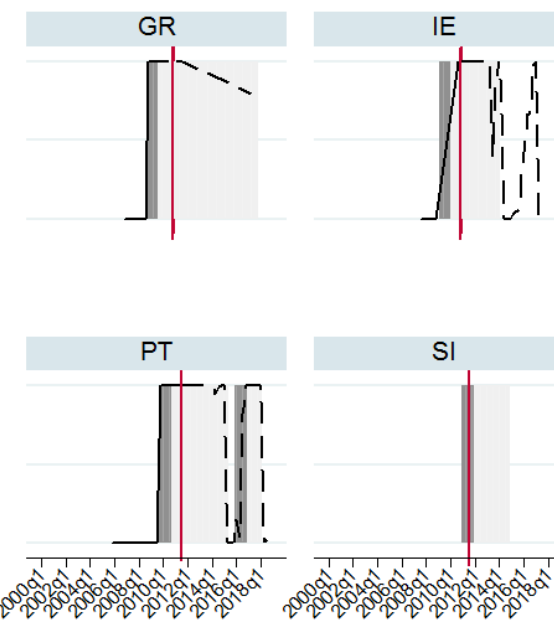

pre-LMA
SI

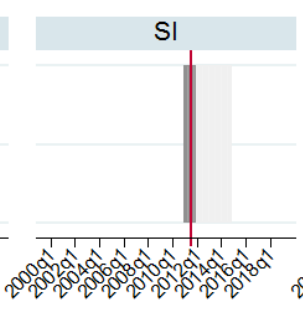

LMA
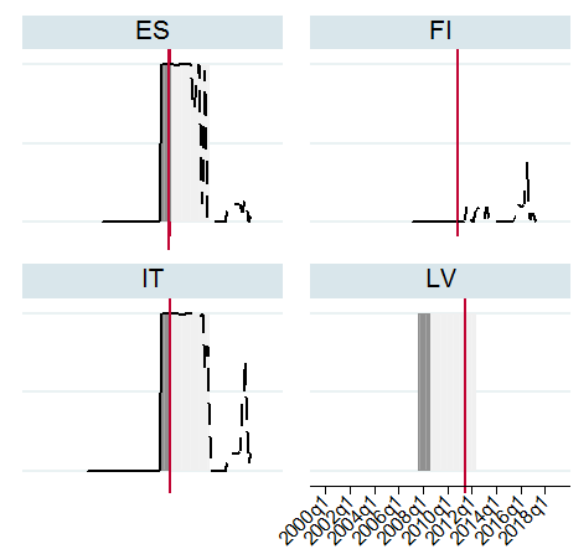

Notes: Probability of market access tensions from Bayesian Model Averaging with logistic regressions. The vertical axis measures the probability of losing market access within up to 4 quarters. LMA shows periods of identified high market access tensions while pre-LMA identifies periods of up to 4 quarters prior to LMA. The red vertical line indicates start of out-of-sample forecast and the dashed line shows out-of-sample forecast probabilities of market access tensions. Country name abbreviations are as follows: $\mathrm{AT}=$ Austria, $\mathrm{BE}=$ Belgium, $\mathrm{DE}=$ Germany, $\mathrm{ES}=\mathrm{Sp}$ ain, $\mathrm{FI}=$ Finland, $\mathrm{FR}=$ France, $\mathrm{GR}=\mathrm{Greece}$, $\mathrm{IE}=\mid \mathrm{reland}$, IT=Italy, LV=Latvia, NL=Netherlands, PT=Portugal, SI=Slovenia, SK=Slovakia.

Overall, Bayesian model averaging increases the rate of detection of loss of market access episodes in the periods leading to the event substantially. Nevertheless, the method generates more false alarms than the penalized and boosted logistic models. Using BMA, the predicted probability of market tensions was especially high for Ireland in 2017-2018. Similarly, as with the penalized and boosted logistic models, the BMA model signals spikes of high market tensions for Slovakia in 2012/2013 and in 2015 despite the fact we have not identified LMA episodes at these points in time for these countries.

\subsection{Comparison of performance}

The previous subsection presented forecast probabilities of high sovereign bond market tensions from different econometric models. Overall, based on Figures 6-8 and 10, it appears all the presented techniques perform quite well in and out of sample. To compare the models' performance more rigorously, we focus on the predicted probabilities of market tensions in the periods of up to four quarters prior to the identified loss of market access. Table 11 summarizes the predicted probabilities from each technique for these periods by country. Probabilities highlighted dark grey are the highest for that country-period from among the applied econometric approaches.

Probabilities from the Bayesian Model Averaging (BMA) approach are the highest from among the tested techniques in all periods for which they are available, apart from the period preceding the second Portuguese LMA episode by three quarters. However, despite the correctly predicted high market tensions probabilities, BMA does not generate forecasts for Ireland, Latvia and Slovenia due to 
increased data limitations for some indicators for these countries. An additional concern with such methods is that BMA generates more false alarms than the other techniques.

Table 11: Predicted probabilities in periods of up to 4 quarters

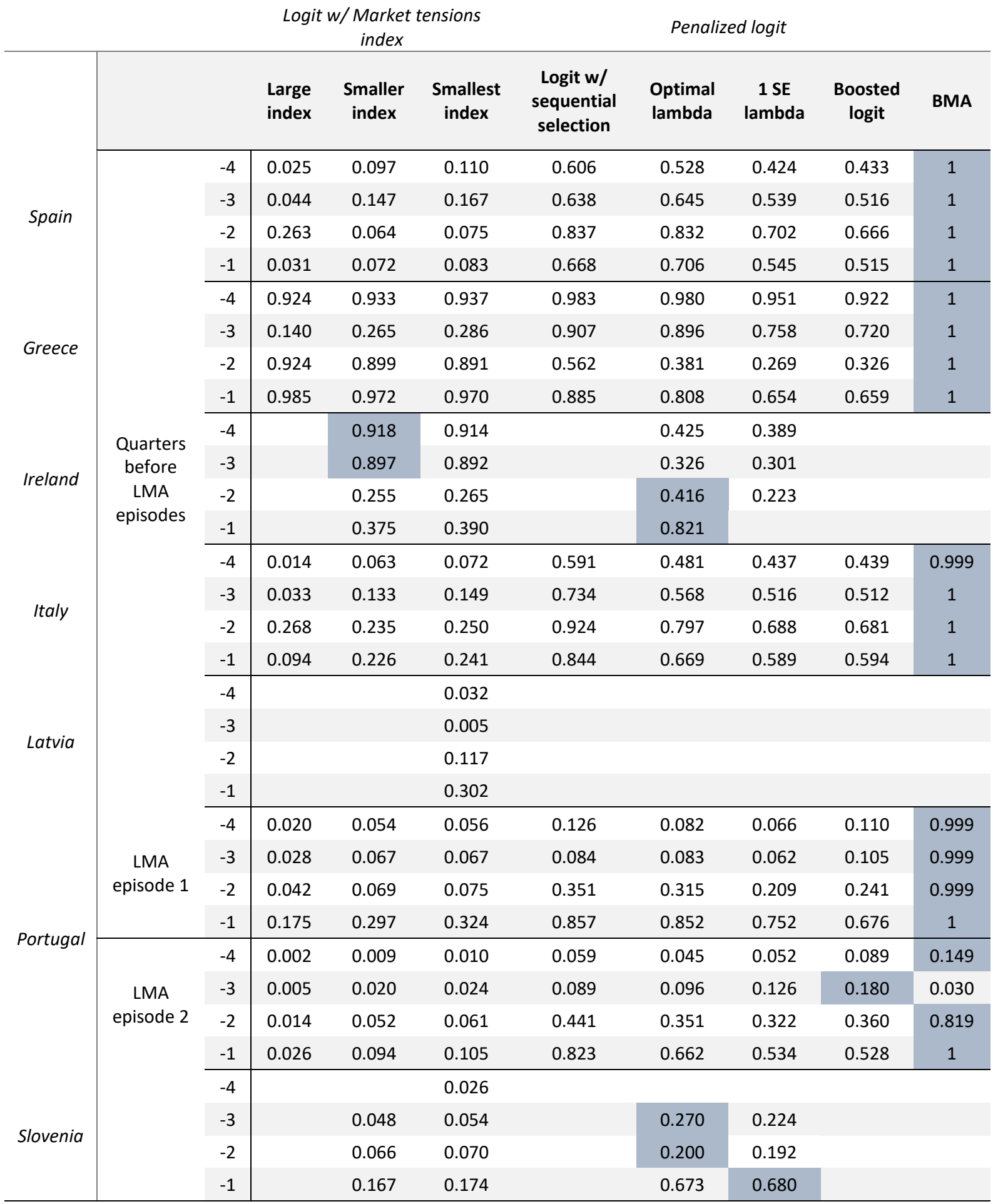

Notes: Optimal lambda denotes loss-minimizing lambda and 1 SE lambda indicates lambda, for which model error is within one standard error of the minimum.

Without including interaction terms among explanatory variables into the set of potential predictors of LMA episodes, the multivariate approaches presented in this paper do not account for conditional relations between right-hand side indicators. Such relationships can be intuitively expressed using 
decision tree structures. Classification and regression trees (CART) and their aggregation using bagging, i.e. the random forest (Breiman, 2001), boosting, i.e. extreme gradient boosting or XGBoost (Chen and Guestrin, 2016), or CRAGGING (Vezzoli and Stone, 2007) are all methods that apply the tree-like partitioning of data using conditional thresholds. For instance, in an economic context Alessi and Detken (2018) apply the random forest to identify excessive credit and the associated build-up of systemic risk in the banking system while Gabriele (2019) combines the regression tree approach with the CRAGGING algorithm to build an early warning model of systemic banking crises. Consequently, CART-based models might be useful to study episodes of loss of market access further as well as to allow for interplay of various indicators within the same framework.

\section{Preferences between missed crises and false alarms}

In practice, policymakers will likely not be indifferent between failing to issue a signal of market access tensions and emitting a false alarm. For this reason, in this section we consider alternative sets of preferences for Type I (missed crisis) and Type II (false alarm) errors. A policymaker who cares less about emitting false alarms than about missing an LMA would put $\theta>0.5$ in the loss function $L$ in equation (4) to penalize failure to issue a signal relatively more than emitting false alarms. Alternatively, a policymaker who wishes to avoid false alarms more than missing crises would choose $\theta<0.5$ in the loss function $L$ in equation (4). To take into account such potential differences in preferences, we repeat the univariate evaluation of our full set of potentially useful LMA indicators on a sample until 2011 Q2 under two alternative preferences. For a policymaker who cares more about failure to provide a signal, we assume weights of $80 \%$ and $20 \%$ for Type I and Type II error, respectively. Symmetrically, we adopt weights of $20 \%$ and $80 \%$ for Type I and Type II error, respectively, for a policymaker who cares more about false alarms.

Tables $A 1$ and $A 2$, in Appendix $A$, present the results of univariate evaluation of the top primary, secondary market and global demand and supply indicators which reflect policymaker's asymmetric preferences. Under both preference schemes, indicators from the primary and secondary market, as well as demand and supply side are represented. Indicators capturing primary market issuance (number/quantity) are retained under alternative preferences. Among secondary market indicators, forward rates, forward premia, the share of foreign investors, and bid-ask spreads remain among the top predictors. Among demand and supply indicators, US GDP growth, debt to GDP ratio, CDS, GDP forecasts and interest rate forecasts are the top indicators regardless of the policymaker's preferences.

Univariate evaluation yields critical thresholds for individual indicators, which allow to visually represent indicator dynamics using country-specific heatmaps. Figure A6 in Appendix A shows the signals provided by the top LMA indicators under preference weights of 80/20 for Type I and Type II errors (on the left) and 20/80 (on the right). For the policymaker with a preference for not missing potential distress, it is particularly noteworthy that most of the indicators flash red throughout our sample, even in countries that did not experience high market access tensions in the past. Instead, when a policymaker cares more about false alarms, the heatmaps stay predominantly blue (below their critical thresholds) but they still flash red in periods in which countries experienced LMA episodes according to our definition. Therefore, heatmaps fail to accurately depict market access tensions when used by a policymaker that cares more about missed crises, but remain useful for a policymaker that is more concerned about issuing too many false alarms. 
As a last step, we use the two alternative sets of top indicators chosen by the $80 / 20$ and the 20/80 policymakers as explanatory variables in one of the multivariate models used in our benchmark calculations, a penalized logistic regression. Tables 12 and 13 evaluate, respectively, the in-sample and out-of-sample performance of the penalized logit model for the specifications under alternative preferences, and compare it to the performance under the baseline specification. We present estimated coefficients for indicators selected endogenously by the model in Tables A3 and A4 under preferences of 80/20 and 20/80 for Type I and Type II errors, respectively. Figure A7 shows in-sample and out-of-sample predicted probabilities of high market access tensions for the two preference specifications as well as for the benchmark specification.

Table 12: In-sample model performance under various preferences

\begin{tabular}{|c|c|c|c|c|c|c|c|c|}
\hline Model & $U$ & Threshold & $\begin{array}{l}\text { Threshold } \\
\text { (percentile) }\end{array}$ & $A \cup C$ & Type I & Type II & $\begin{array}{c}\text { True } \\
\text { positive }\end{array}$ & $\begin{array}{c}\text { True } \\
\text { negative }\end{array}$ \\
\hline $\begin{array}{c}\text { Model A } \\
\text { (benchmark) }\end{array}$ & 0.122 & 0.270 & 0.863 & 0.951 & $10.5 \%$ & $7.1 \%$ & $89.5 \%$ & $92.9 \%$ \\
\hline $\begin{array}{c}\text { Model B } \\
\text { (benchmark) }\end{array}$ & 0.114 & 0.209 & 0.862 & 0.939 & $11.1 \%$ & $8.0 \%$ & $88.9 \%$ & $92.0 \%$ \\
\hline $\begin{array}{c}\text { Model A } \\
\text { (missing/false: } \\
80 / 20 \text { ) }\end{array}$ & 0.174 & 0.222 & 0.890 & 0.993 & $5.9 \%$ & $1.8 \%$ & $94.1 \%$ & $98.2 \%$ \\
\hline $\begin{array}{c}\text { Model B } \\
\text { (missing/false: } \\
\text { 80/20) }\end{array}$ & 0.144 & 0.159 & 0.866 & 0.970 & $0.0 \%$ & $7.1 \%$ & $100.0 \%$ & $92.9 \%$ \\
\hline $\begin{array}{c}\text { Model A } \\
\text { (missing/false: } \\
\text { 20/80) }\end{array}$ & 0.193 & 0.391 & 0.894 & 0.999 & $0.0 \%$ & $0.9 \%$ & $100.0 \%$ & $99.1 \%$ \\
\hline $\begin{array}{c}\text { Model B } \\
\text { (missing/false: } \\
\text { 20/80) }\end{array}$ & 0.189 & 0.299 & 0.890 & 0.998 & $0.0 \%$ & $1.4 \%$ & $100.0 \%$ & $98.6 \%$ \\
\hline
\end{tabular}

Notes: Model A stands for penalized logistic regression with loss-minimizing lambda while model B stands for penalized logistic regression with lambda, for which model error is within one standard error of the minimum. $U$ stands for usefulness of a model calculated from equation (3) given a policymaker's preference for Type I and Type II error. AUC stands for the area under receiver's operating characteristics curve (ROC).

Compared to 50/50 preferences, an 80/20 policymaker would lower Type I but also Type II errors. Instead, a 20/80 policymaker would lower Type II error relatively even more in sample. Things change out of sample. Across all weight specifications, there is a relatively large increase in Type I error while the false alarms rate tends to slightly decrease compared to in-sample performance. Models under 20/80 tend to deteriorate comparatively more with respect to Type I error. One reason for this could be the presence of collinearity among explanatory variables. ${ }^{23} \mathrm{~A}$ more likely explanation is that, as observed in Figure 7 and Table 11, the penalized logit tends to generate more Type I than Type II errors out of sample. Under the 20/80 preference specification, a policymaker penalizes missing events much less than false alarms, inflating the Type I error rate compared to the 50/50 benchmark.

${ }^{23}$ Two of the candidate indicators in this specification, deficit forecast and primary balance forecast, are indeed very highly correlated. The resulting model, however, contains only one of these indicators, deficit forecast. Nevertheless, we reestimated the penalized logit using the input set of candidate indicators that excludes primary balance forecast. We find that the final model contains the same 9 indicators for which even the estimated coefficients are identical to those in the original calculation under these unequal preferences. Consequently, we do not believe collinearity is the issue here. 
Table 13: Out-of-sample model performance under various preferences

\begin{tabular}{c|cccc}
\hline Model & Type I & Type II & True positive & True negative \\
\hline Model A (benchmark) & $37.5 \%$ & $1.8 \%$ & $62.5 \%$ & $98.2 \%$ \\
Model B (benchmark) & $37.5 \%$ & $1.9 \%$ & $62.5 \%$ & $98.1 \%$ \\
\hline Model A (missing/false: 80/20) & $33.3 \%$ & $1.9 \%$ & $66.7 \%$ & $98.1 \%$ \\
Model B (missing/false: 80/20) & $33.3 \%$ & $2.2 \%$ & $66.7 \%$ & $97.8 \%$ \\
\hline Model A (missing/false: 20/80) & $66.7 \%$ & $0.0 \%$ & $33.3 \%$ & $100.0 \%$ \\
Model B (missing/false: 20/80) & $66.7 \%$ & $0.0 \%$ & $33.3 \%$ & $100.0 \%$ \\
\hline
\end{tabular}

Notes: Model A stands for penalized logistic regression with loss-minimizing lambda while model B stands for penalized logistic regression with lambda, for which model error is within one standard error of the minimum.

The performance of the penalized logit model under different preferences can be visually summarized using heatmaps as in Figure A8 in the Appendix. The predicted probabilities of market access tensions generally exceed identified probability thresholds in quarters around identified LMA episodes. The models which penalize false alarms relatively more fail to issue signals during the second Portuguese LMA episode, while models penalizing failure to signal emit a false alarm for Slovakia.

Overall, our results show that following signals from multivariate models with indicator selection provides a more reliable early warning signal of market access tensions under policymaker's alternative preferences than output from a univariate analysis of the top indicators of LMA.

\section{Robustness checks}

To test the stability of our benchmark results, as well as their sensitivity to different specifications, such as definition of the loss of market access episodes and indicator availability, we perform a series of robustness exercises within the setting of policymaker's equal preferences. The first robustness exercise applies a different definition of market access episodes. More specifically, we apply only the first two conditions for identification of LMAs from Table 1: ESM/IMF program dates and episodes identified by Guscina et al. (2017). Second, we exclude forward rate, forward premium and CDS rate indicators from our set of LMA predictors. The reasoning behind this decision arises from concerns about self-fulfilling forward market movements that might impact sovereign bond spot markets in the future. Furthermore, CDS rates can move the underlying bond spot rates. ${ }^{24}$

The results of both sets of robustness exercises are presented in sections B1 and B2 in the Appendix, respectively. When forward rate difference to top performer, forward premium and CDS rate are excluded due to potential endogeneity, the importance of the same primary and secondary market indicators as in our baseline framework is confirmed. However, the set of global demand and supply indicators identified by multivariate approaches expanded to include economic policy uncertainty index, banking sector index, government debt and gross financing needs.

Notably, when we adopt the alternative definition of LMA episodes to exclude those identified by the spread level condition (third column of Table 1), the importance of the forward rate difference from the best performer, our best single predictor decreases. Under this narrower LMA definition, all models

\footnotetext{
${ }^{24}$ Fontana and Scheicher (2016), who analyse euro area sovereign bond and CDS markets, observe that while in some countries price discovery takes place in the CDS market, in others price discovery is observed in the bond market.
} 
still report small to moderate increases in market access distress probabilities in late 2011/2012 for Italy. ${ }^{25}$

\section{Conclusions}

In this paper we study episodes of sovereign loss of market access. We construct a detailed dataset with potential indicators of market access tensions, as identified by market experts and the academic literature, and evaluate their ability to forecast market access tensions.

Univariate analysis shows that factors associated with high market access tensions are not limited to financial markets, but encompass also developments in global demand, macroeconomic factors and the fiscal stance. Forward rate difference from the best performer emerged as the most important predictor of market access tensions. The identified informative indicators of market access tensions are, however, too numerous to be meaningfully included within a multivariate model that generalizes well out of sample. To select which variables should be included in the final model, we apply several approaches to resolving model uncertainty; we construct a market tensions index (MTI) to use as a single predictor; we sequentially eliminate variables one by one from conventional logit model; and we estimate lasso and boosted logit models. Lastly, we run logit models using many combinations of the top identified LMA indicators and report the weighted results from the model space. We find that the more complex methods outperform predicted probabilities from simple logit with MTI, which are generally quite low in the quarters preceding LMA outbreaks. The most complex method, BMA, yields the highest probabilities of LMA in the quarters leading to the LMA incidence across countries included in our panel. In contrast, BMA also generates more false alarms than the other methods.

We consider two scenarios when a policymaker is not indifferent between missing an LMA episode and issuing a false alarm. In one scenario, a policymaker cares more about missing an LMA event. In the other, she is more concerned about issuing false alarms. Regardless of the policymaker's preference, the number and quantity of primary market issuance, forward rates, forward premia, bid-ask spreads, the share of foreign investors, US GDP growth, debt to GDP ratio, CDS, GDP forecasts and interest rate forecasts are among the top indicators of market access tensions. We further show that a policymaker who cares more about missing an LMA episode would not be able to provide an appropriate policy response based on univariate signals from individual indicators which flash red over most periods in our sample, even in countries that did not experience high market access tensions. Instead, signals from a univariate analysis would still be useful and flash red in periods in which countries experienced an LMA episode if the policymaker is more concerned about issuing false alarms. In a multivariate setting, models with indicator selection provide a more reliable early warning signal of market access tensions than individual indicators separately under both types of policymaker's asymmetric preferences.

Our results point to a trade-off between transparency/communicability and accuracy that policymakers face in the search for tools to evaluate risks to market access. While transparent and easy to communicate, single indices of market tensions can capture worsening conditions in accessing financing from bond markets but do not typically yield satisfactory out-of-sample results. Conversely, multivariate models perform better, but are harder to explain in a simple and transparent way.

\footnotetext{
${ }^{25}$ The spike in the projected probability of tensions in the Italian bond market represents, in a strict sense, a false alarm. One could, however, link this increase in predicted market tensions to another policy reaction, which reportedly aimed at reducing tensions in sovereign bond markets, because they were hampering the transmission of monetary policy - Draghi's "Whatever it takes" speech.
} 


\section{References}

Abbas, A., Blattner, L., De Broeck, M., El-Ganainy, A., \& Hu, M., 2014. "Sovereign Debt Composition in Advanced Economies: A Historical Perspective". IMF Working Papers 14/162.

Alesina, A., De Broeck, M., Prati, A. \& Tabellini, G., 1992. "Default risk on government debt in OECD countries". Economic Policy, vol. 15, pp. 427-451.

Alessi, L. \& Detken, C., 2011. "Quasi real time early warning indicators for costly asset price boom/bust cycles: A role for global liquidity". European Journal of Political Economy, vol. 27(3), pp 520-533.

Alessi,L. \& Detken, C., 2018. "Identifying excessive credit growth and leverage". Journal of Financial Stability, vol. 35, pp. 215-225.

Arellano, C., \& Ramanarayanan, A., 2012. "Default and the Maturity Structure in Sovereign Bonds". Journal of Political Economy, vol. 120(2), pp. 187-232.

Ariccia, G., Ferreira, C., Jenkinson, N., Laeven, L., Martin, A., Minoiu, C., \& Popov. A, 2018. “Managing the sovereign-bank nexus". ECB Working Paper no. 2177.

Arslanalp, S., \& Poghosyan, T., 2014. "Foreign Investor Flows and Sovereign Bond Yields in Advanced Economies". IMF Working Papers 14/27.

Arslanalp, S., \& Liao, Y., 2014. "Banking sector contingent liabilities and sovereign risk". Journal of Empirical Finance, vol. 29, pp. 316-330.

Baker, S., Bloom, N., \& Davis, S., 2016. "Measuring Economic Policy Uncertainty". The Quarterly Journal of Economics, vol. 131(4), pp. 1593-1636.

Baldacci, E., Petrova, I. K., Belhocine, N., Dobrescu, G. \& Mazraani, S., 2011. "Assessing Fiscal Stress". IMF Working Papers 11/100.

Baldacci, E., McHugh, J., \& Petrova, I., 2011. "Measuring Fiscal Vulnerability and Fiscal Stress: A Proposed Set of Indicators". IMF Working Paper 11/94.

Balteanu, I., \& Erce, A., 2017. "Linking Bank Crises and Sovereign Defaults: Evidence from Emerging Markets". ESM Working Paper, 22/2017.

Bassanetti, A., Cottarelli, C., \& A. Presbitero, 2016. "Lost and Found: Market Access and Public Debt Dynamics. IMF Working Paper 16/253.

Baur, D., \& Lucey, B., 2009. "Flights and contagion-An empirical analysis of stock- bond correlations". Journal of Financial Stability, vol. 5(4), pp. 339-352.

Belton, T., Dawsey, K., Greenlaw, D., Huacen, L., Ramaswamy, S., \& B. Sack, 2018. “Optimizing the Maturity Structure of US Treasury Debt: A Model-Based Framework," Hutchins Centre, Working Paper No. 46.

Beetsma, R., Giuliodori, M., Hanson, J. \& De Jong, F., 2018. "Cross-border auction cycle effects of sovereign bond issuance in the Euro Area". Journal of Money, Credit and Banking, forthcoming.

Beetsma, R., Giuliodori, M., Hanson, J. \& De Jong, F., 2018. "Bid-to-cover and yield changes around public debt auctions in the euro area". Journal of Banking \& Finance, 87, pp. 118-134.

Bernoth, K., von Hagen, J., Schuknecht, L., 2004. "Sovereign risk premia in the European government bond market". ECB Working Paper 369. 
Bordo, M., \& Haubrich, J., 2008. "The yield curve as a predictor of growth: Long-run evidence 18751997". Review of Economics and Statistics, vol. 90, pp. 182-185.

Breiman, L. (2001): "Random forests." Machine Learning 45 (1), pp. 5-32.

Broner, F.A., Lorenzoni, G. \& Schmukler, S.L., 2013. "Why do emerging economies borrow short term?" Journal of the European Economic Association, Vol.11 (S1), pp. 67-100.

Buhlmann, P., 2006. "Boosting for high-dimensional linear models". The Annals of Statistics, vol. 34, pp. 559-583.

Buhlmann, P. \& Yu, B., 2003. "Boosting with the L2 loss: Regression and classification". Journal of the American Statistical Association, vol. 98, pp. 324-338.

Bussiere, M. \& Fratzscher, M., 2006. "Towards a new early warning system of financial crises," Journal of International Money and Finance, Elsevier, vol. 25(6), pp. 953-973, October.

Candelon, B., Dumitrescu E. \& Hurlin, C., 2012. "How to Evaluate an Early-Warning System: Toward a Unified Statistical Framework for Assessing Financial Crises Forecasting Methods". IMF Economic Review, vol. 60(1), pp. 75-113.

Casalinho, C., Kalozois, P., O'Connor, F., de Ramon-Laca, P., Rojas, J., \& R. Strauch, 2016. "Accessing sovereign markets - the recent experiences of Ireland, Portugal, Spain and Cyprus", ESM Discussion Paper Series No.2.

Chen, T. \& Guestrin, C., 2016. "XGBoost: A Scalable Tree Boosting System". Proceedings of the 22nd ACM SIGKDD International Conference on Knowledge Discovery and Data Mining, San Francisco, California, USA, pp. 785-794.

Clyde, M., Littman, M., Wang, Q., Ghosh, J. \& Li, Y., 2018. "Bayesian Variable Selection and Model Averaging using Bayesian Adaptive Sampling", mimeo.

Cruz, P., \& Koc, F., 2018. "The liquidity buffer practices of public debt managers in OECD countries". OECD Working Papers on Sovereign Borrowing and Public Debt Management, No. 9, OECD.

De Broeck, M., \& Guscina, A., 2011. "Government Debt Issuance in the Euro Area: The Impact of the Financial Crisis", IMF Working Paper 11/21.

Engle, R., \& J. Rangel, 2008. "The spline GARCH model for low frequency volatility and its global macroeconomic causes". The Review of Financial Studies, vol. 21(3), pp. 1187-1222.

Estrella, A., \& Hardouvelis, G., 1991. "The Term Structure as a Predictor of Real Economic Activity". The Journal of Finance, Vol. 46, No. 2, pp. 555-576.

Estrella, A., \& Mishkin, F., 1998. "Predicting U.S. Recessions: Financial Variables as Leading Indicators". The Review of Economics and Statistics, Vol, 80, pp. 45-61.

Eidam, F., 2017. "Gap-Filling Government Debt Maturity Choice," ZEW Discussion Papers 18-025.

Gabriele, C., 2019. "Learning from Trees: A Mixed Approach to Building Early Warning Systems for Systemic Banking Crises". ESM Working Paper 40/2019.

Gabriele, C., Erce, A., Athanasopoulou, M., \& Rojas, J., 2017. “Debt Stocks Meet Gross Financing Needs: A Flow Perspective into Sustainability". ESM Working Paper 24/2017.

Gelper, S., \& Croux, C., 2010. "On the Construction of the European Economic Sentiment Indicator". Oxford Bulletin of Economics and Statistics, vol. 72(1), pp. 47-62. 
P.R. Fisher, 2012. "Thoughts on Debt Sustainability: Supply and Demand," keynote remarks published in Is U.S. Government Debt Different?" Wharton Financial Institutions Centre Press.

Fontana, A., \& Scheicher, M., 2016. "An analysis of euro area sovereign CDS and their relation with government bonds". Journal of Banking \& Finance, Volume 62, pp. 126-140,

Friedman, J., Hastie, T. \& Tibshirani, R., 2008. "Regularization Paths for Generalized Linear Models via Coordinate Descent", available at: https://web.stanford.edu/ hastie/Papers/glmnet.pdf

Gelos, G., Sahay, R., \& G. Sandleris, 2004. "Sovereign Borrowing by Developing Economies: What Determines Market Access?" IMF Working Paper 04/221.

Gerlach, S., \& Stuart, R., 2018. "The Slope of the Term Structure and Recessions: The Pre-Fed Evidence, 1857-1913”. CEPR Discussion Paper No. DP13013.

Guscina, A., Malik, S. \& Papaioannou, M., 2017. "Assessing Loss of Market Access: Conceptual and Operational Issues". IMF Working Papers 17/246.

Hastie, T., Tibshirani, R. \& Friedman, J., 2009. "The Elements of Statistical Learning: Data Mining, Inference, and Prediction". Springer, New York.

Hauner, D. \& Kumar, M., 2006. "Fiscal Policy and Interest Rates--How Sustainable Is the New Economy?" IMF Working Paper No. 06/112.

Jaramilllo, L., \& Zhang, Y., 2013. "Real Money Investors and Sovereign Bond Yields". IMF Working Papers 13/254.

Jonasson, T., \& Papaioannou, M., 2018. "Sovereign Debt Management During Debt Distress Periods" Journal of Investing, Vol. 27, Issue 3, pp. 65-73.

Jonasson, T., \& Papaioannou, M., 2018. "A primer on managing sovereign debt-portfolio risks". IMF Working Paper 18/74.

Koop, G., 2003. "Bayesian Econometrics". John Wiley \& Sons.

Lang, J. H., Izzo, C., Fahr, S., \& Ruzicka, J., 2019. "Anticipating the bust: a new cyclical systemic risk indicator to assess the likelihood and severity of financial crises", ECB Occasional Paper Series No. 219.

Roecker, E. B., 1991. "Prediction error and its estimation for subset - selected models". Technometrics, vol. 33, pp. 459-468.

Schalck, C., 2017. "Public Debt Management in Developed Economies During the Crisis", Global Financial Crisis and Its Ramifications on Capital Markets, Contributions to Economics (Haciogllu \& Dincer).

Sigaux, J.D., 2018." Trading ahead of Treasury auctions", ECB Working Paper Series No. 2208.

Vezzoli, M. and C. Stone, 2007. "Cragging", manuscript, Department of Statistics, University of California, Berkeley. 


\section{Appendix}

\section{Section A}

Figure A1: Median indicator dynamics around start of LMA episodes
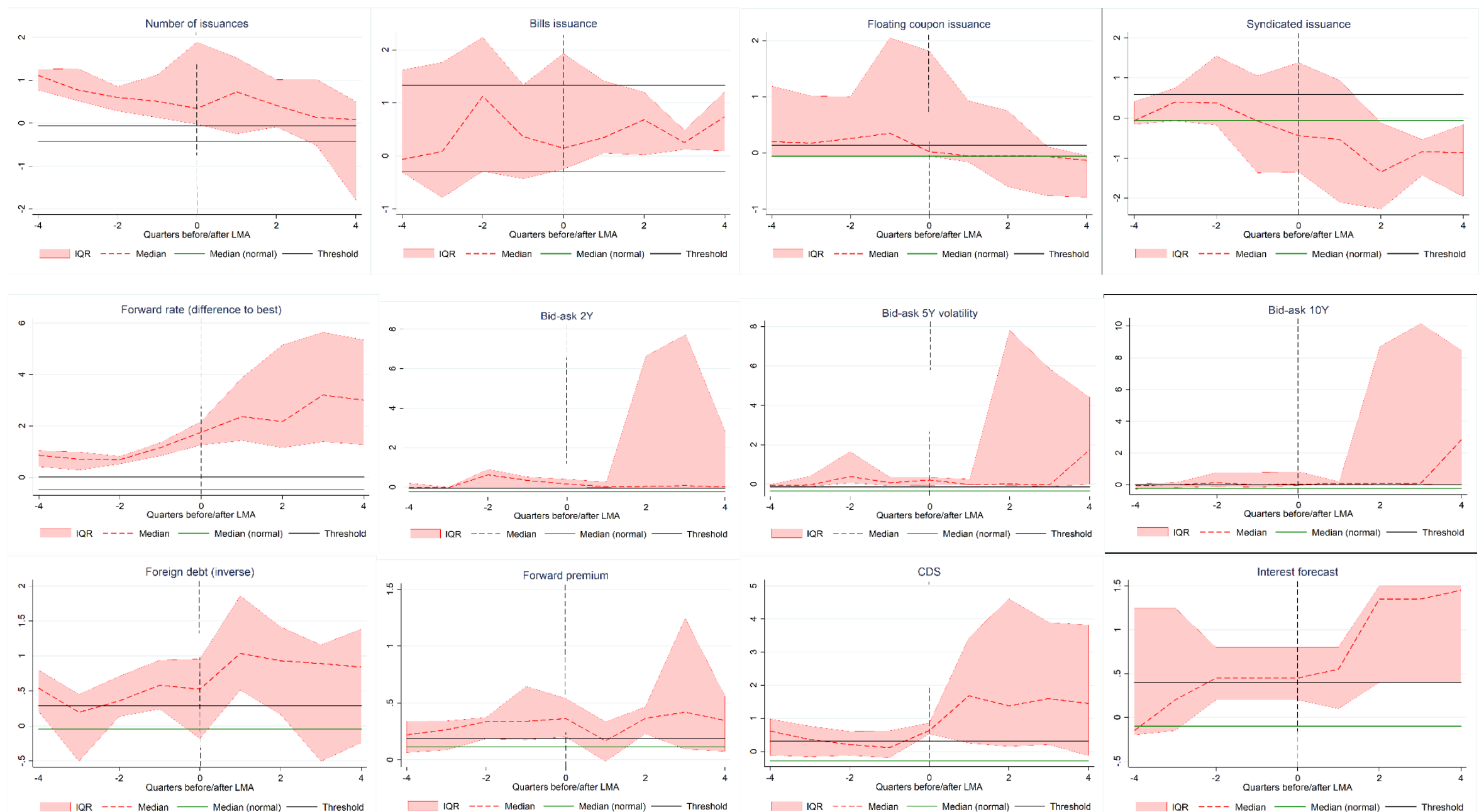

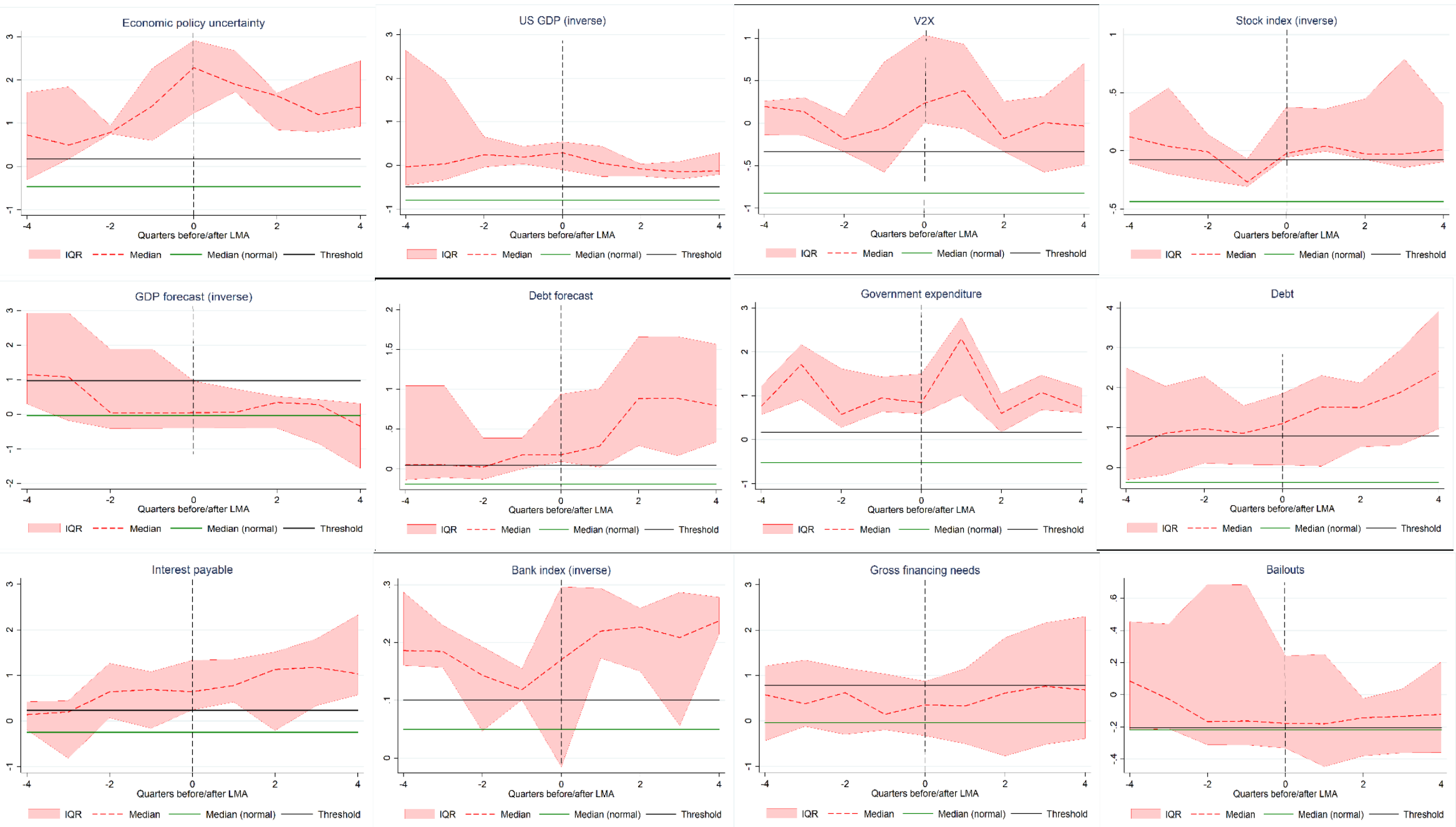

Notes: IQR stands for interquartile range; the difference between $75^{\text {th }}$ and $25^{\text {th }}$ percentile of indicator distribution 
Figure A2. Indicator dynamics vis-à-vis their respective thresholds: Heatmaps
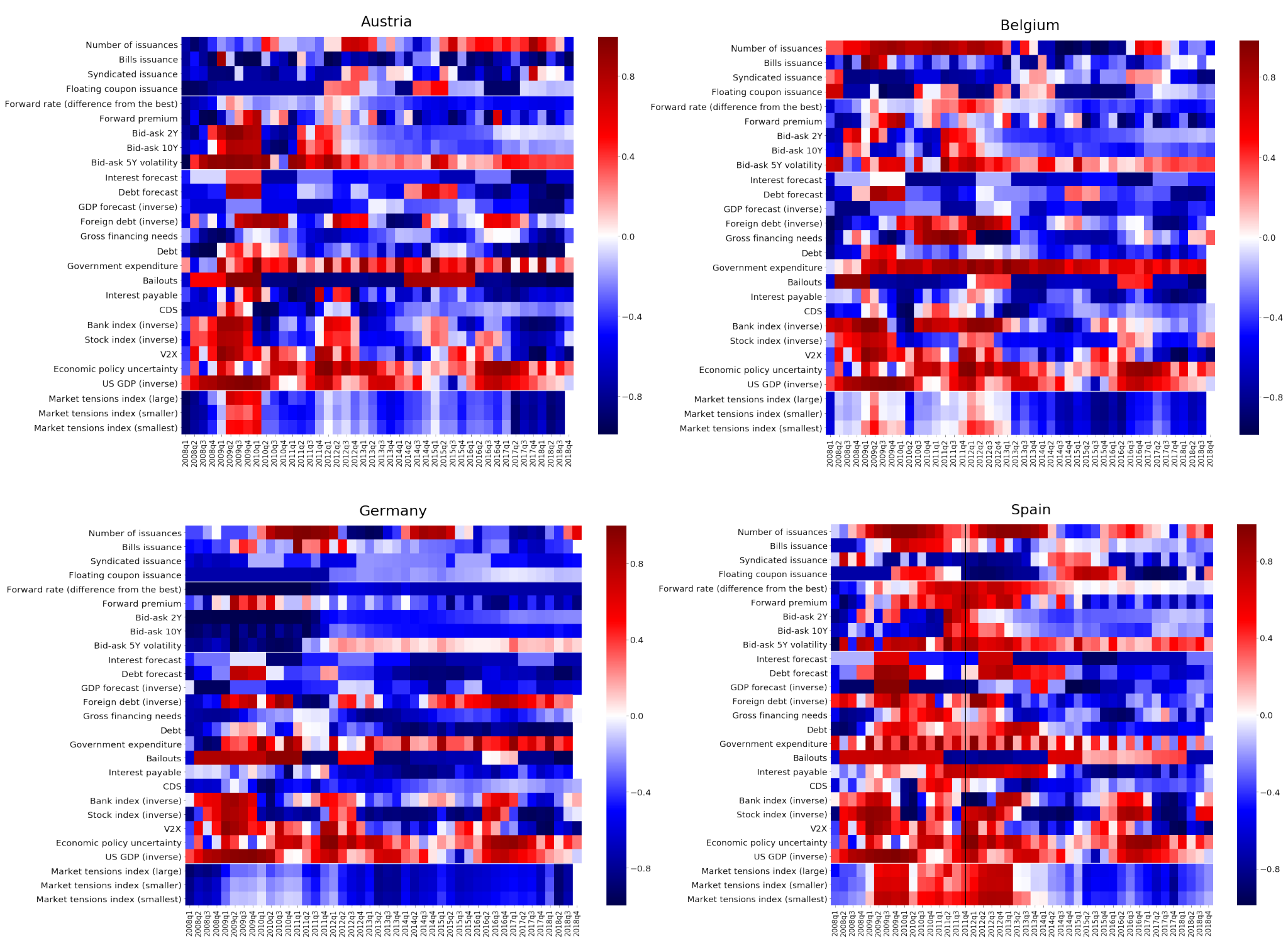

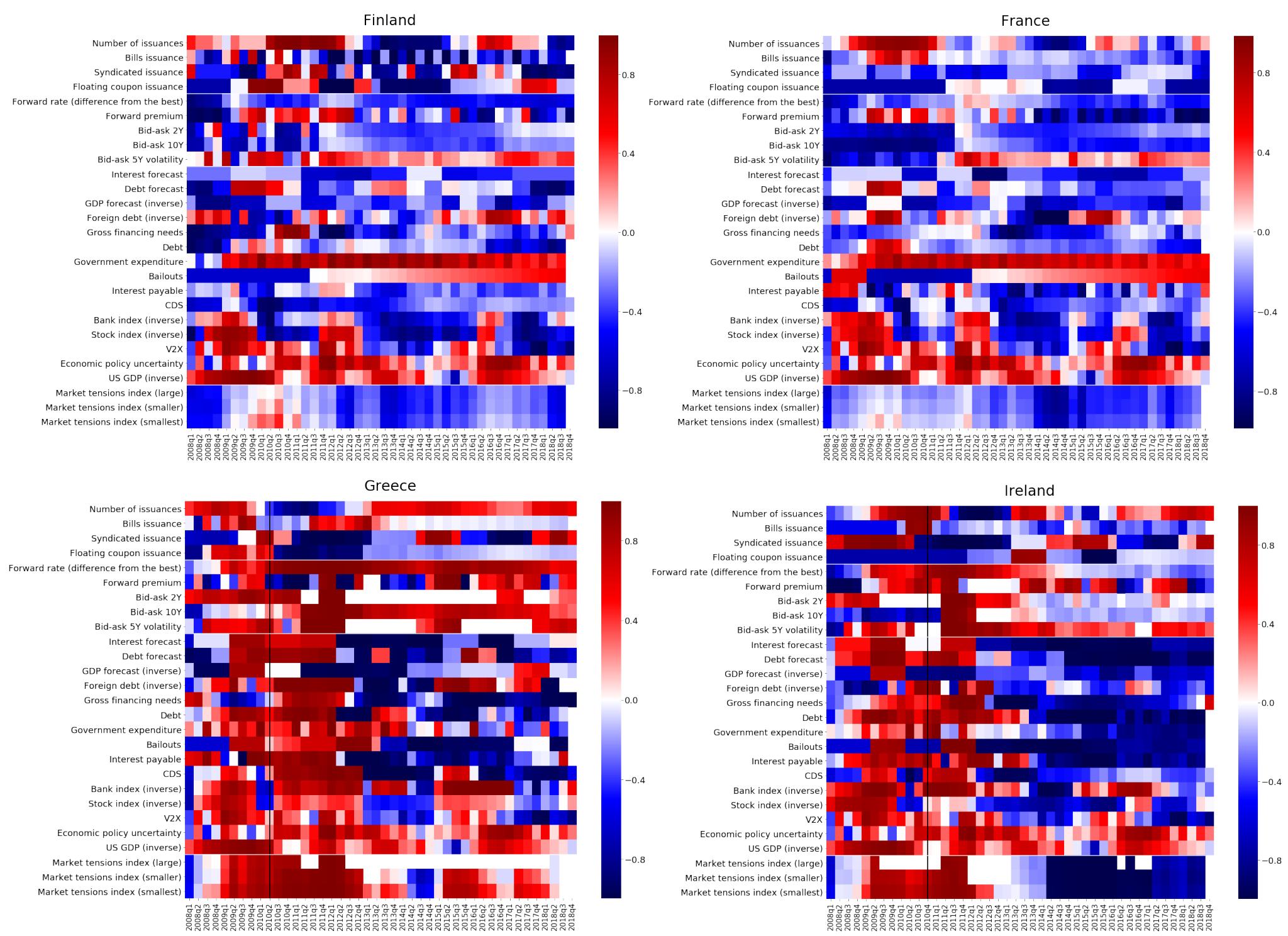

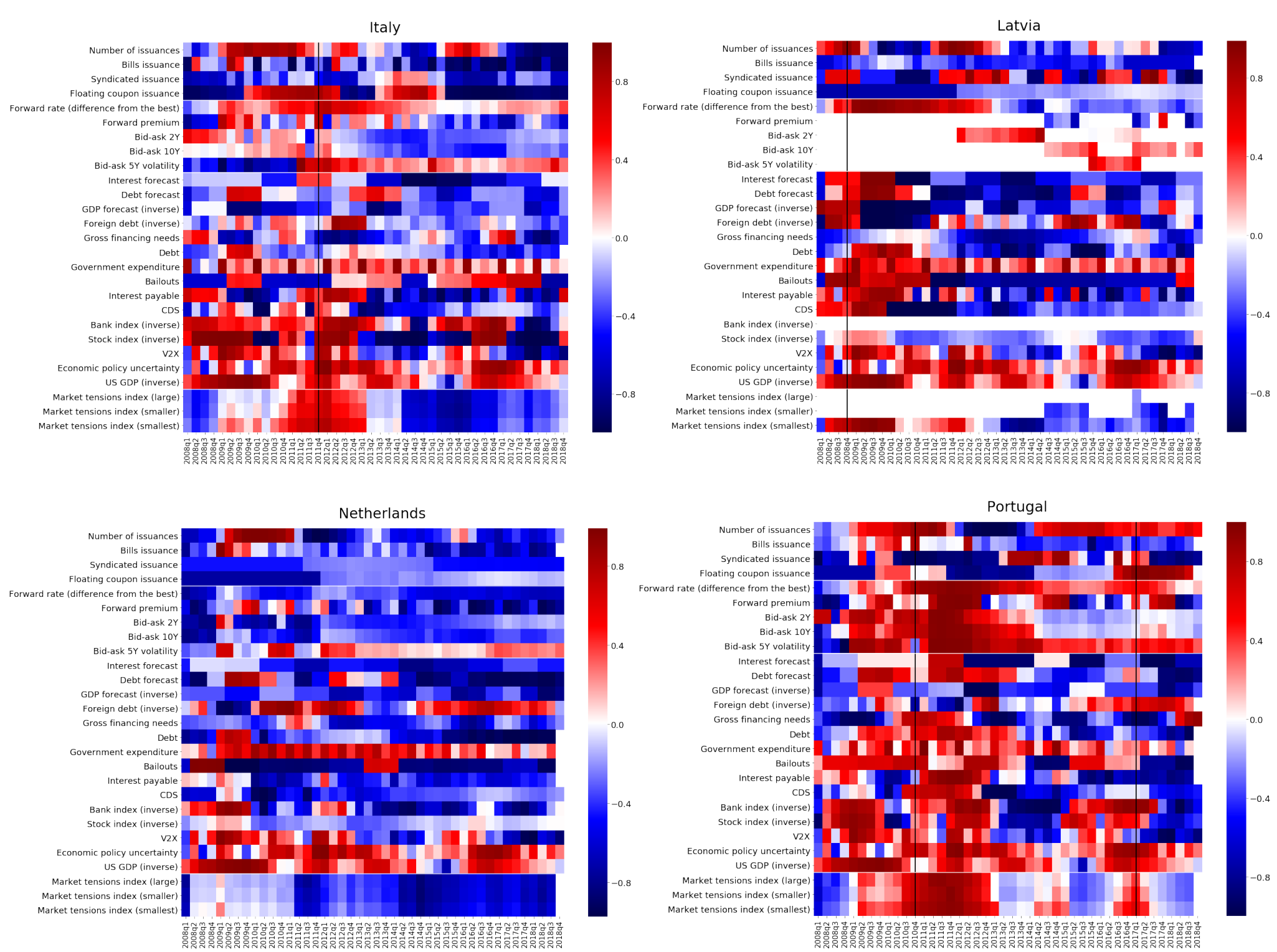

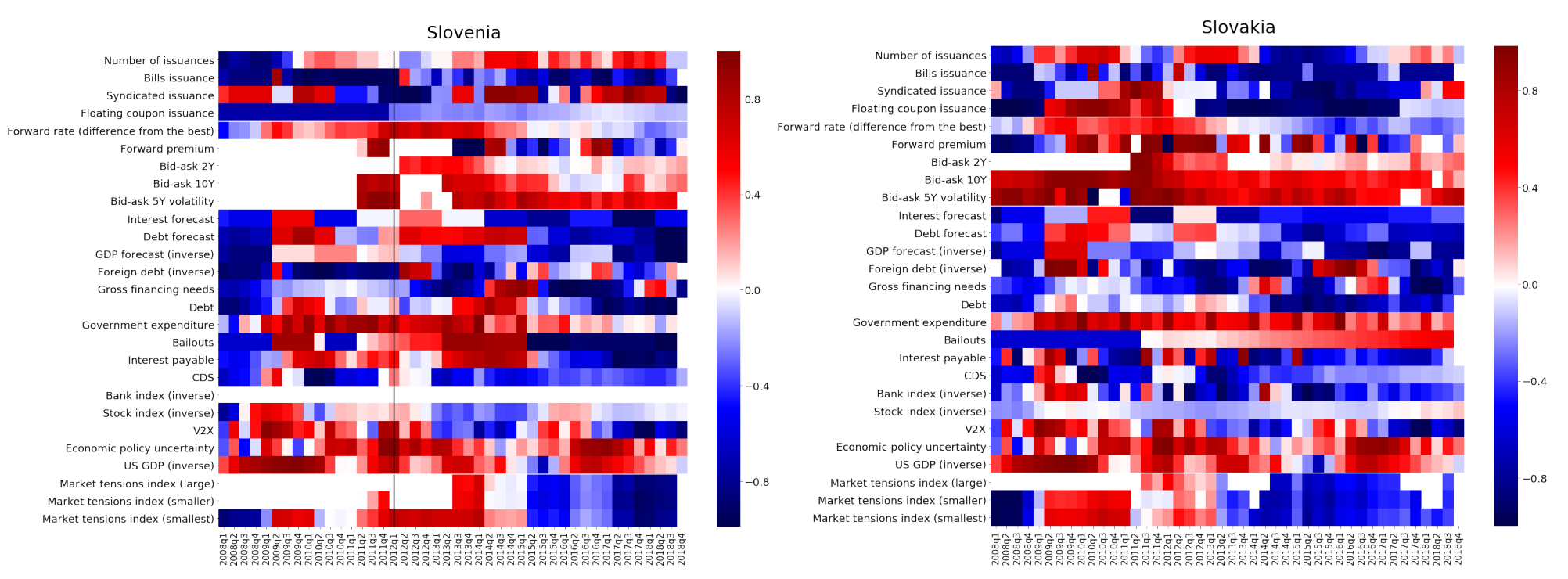

Notes: The black vertical line shows year-quarter of the start of identified LMA episodes. 


\section{Figure A3. Overview of LMA episodes per country and definition}

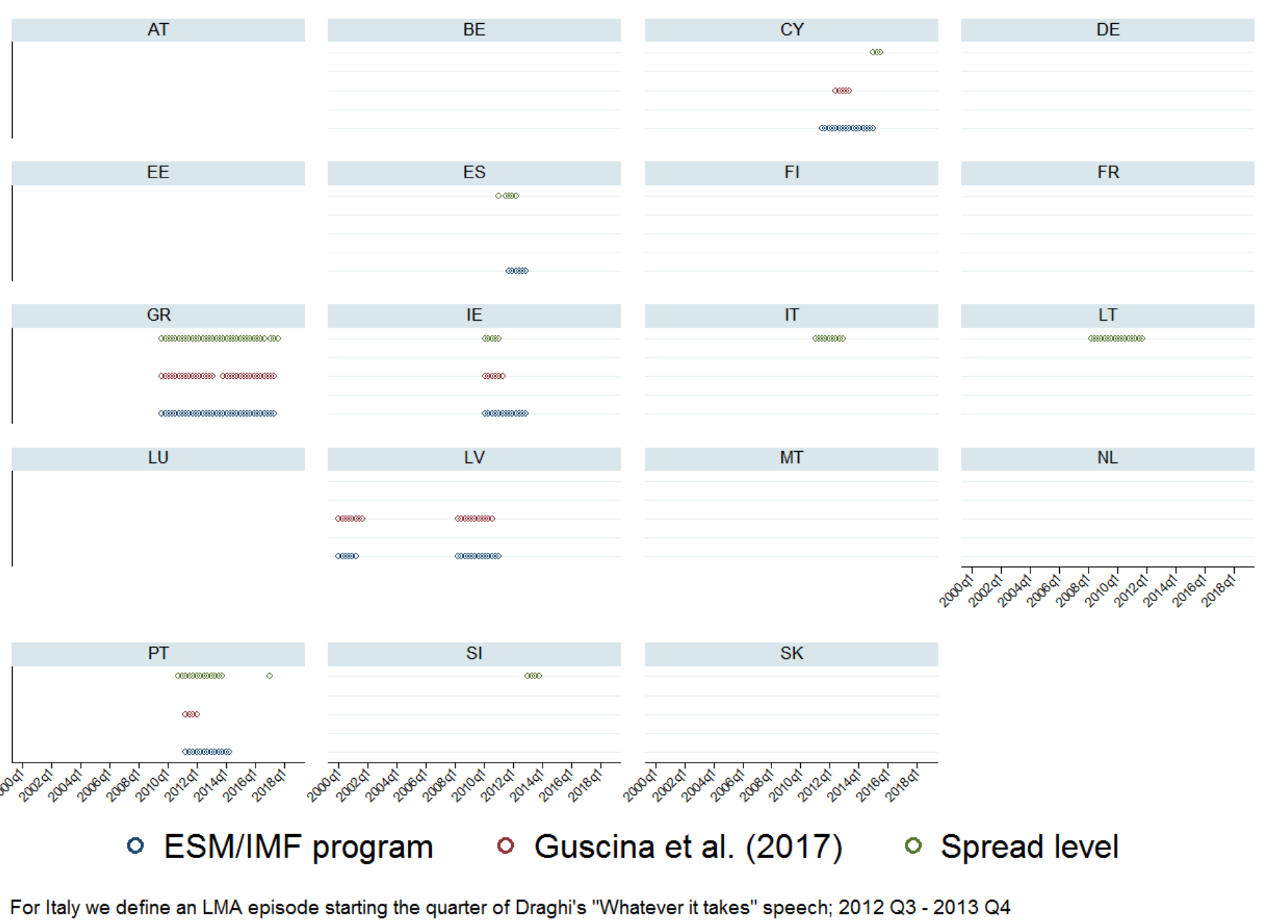

Notes: Country name abbreviations are as follows: $A T=A$ Astria, $B E=B e l g i u m, D E=G e r m a n y, E S=S p a i n, F I=F i n l a n d, F R=F r a n c e, G R=G r e e c e, I E=I r e l a n d, I T=I t a l y, L V=L a t v i a, N L=N e t h e r l a n d s$, PT=Portugal, SI=Slovenia, SK=Slovakia. 
Figure A4. Decomposition of the smallest MTI

Austria
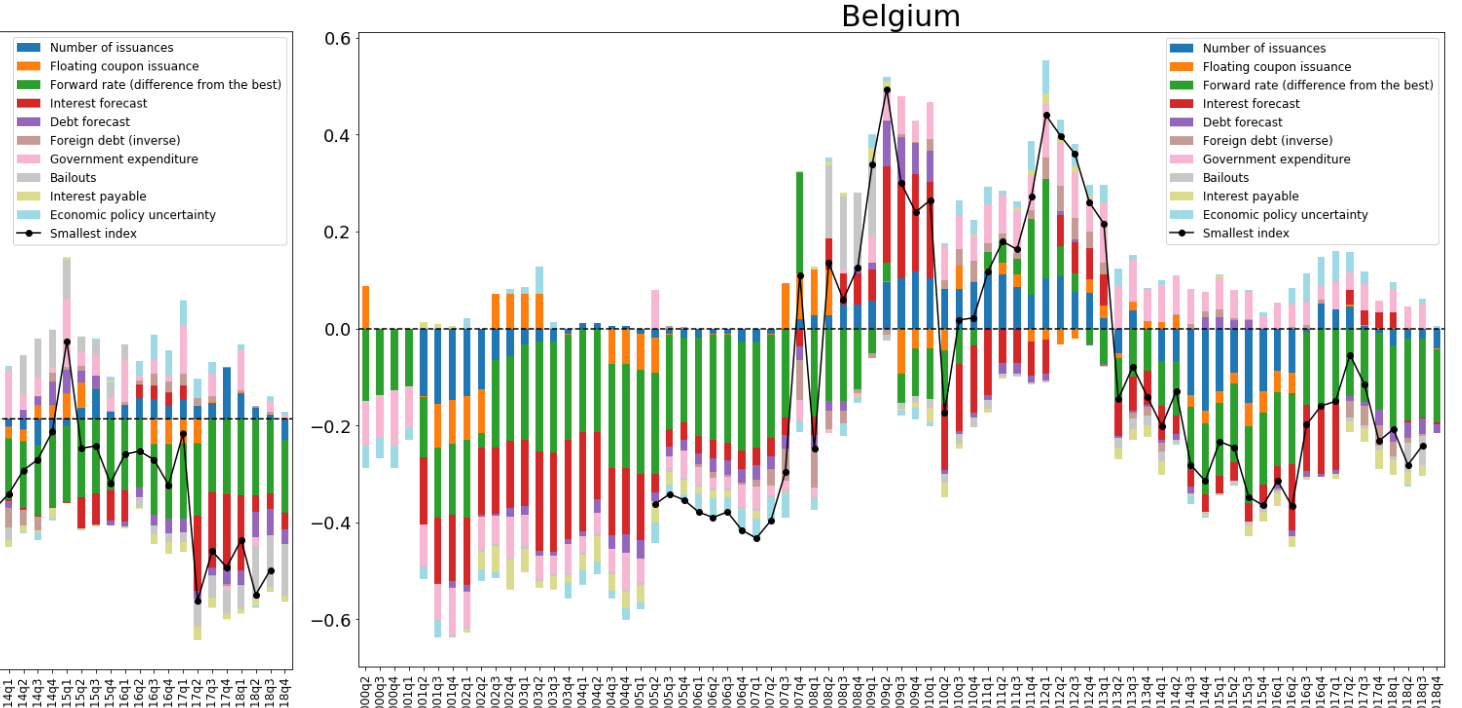

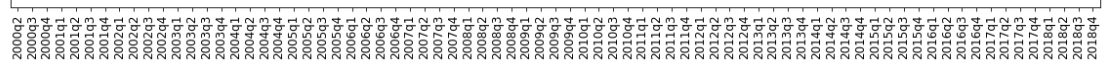

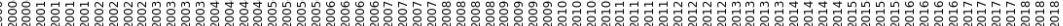
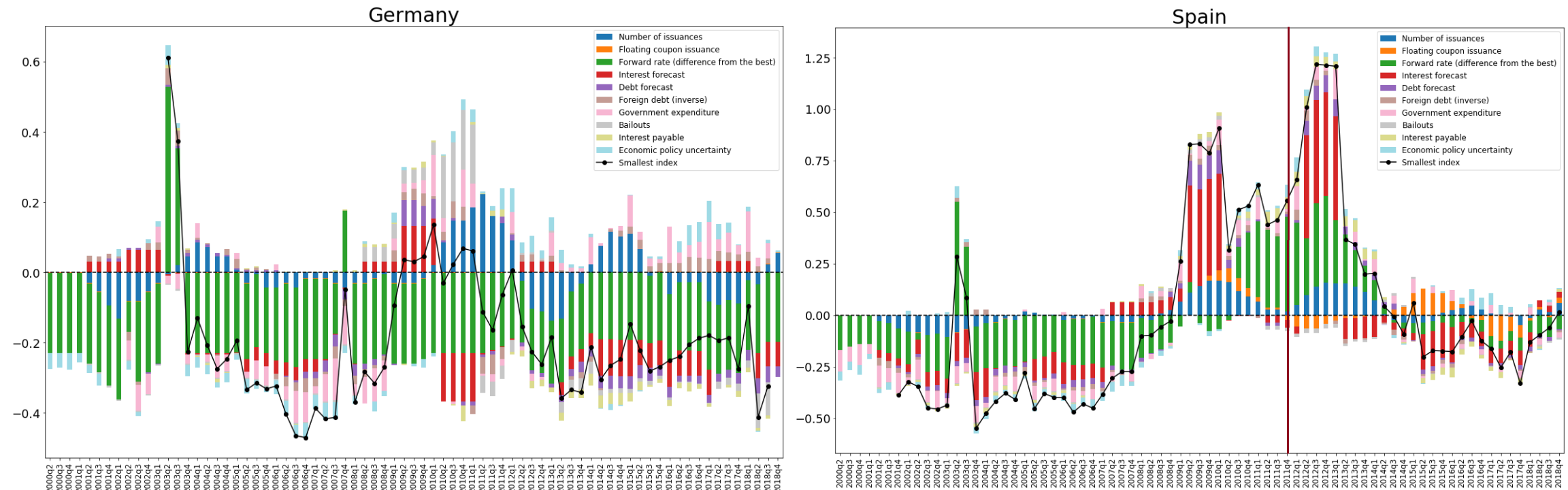
Finland

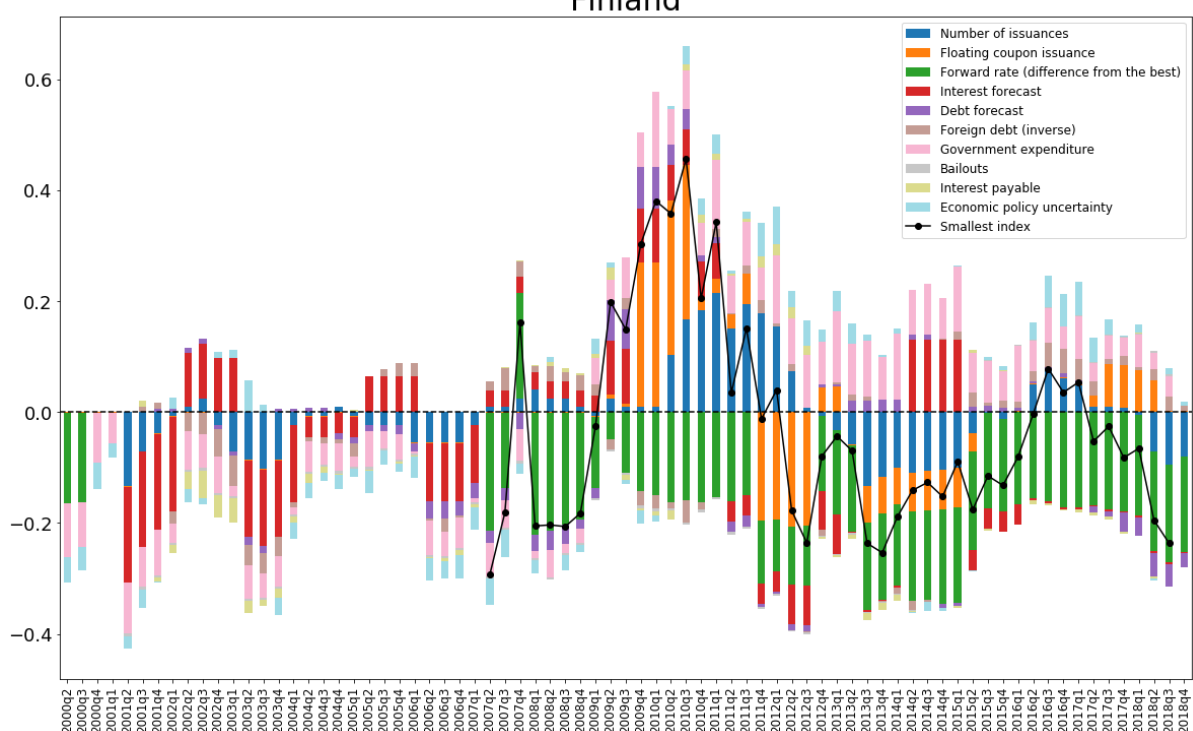

Greece

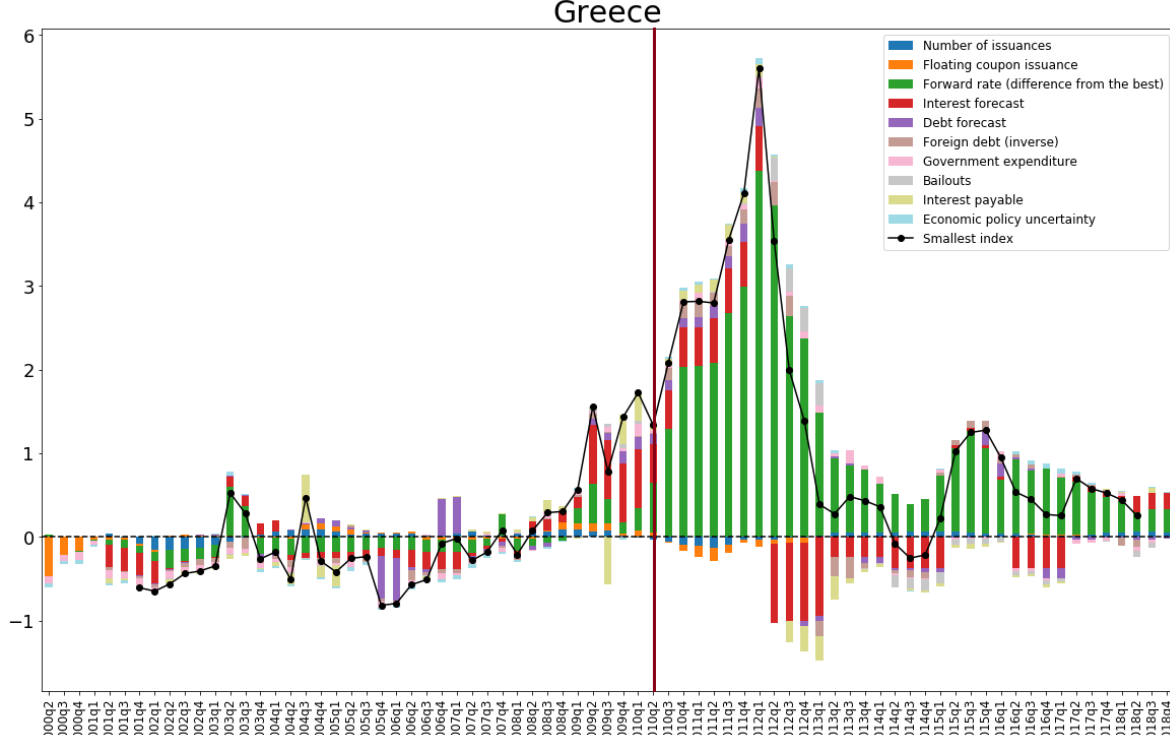

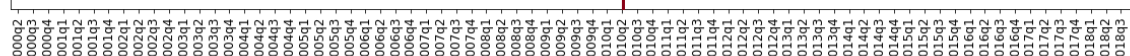

France

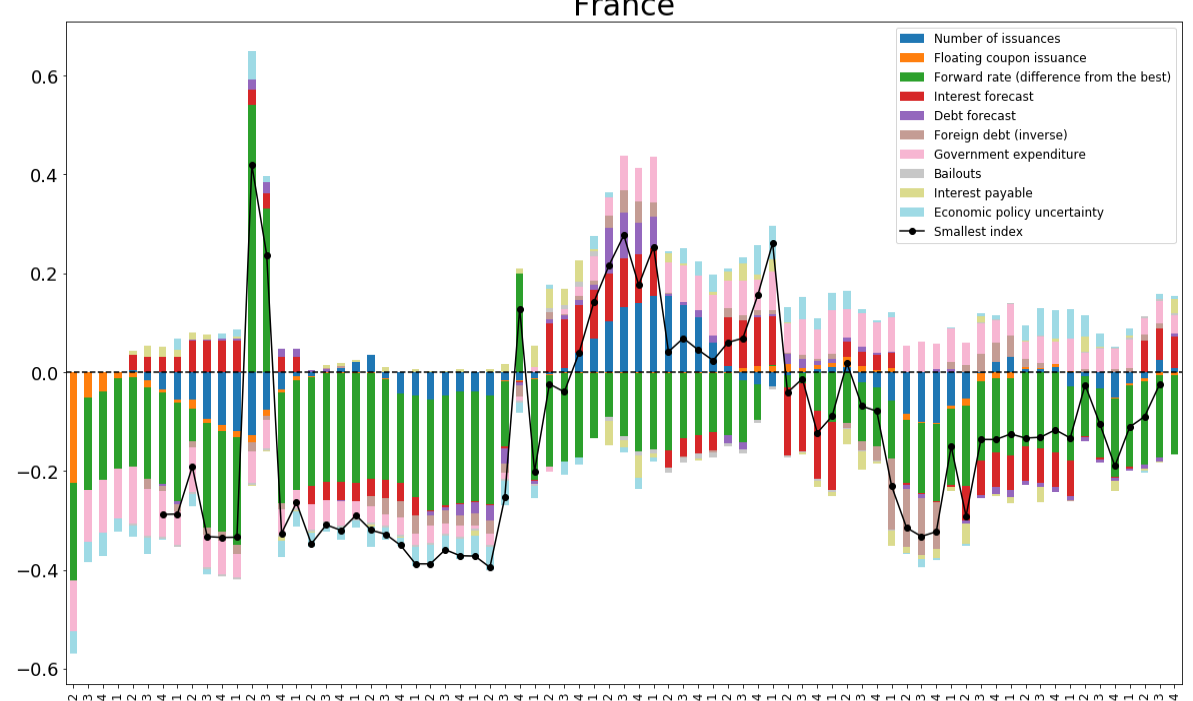

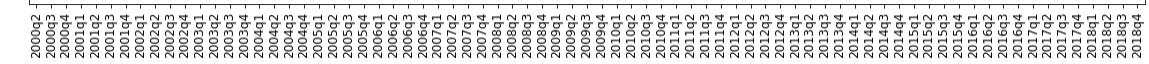

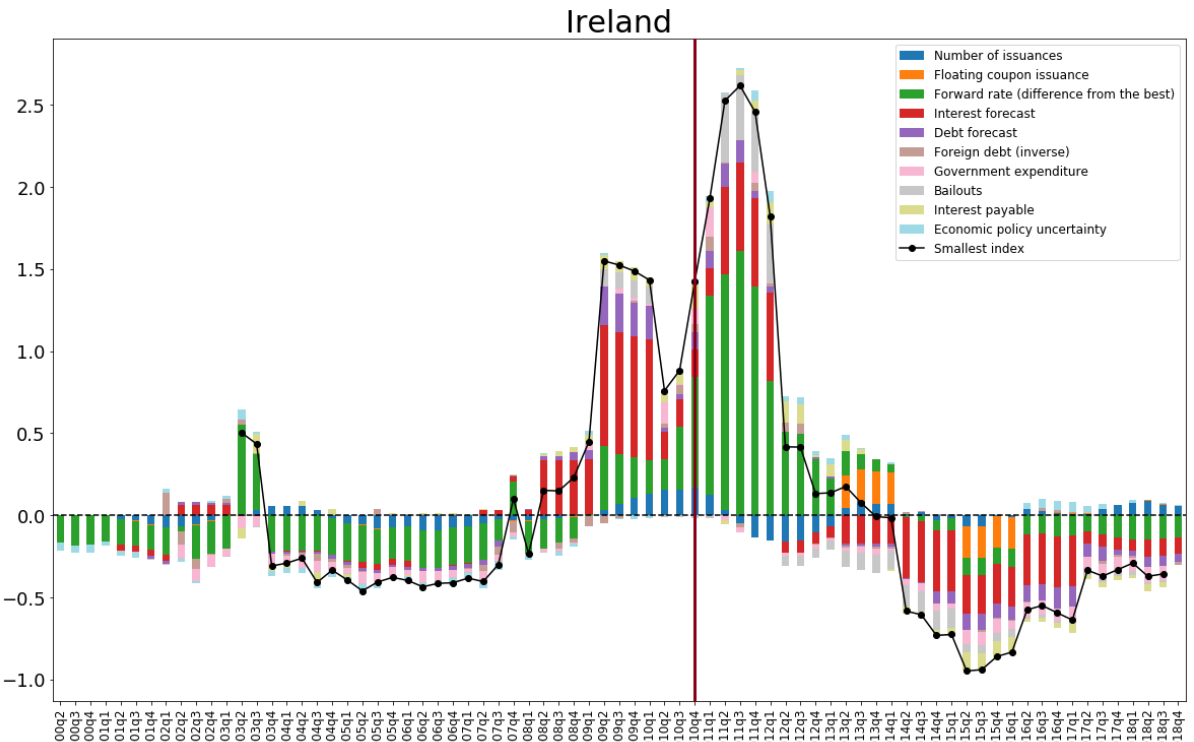



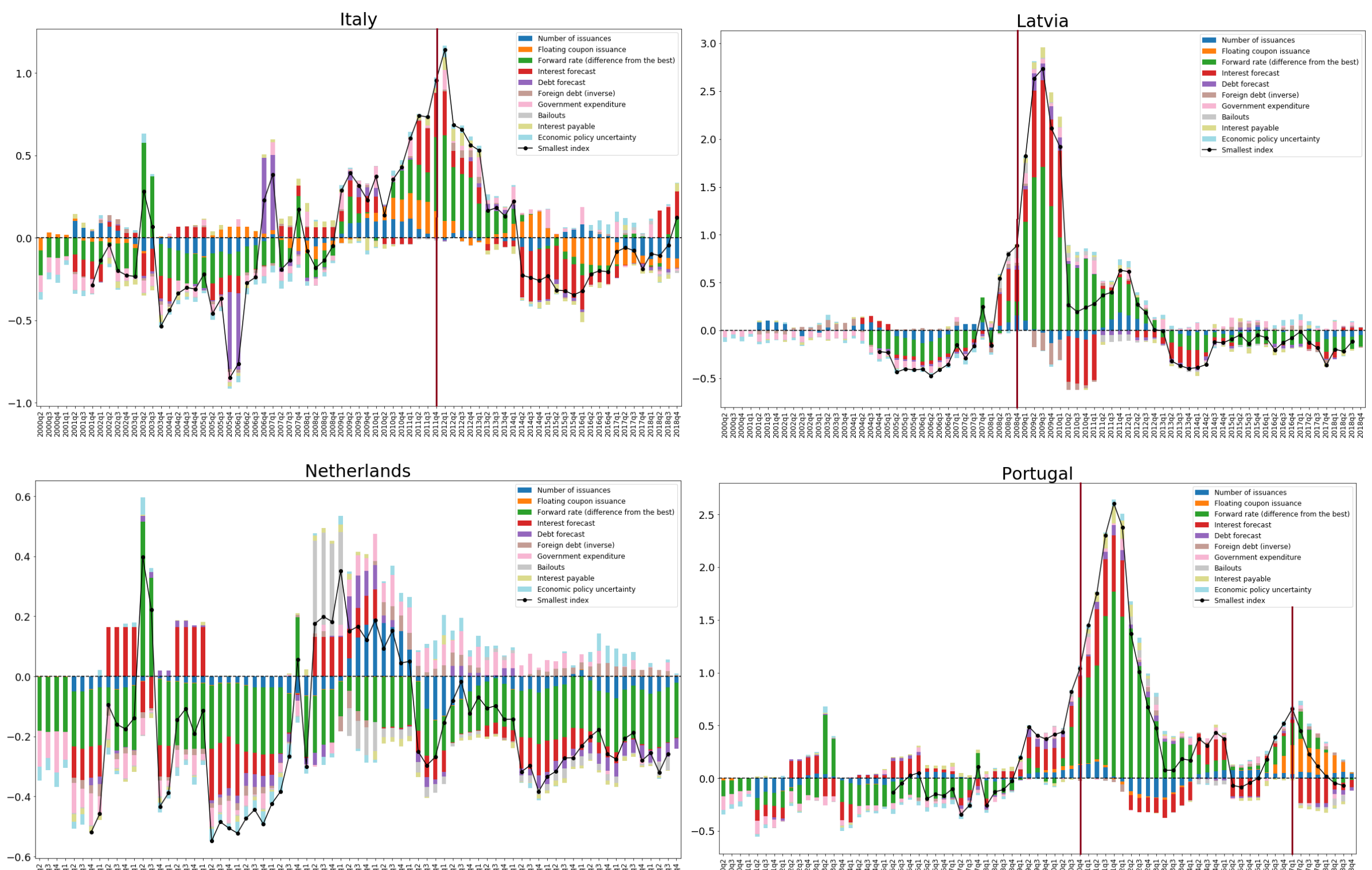

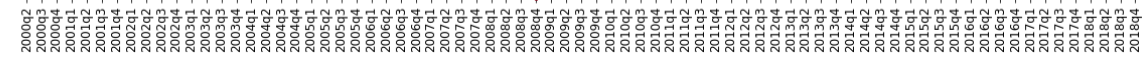

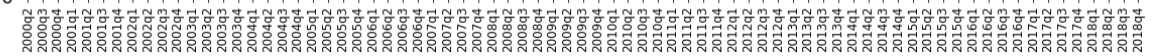

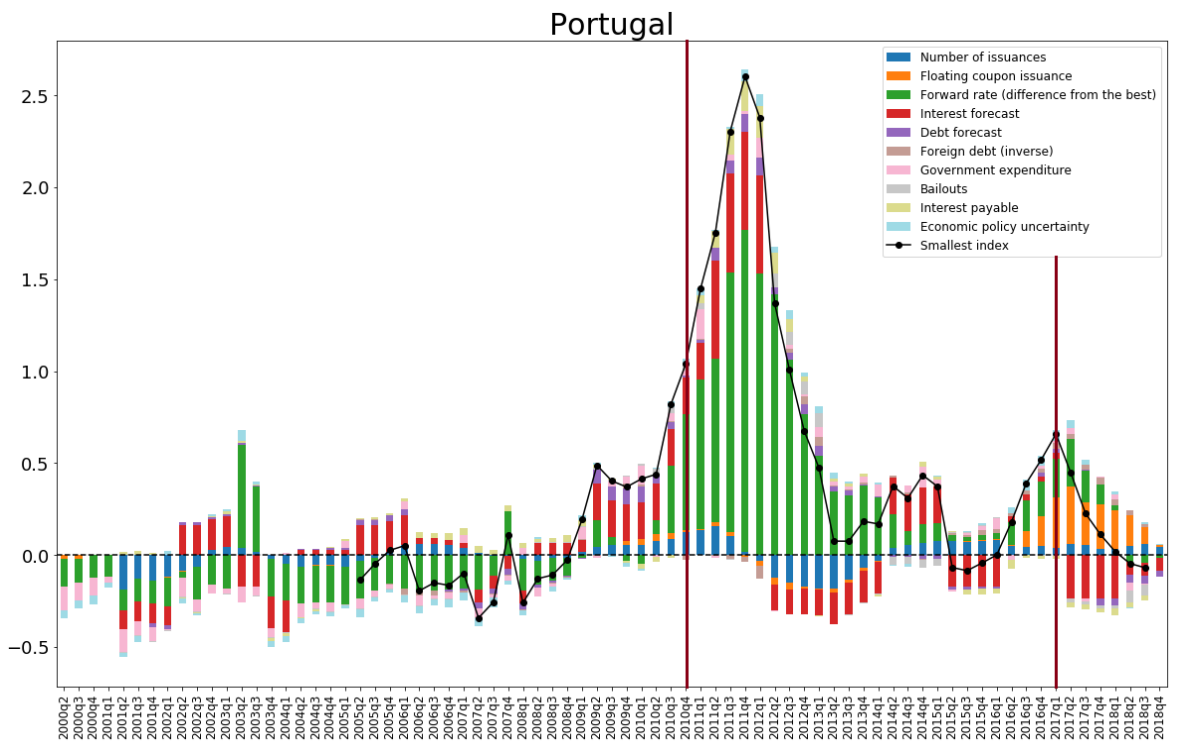


Slovenia

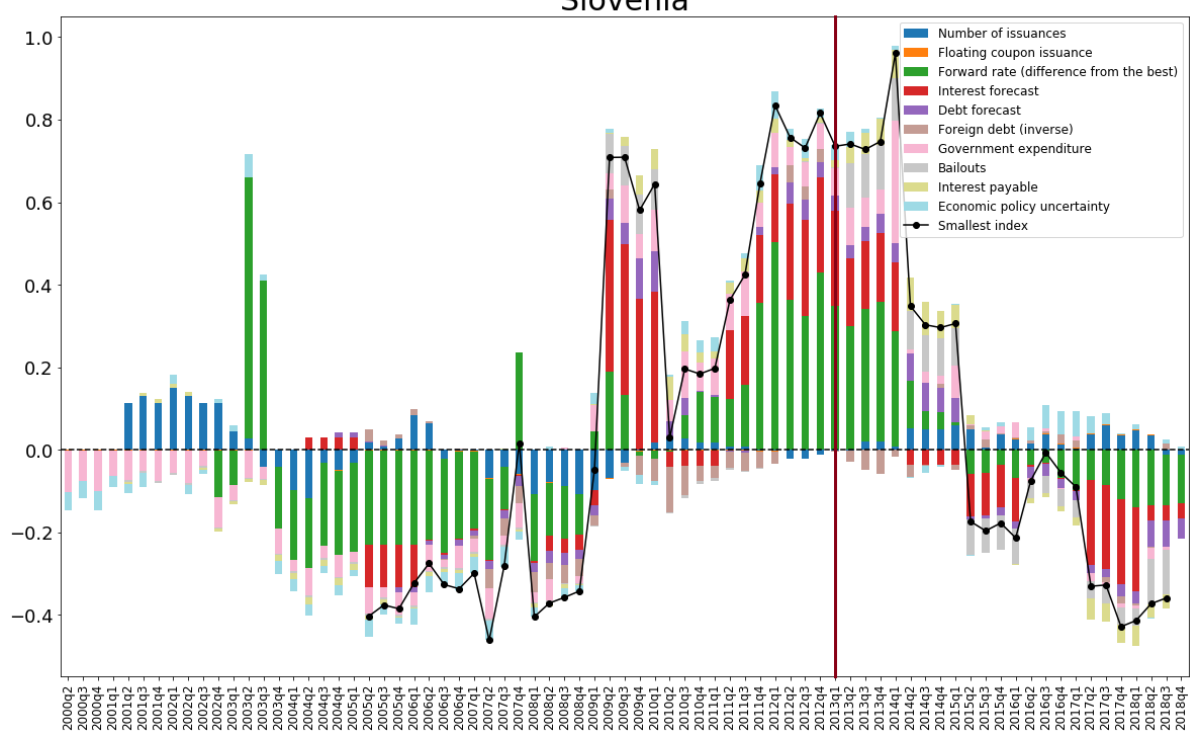

Notes: The red vertical line shows year-quarter of the start of identified LMA episodes.
Slovakia

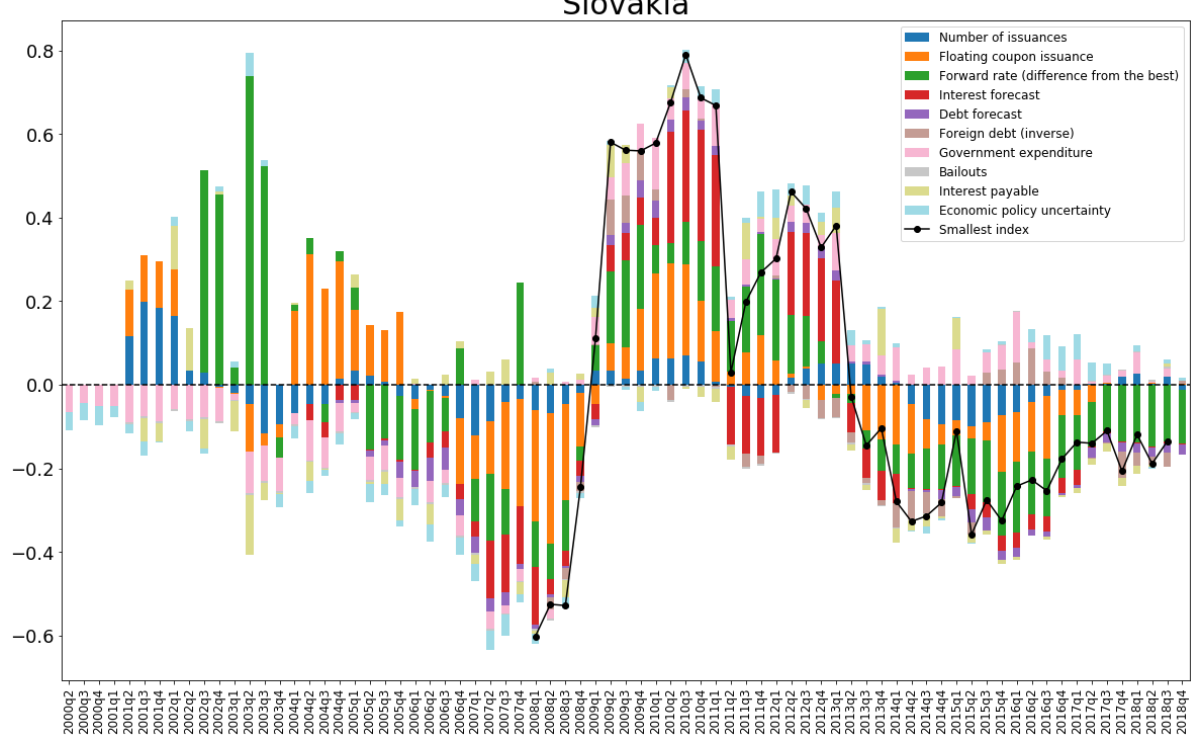


Figure A5. LMA identification from alternative spread level definition (two standard deviations above country-specific historical rolling average)
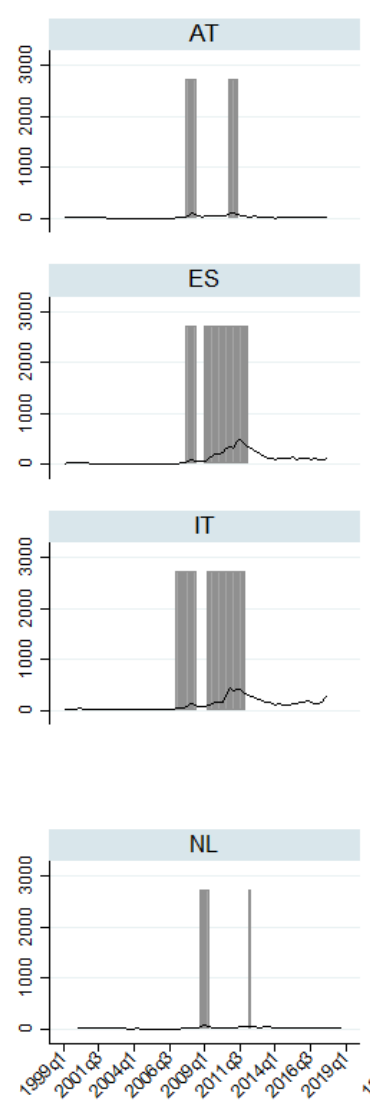

BE
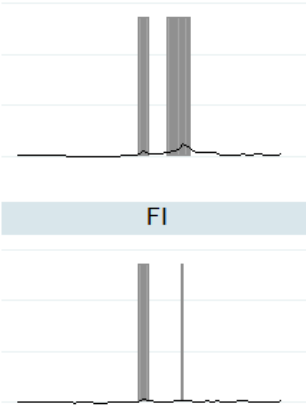

LT

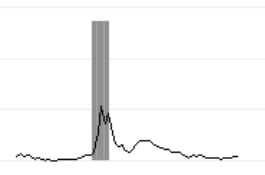

PT

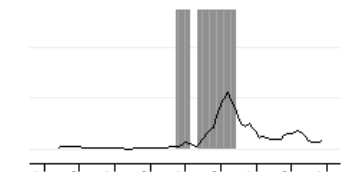

FR
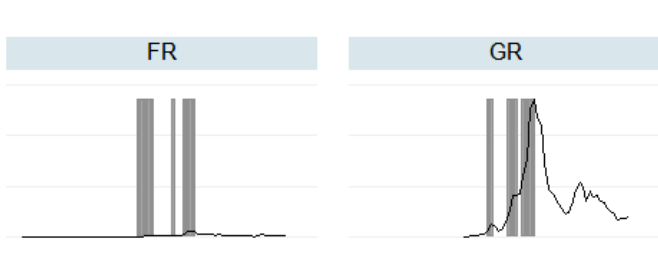

LV

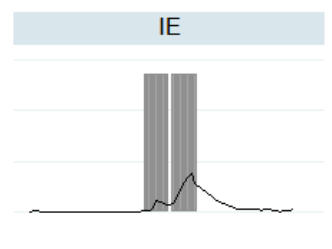

MT

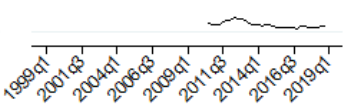




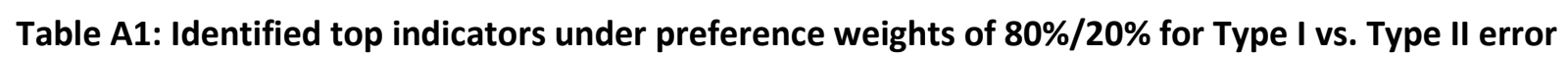

\begin{tabular}{|c|c|c|c|c|c|c|}
\hline Variable & Usefulness & Threshold & Threshold (percentile) & $A \cup C$ & Type I & Type II \\
\hline \multicolumn{7}{|l|}{ Primary market } \\
\hline No. of issuances & 0.116 & -0.064 & 0.555 & 0.819 & 0.000 & 0.418 \\
\hline Syndicated issuance & 0.022 & -0.506 & 0.432 & 0.674 & 0.083 & 0.558 \\
\hline \multicolumn{7}{|l|}{ Secondary market } \\
\hline Slope of yield curve & 0.169 & 0.803 & 0.789 & 0.949 & 0.000 & 0.158 \\
\hline Forward rate (difference from the best) & 0.139 & -0.242 & 0.640 & 0.916 & 0.000 & 0.305 \\
\hline Forward premium & 0.096 & 0.026 & 0.462 & 0.848 & 0.000 & 0.519 \\
\hline Bid-ask $5 Y$ & 0.098 & -0.276 & 0.464 & 0.748 & 0.000 & 0.511 \\
\hline Bid-ask $10 Y$ volatility & 0.028 & -0.153 & 0.536 & 0.738 & 0.105 & 0.440 \\
\hline Bid-ask $5 Y$ volatility & 0.035 & -0.151 & 0.596 & 0.729 & 0.111 & 0.380 \\
\hline Foreign debt (inverse) & 0.051 & -0.816 & 0.241 & 0.670 & 0.000 & 0.746 \\
\hline \multicolumn{7}{|l|}{ Global demand and supply } \\
\hline CDS & 0.025 & -0.208 & 0.589 & 0.797 & 0.130 & 0.354 \\
\hline Government expenditure & 0.139 & 0.172 & 0.650 & 0.852 & 0.000 & 0.306 \\
\hline GDP forecast (inverse) & 0.094 & 0.394 & 0.754 & 0.843 & 0.083 & 0.197 \\
\hline Debt & 0.061 & -0.603 & 0.277 & 0.788 & 0.000 & 0.695 \\
\hline Interest forecast & 0.076 & -0.200 & 0.352 & 0.797 & 0.000 & 0.621 \\
\hline Economic policy uncertainty & 0.072 & -0.496 & 0.334 & 0.727 & 0.000 & 0.640 \\
\hline US GDP (inverse) & 0.072 & -0.488 & 0.334 & 0.679 & 0.000 & 0.640 \\
\hline$V I X$ & 0.073 & -0.418 & 0.334 & 0.618 & 0.000 & 0.634 \\
\hline Ratio of loans to bonds & 0.067 & -0.540 & 0.305 & 0.611 & 0.000 & 0.664 \\
\hline Bank index (inverse) & 0.019 & -0.044 & 0.515 & 0.680 & 0.111 & 0.460 \\
\hline
\end{tabular}

Notes: AUC stands for the area under receiver's operating characteristics curve (ROC). 
Table A2: Identified top indicators under preference weights of $20 \% / 80 \%$ for Type I vs. Type II error

\begin{tabular}{|c|c|c|c|c|c|c|}
\hline Variable & Usefulness & Threshold & Threshold (percentile) & $A \cup C$ & Type I & Type II \\
\hline \multicolumn{7}{|l|}{ Primary market } \\
\hline Quantity issued & 0.030 & 1.903 & 0.944 & 0.725 & 0.667 & 0.045 \\
\hline Bills issuance & 0.046 & 1.609 & 0.927 & 0.708 & 0.542 & 0.058 \\
\hline Floating coupon issuance & 0.013 & 0.356 & 0.871 & 0.609 & 0.458 & 0.119 \\
\hline $\begin{array}{c}\text { Domestic long-term fixed coupon issuance } \\
\text { (inverse) }\end{array}$ & 0.018 & 1.387 & 0.909 & 0.552 & 0.667 & 0.061 \\
\hline \multicolumn{7}{|l|}{ Secondary market } \\
\hline Slope of yield curve & 0.096 & 1.504 & 0.937 & 0.949 & 0.389 & 0.033 \\
\hline Forward rate (difference from the best) & 0.084 & 0.427 & 0.832 & 0.916 & 0.167 & 0.103 \\
\hline Forward premium & 0.061 & 0.487 & 0.908 & 0.838 & 0.421 & 0.068 \\
\hline Foreign debt & 0.048 & 1.979 & 0.953 & 0.728 & 0.667 & 0.023 \\
\hline Bid-ask 5Y (skewness) & 0.001 & 1.412 & 0.912 & 0.635 & 0.667 & 0.082 \\
\hline \multicolumn{7}{|l|}{ Global demand and supply } \\
\hline$C D S$ & 0.069 & 0.618 & 0.886 & 0.797 & 0.478 & 0.044 \\
\hline GDP forecast (inverse) & 0.062 & 0.679 & 0.835 & 0.843 & 0.208 & 0.120 \\
\hline Debt & 0.029 & 1.111 & 0.850 & 0.788 & 0.417 & 0.109 \\
\hline Interest forecast & 0.075 & 0.400 & 0.873 & 0.781 & 0.333 & 0.073 \\
\hline Gross financing needs & 0.030 & 1.089 & 0.872 & 0.776 & 0.500 & 0.088 \\
\hline Debt forecast & 0.034 & 1.098 & 0.940 & 0.738 & 0.667 & 0.041 \\
\hline Bailouts & 0.052 & 0.106 & 0.881 & 0.610 & 0.417 & 0.081 \\
\hline US GDP & 0.026 & 1.604 & 0.913 & 0.576 & 0.625 & 0.061 \\
\hline Deficit forecast & 0.052 & 3.000 & 0.904 & 0.573 & 0.542 & 0.050 \\
\hline Primary balance forecast & 0.043 & 0.952 & 0.894 & 0.559 & 0.542 & 0.060 \\
\hline German GDP & 0.039 & 1.516 & 0.913 & 0.520 & 0.583 & 0.056 \\
\hline
\end{tabular}


Figure A6. Indicator dynamics vis-à-vis their respective thresholds under unequal preferences: Heatmaps
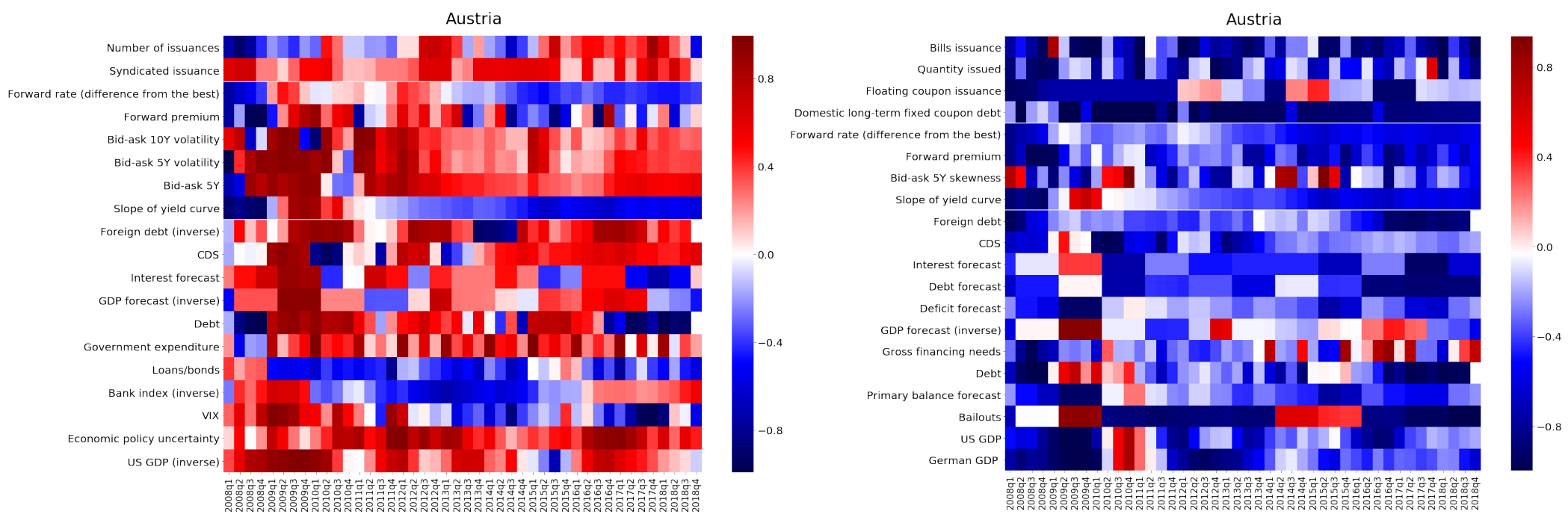

Preferene wasts
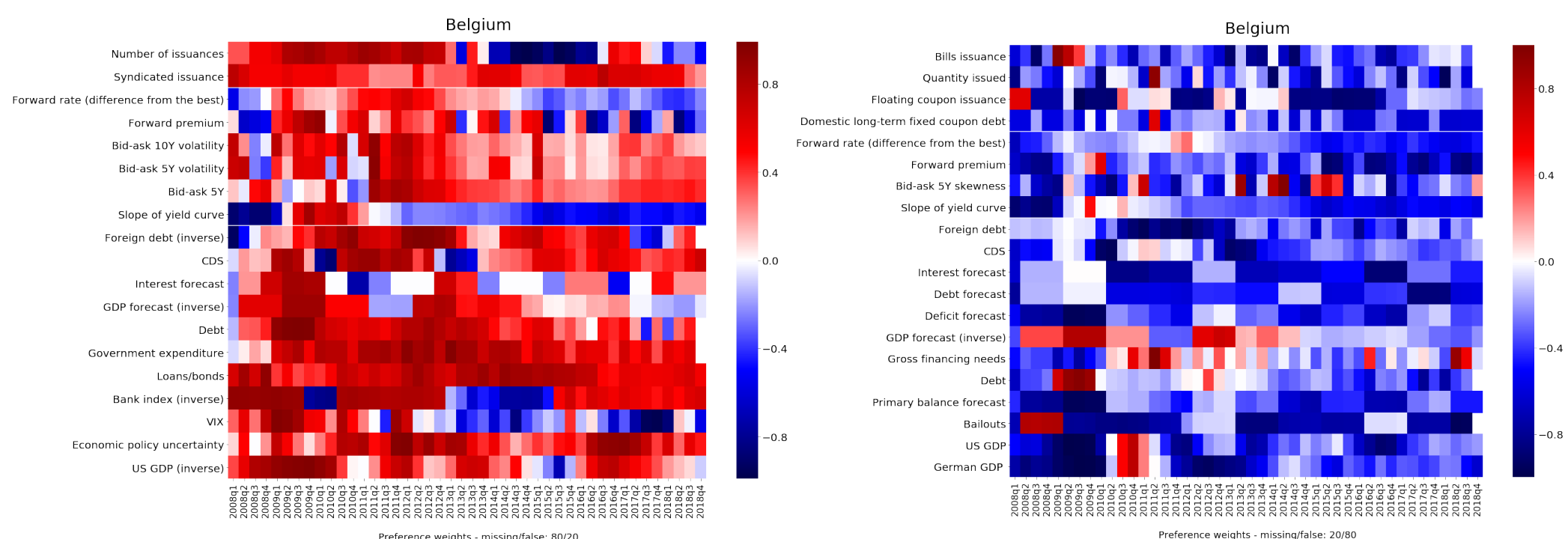

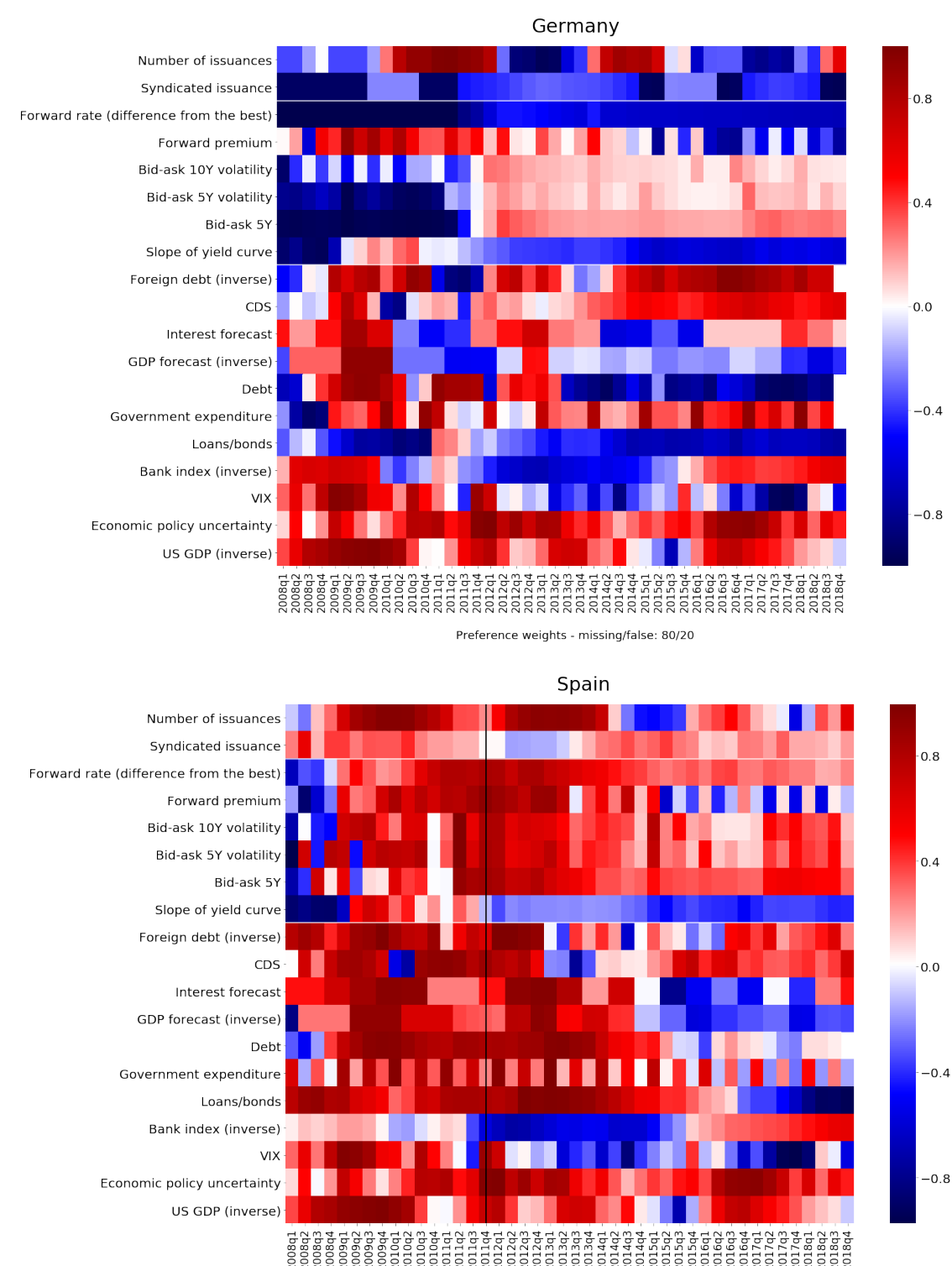
Preference weights - missingffralse: $80 / 20$

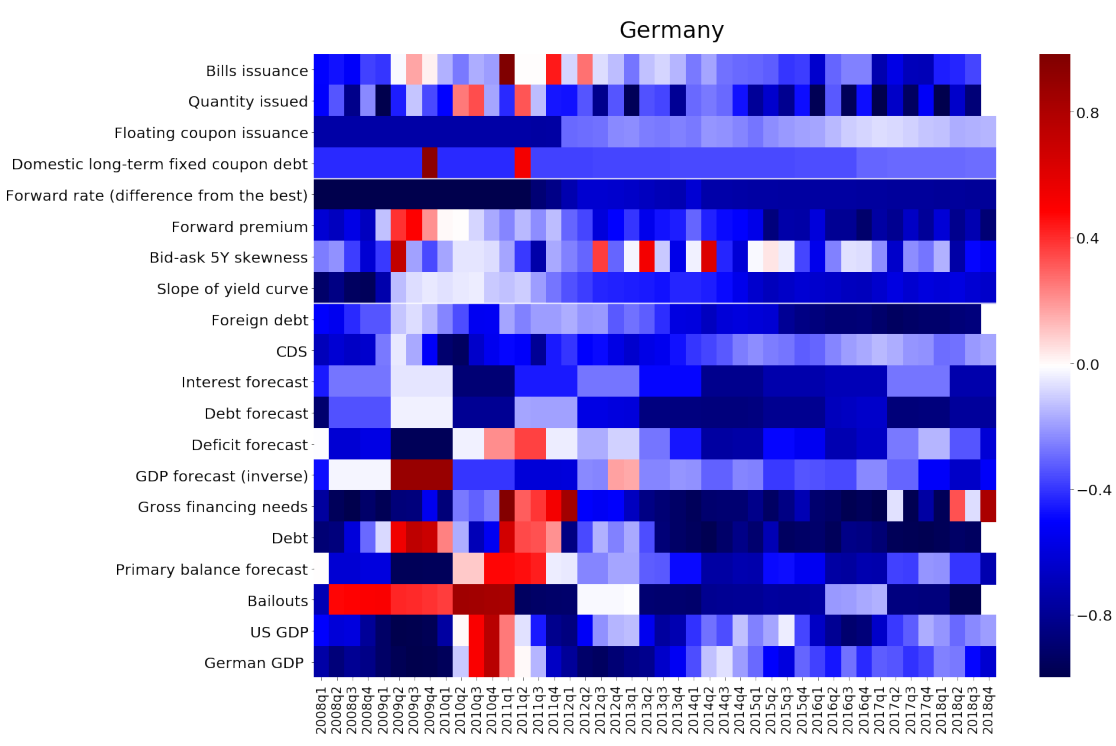
Preference weights - missing/false: 20

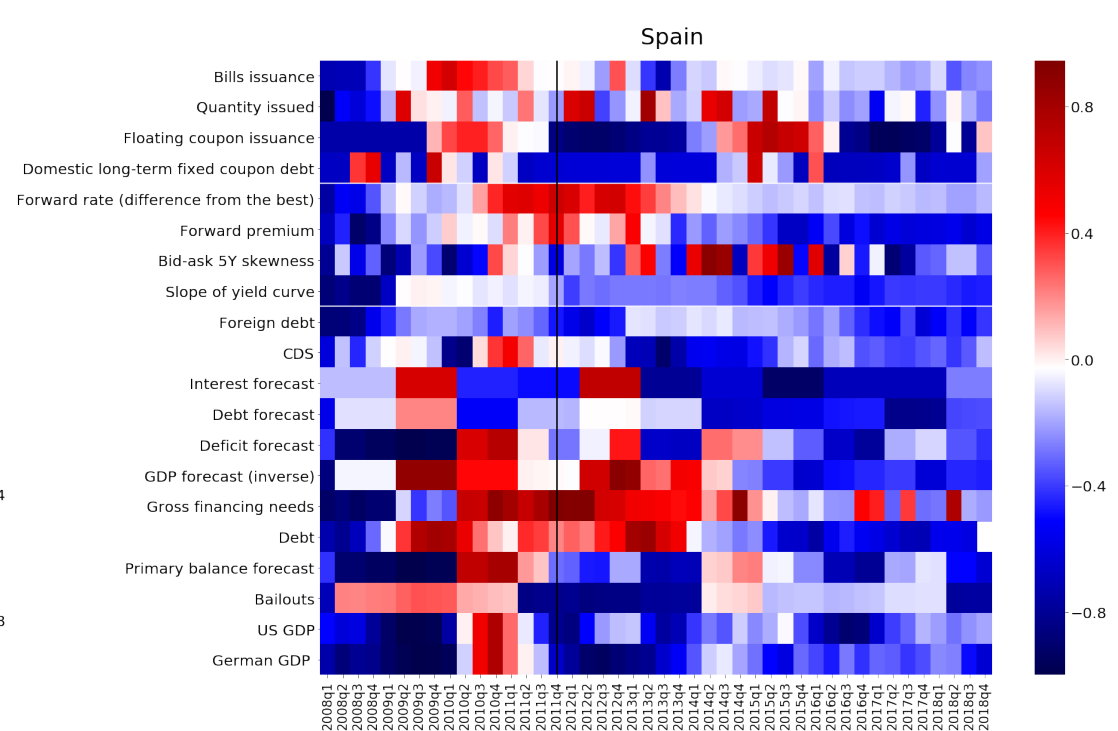

Preference weights - missingffalase: 20/80 


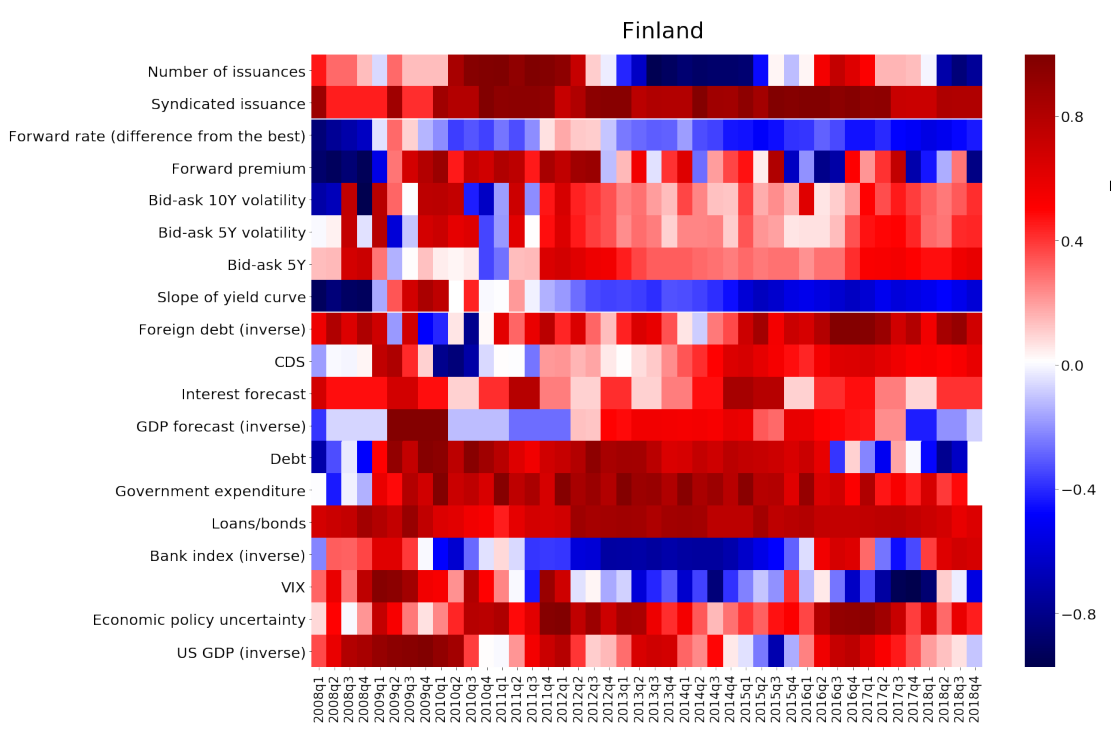
Preference weights - missingffalse: 80/20

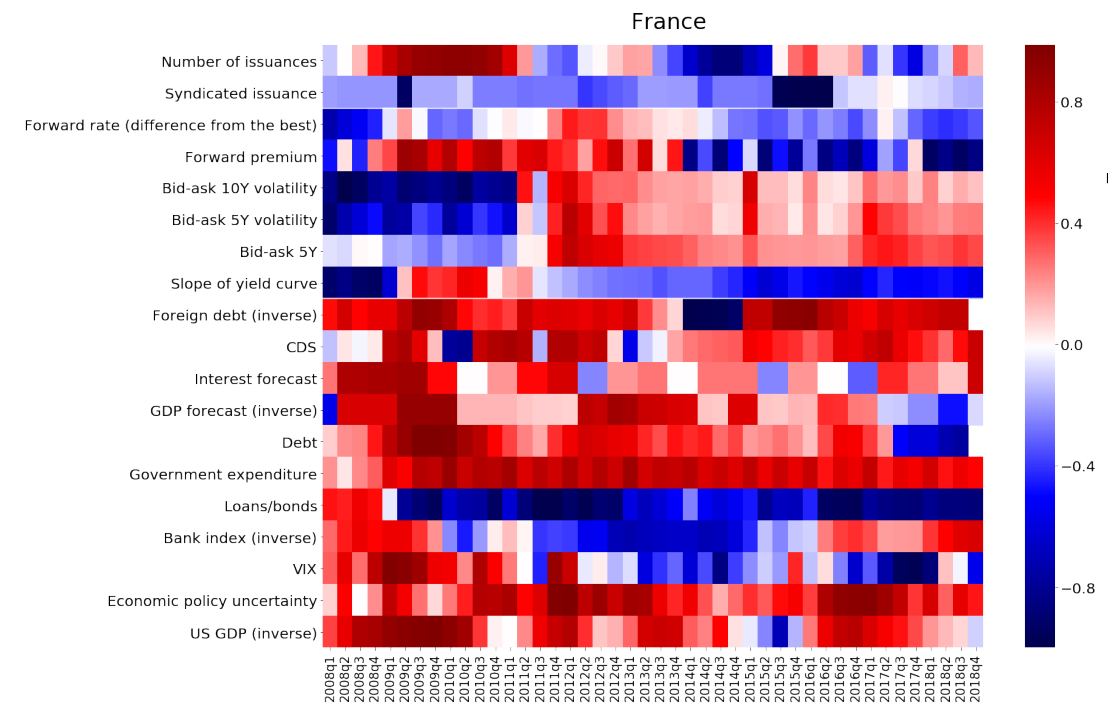
Preference weights - missingyffalse: 80/20

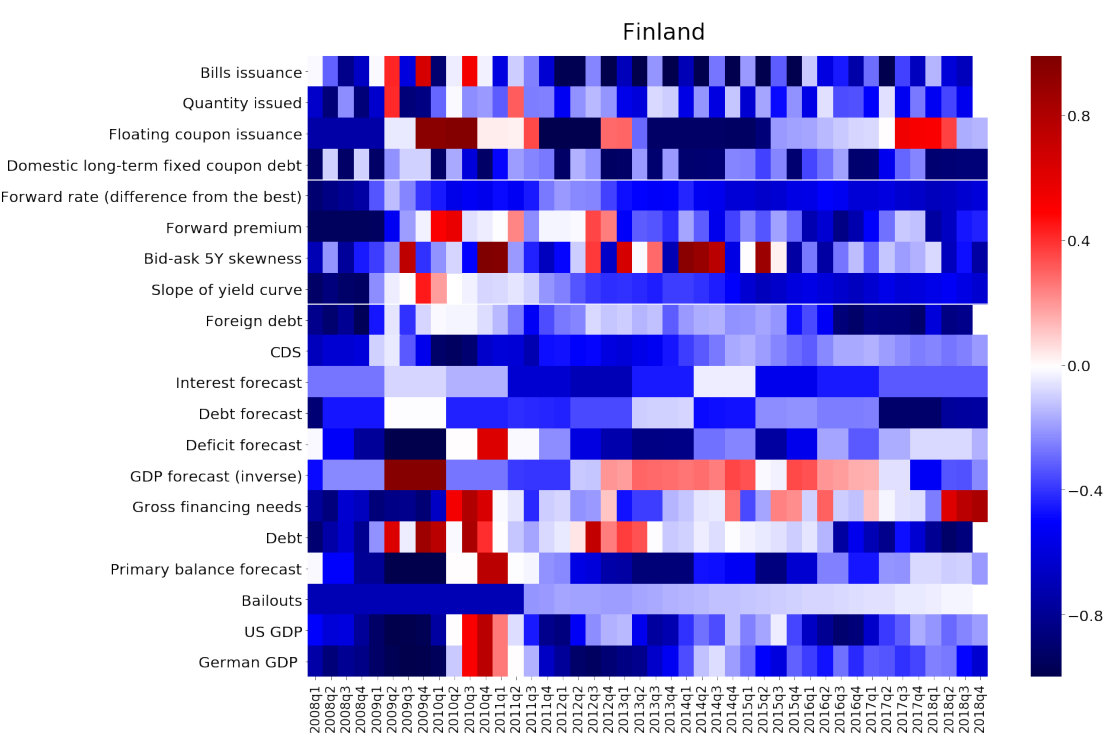

Preference weights - missingoffalse: 20/80

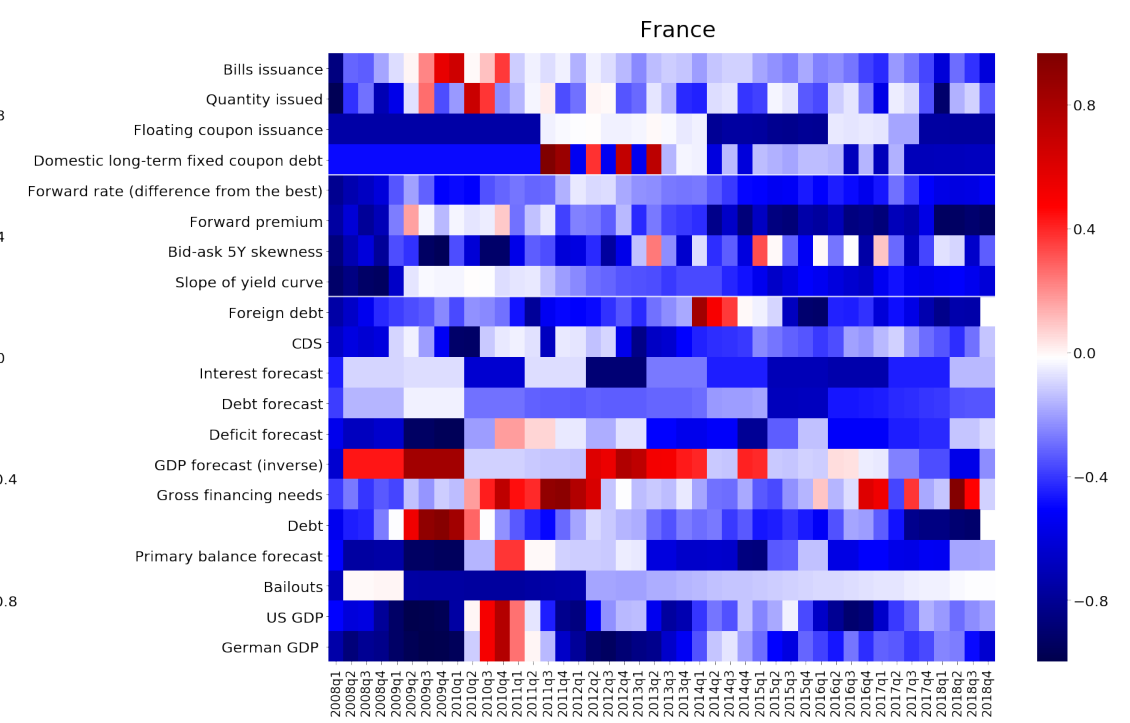

Preference weights - missingffalse: 20/80 

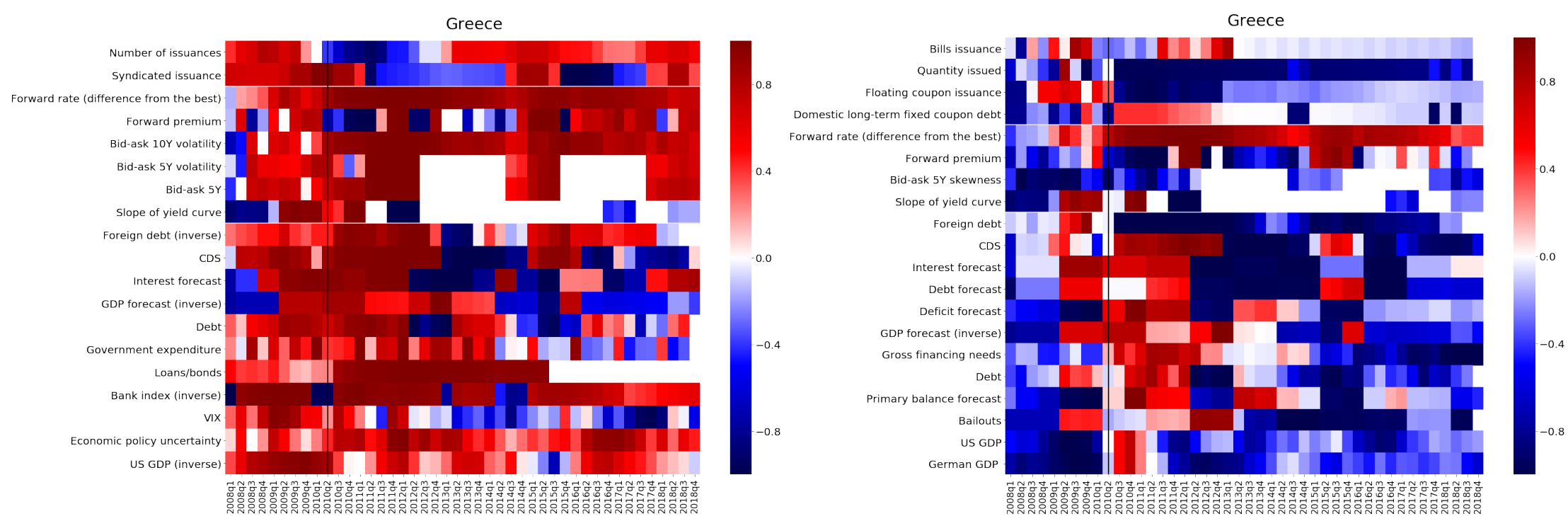

Preference weights - missing ffise: Preference

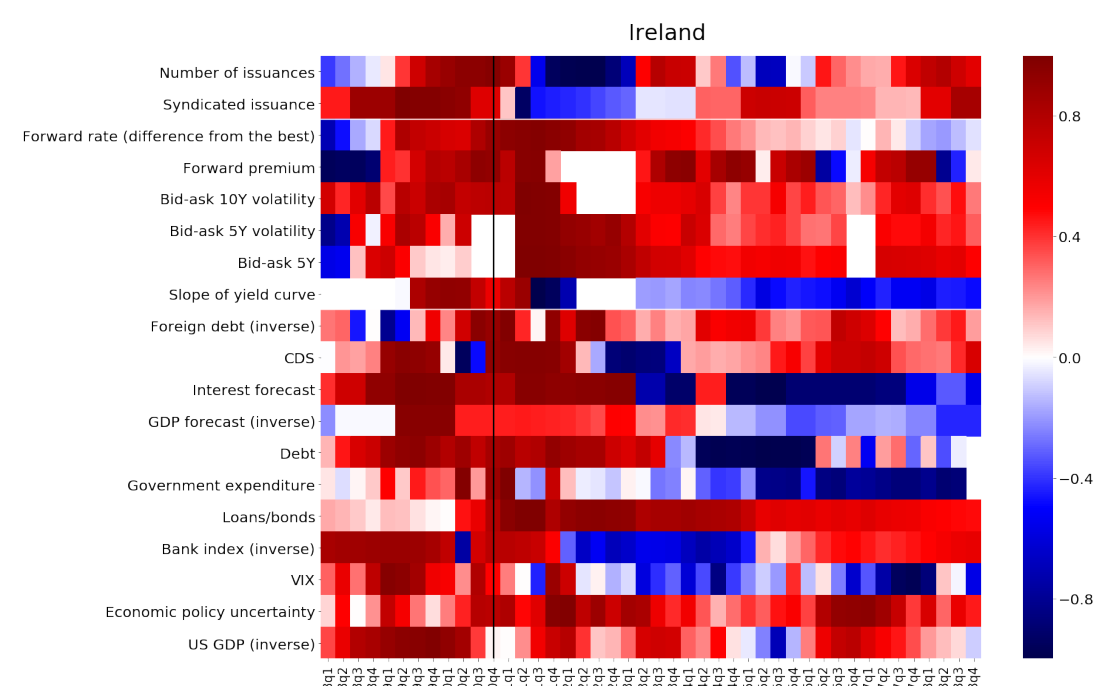

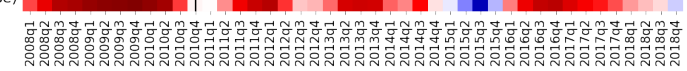

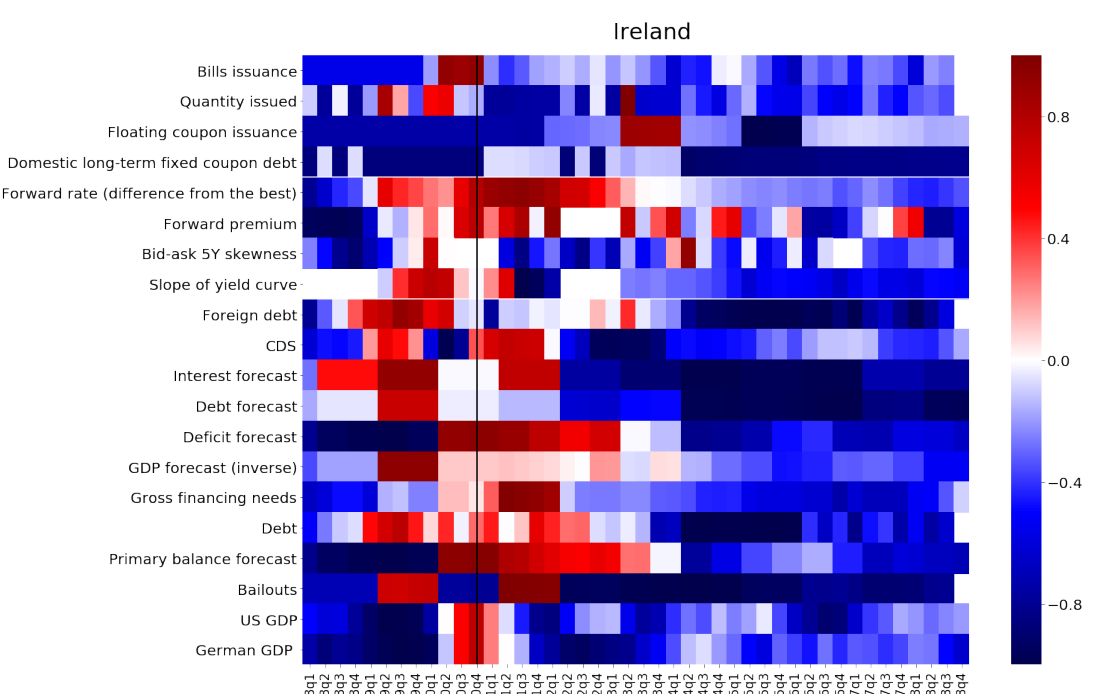

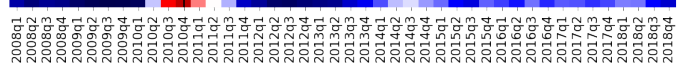
preference weights missing/talse: 20190 


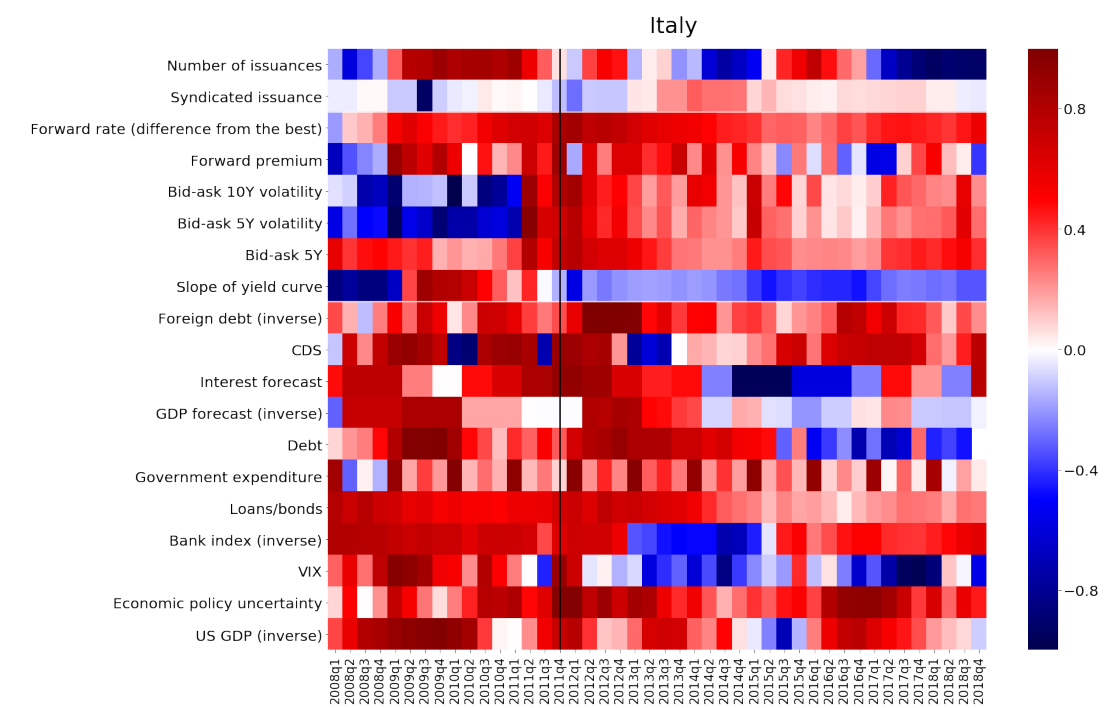

Preference weights - missing alse, so20
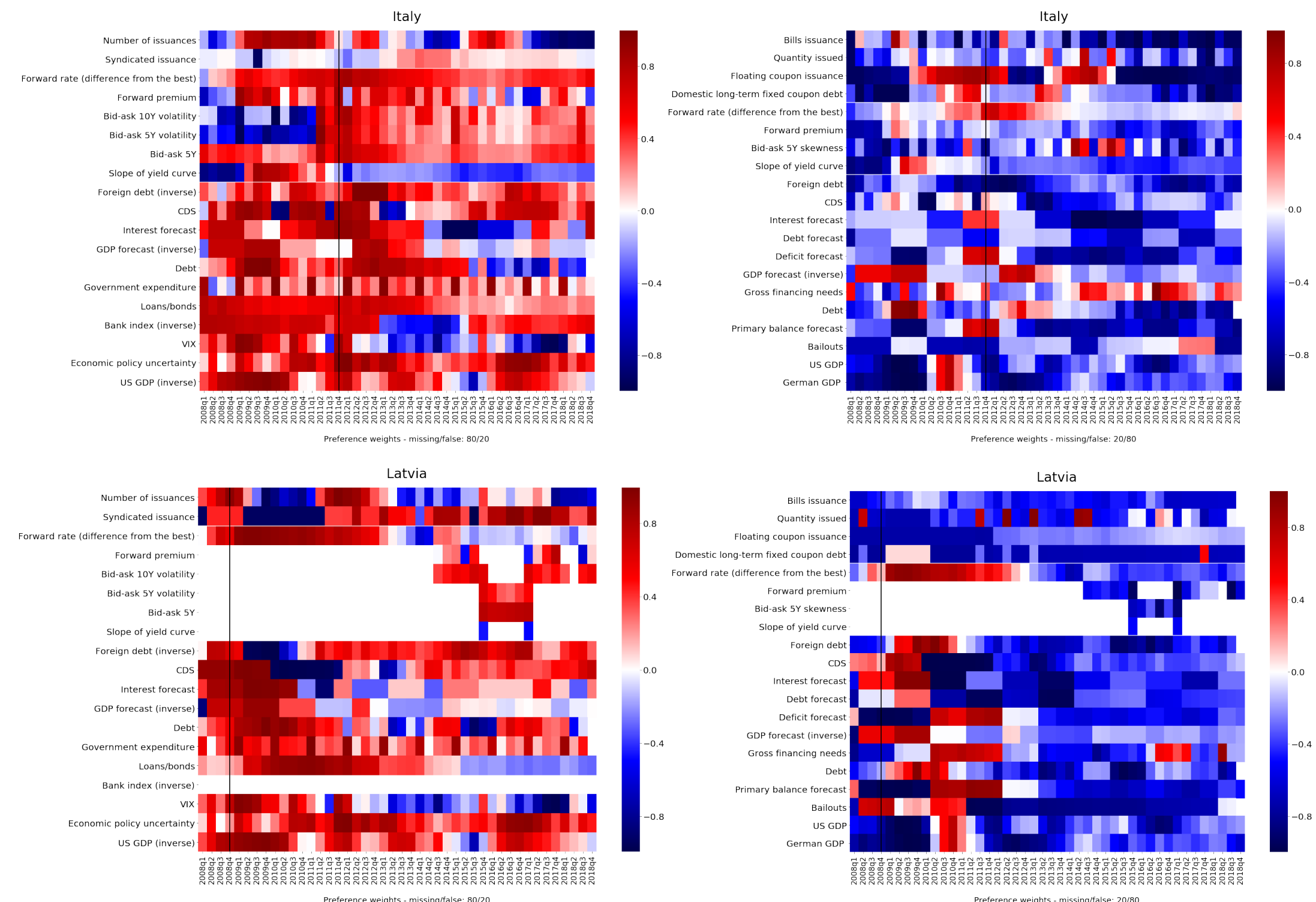

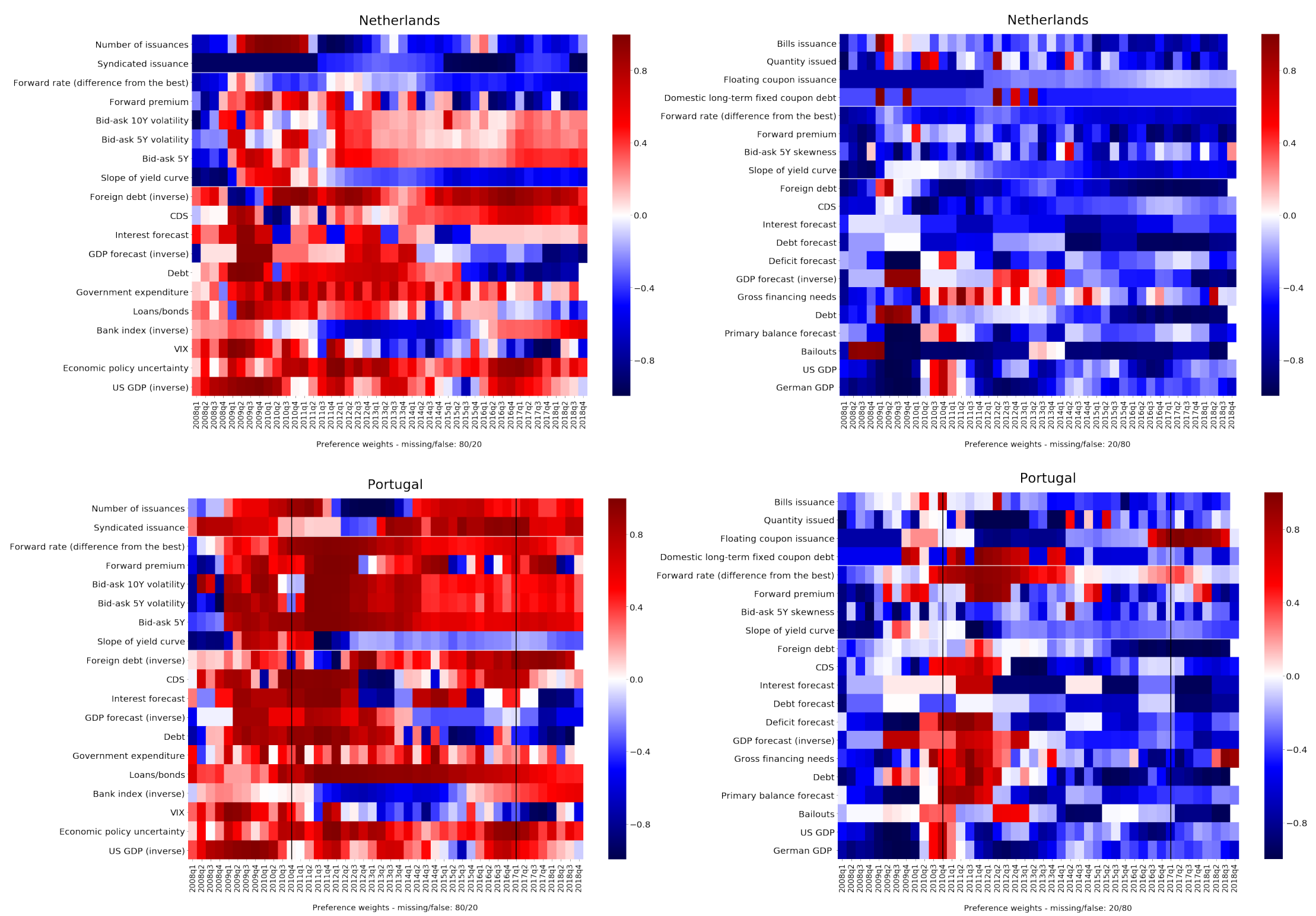

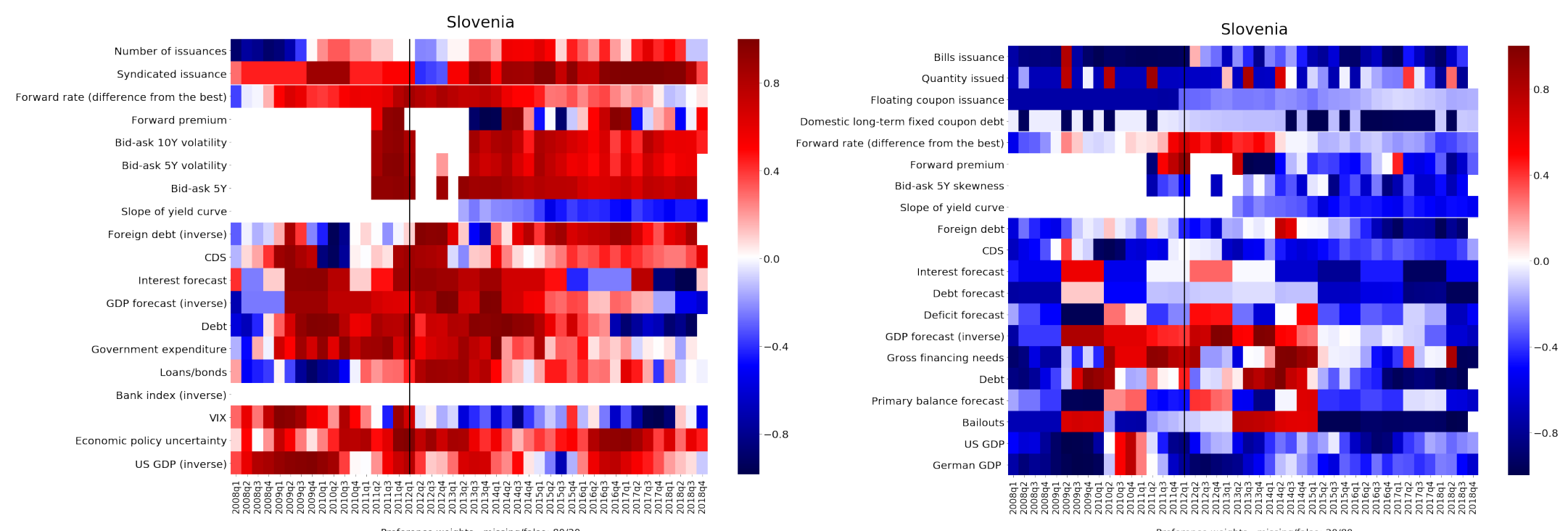

Preference weights - missingffalase: 80/20
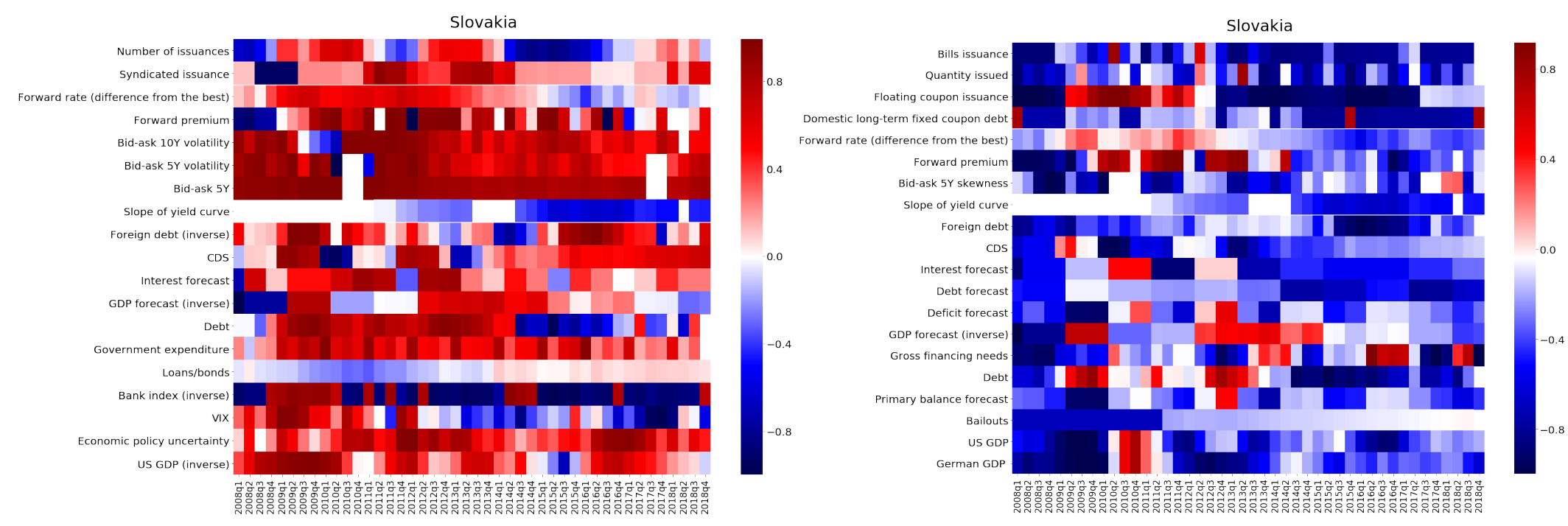

Notes: Left: preferences of $80 \% / 20 \%$ for Type I vs. Type II errors, Right: preferences of $20 \% / 80 \%$ for Type I vs. Type II errors. 
Table A3: Selected Indicators and estimated coefficients - preferences: $\mathbf{8 0} / \mathbf{2 0 \%}$ for Type I/Type II

\begin{tabular}{|c|c|c|}
\hline \multicolumn{3}{|c|}{ Penalized logit (Type I/Type II error weights: $80 \% / 20 \%)$} \\
\hline Indicator & Coefficient (lambda min) & Coefficient (lambda 1SE) \\
\hline \multicolumn{3}{|l|}{ Primary market } \\
\hline \multicolumn{3}{|l|}{ No. of issuances } \\
\hline \multicolumn{3}{|l|}{ Syndicated issuance } \\
\hline \multicolumn{3}{|l|}{ Secondary market } \\
\hline Slope of yield curve & 1.680 & 1.420 \\
\hline Forward rate (difference from the best) & 3.971 & 3.491 \\
\hline \multicolumn{3}{|l|}{ Forward premium } \\
\hline Bid-ask $5 Y$ & 0.720 & 0.598 \\
\hline Bid-ask $10 Y$ volatility & 1.031 & 0.807 \\
\hline \multicolumn{3}{|l|}{ Bid-ask $5 Y$ volatility } \\
\hline \multicolumn{3}{|l|}{ Foreign debt (inverse) } \\
\hline \multicolumn{3}{|l|}{ Global demand and supply } \\
\hline CDS & -0.087 & \\
\hline \multicolumn{3}{|l|}{ Government expenditure } \\
\hline \multicolumn{3}{|l|}{ GDP forecast (inverse) } \\
\hline Debt & -0.019 & \\
\hline Interest forecast & -0.425 & -0.181 \\
\hline \multicolumn{3}{|l|}{ Economic policy uncertainty } \\
\hline \multicolumn{3}{|l|}{ US GDP (inverse) } \\
\hline VIX & -0.832 & -0.707 \\
\hline \multicolumn{3}{|l|}{ Ratio of loans to bonds } \\
\hline \multicolumn{3}{|l|}{ Bank index (inverse) } \\
\hline (Intercept) & -4.027 & -3.829 \\
\hline
\end{tabular}


Table A4: Selected Indicators and estimated coefficients - preferences: $20 \% / 80 \%$ for Type I/Type II

\begin{tabular}{|c|c|c|}
\hline \multicolumn{3}{|c|}{ Penalized logit (Type I/Type II error weights: $20 \% / 80 \%)$} \\
\hline Indicator & Coefficient (lambda min) & Coefficient (lambda 1SE) \\
\hline \multicolumn{3}{|l|}{ Primary market } \\
\hline Quantity issued & -0.110 & \\
\hline \multicolumn{3}{|l|}{ Bills issuance } \\
\hline \multicolumn{3}{|l|}{ Floating coupon issuance } \\
\hline $\begin{array}{c}\text { Domestic long-term fixed coupon issuance } \\
\text { (inverse) }\end{array}$ & 0.975 & 0.801 \\
\hline \multicolumn{3}{|l|}{ Secondary market } \\
\hline Slope of yield curve & 1.798 & 1.467 \\
\hline Forward rate (difference from the best) & 4.317 & 3.607 \\
\hline \multicolumn{3}{|l|}{ Forward premium } \\
\hline \multicolumn{3}{|l|}{ Foreign debt } \\
\hline Bid-ask $5 Y$ (skewness) & 0.248 & 0.174 \\
\hline \multicolumn{3}{|l|}{ Global demand and supply } \\
\hline$C D S$ & -0.406 & -0.154 \\
\hline \multicolumn{3}{|l|}{ GDP forecast (inverse) } \\
\hline \multicolumn{3}{|l|}{ Debt } \\
\hline Interest forecast & 0.001 & \\
\hline \multicolumn{3}{|l|}{ Gross financing needs } \\
\hline \multicolumn{3}{|l|}{ Debt forecast } \\
\hline \multicolumn{3}{|l|}{ Bailouts } \\
\hline US GDP & 0.131 & 0.109 \\
\hline Deficit forecast & 0.037 & 0.029 \\
\hline \multicolumn{3}{|l|}{ Primary balance forecast } \\
\hline \multicolumn{3}{|l|}{ German GDP } \\
\hline (Intercept) & 0.251 & 0.125 \\
\hline
\end{tabular}


Figure A7. Predicted probability from penalized logistic regression under different policymaker's preferences

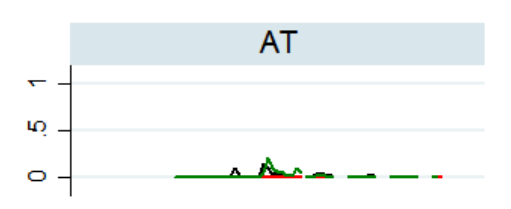

FI

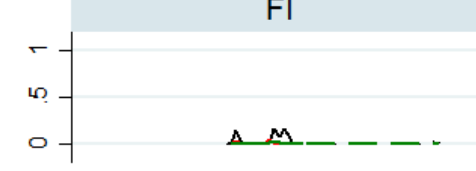

IT

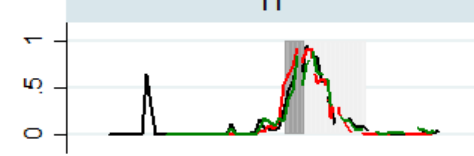

SI
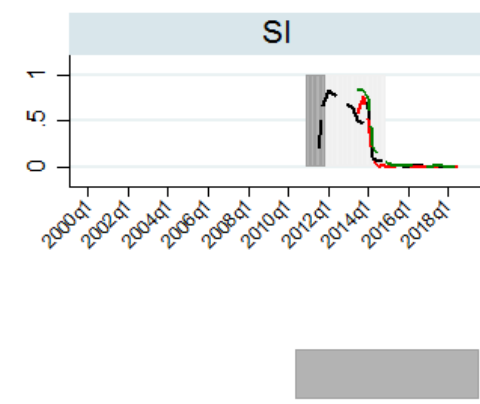

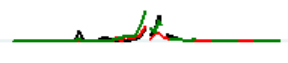

FR

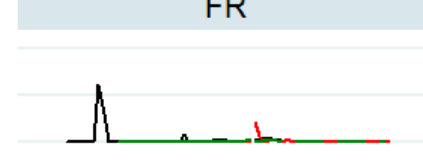

LV
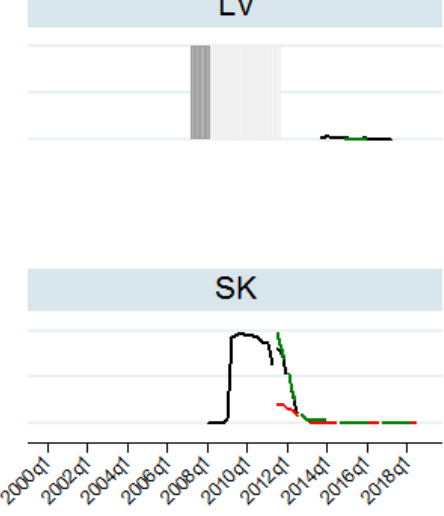

DE

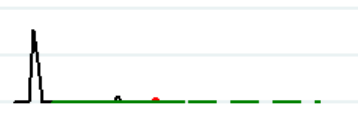

GR

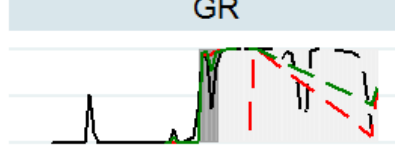

NL

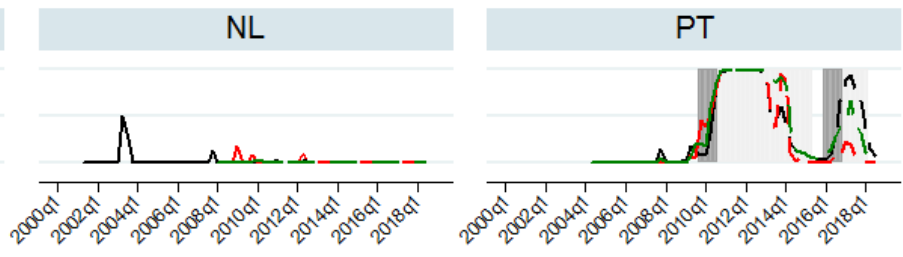

pre-LMA

LMA

Probability (missing/false: $50 / 50$ )

Probability (missing/false: 20/80)

Notes: Probability of market access tensions from penalized logistic regression with loss-minimizing lambda under different preferences for Type I and Type II error. The vertical axis measures the probability of losing market access within up to 4 quarters. The dash line indicates out-of-sample predicted probabilities of market access tensions. LMA shows periods of identified high market access tensions while pre-LMA identifies periods of up to 4 quarters prior to LMA. Country name abbreviations are as follows: $A T=A u s t r i a, B E=B e l g i u m, D E=G e r m a n y, ~ E S=S p a i n, F I=F i n l a n d$, FR=France, GR=Greece, IE=Ireland, IT=Italy, LV=Latvia, NL=Netherlands, PT=Portugal, SI=Slovenia, SK=Slovakia. 
Figure A8. Penalized logit probability vis-à-vis model thresholds under different preferences: Heatmaps

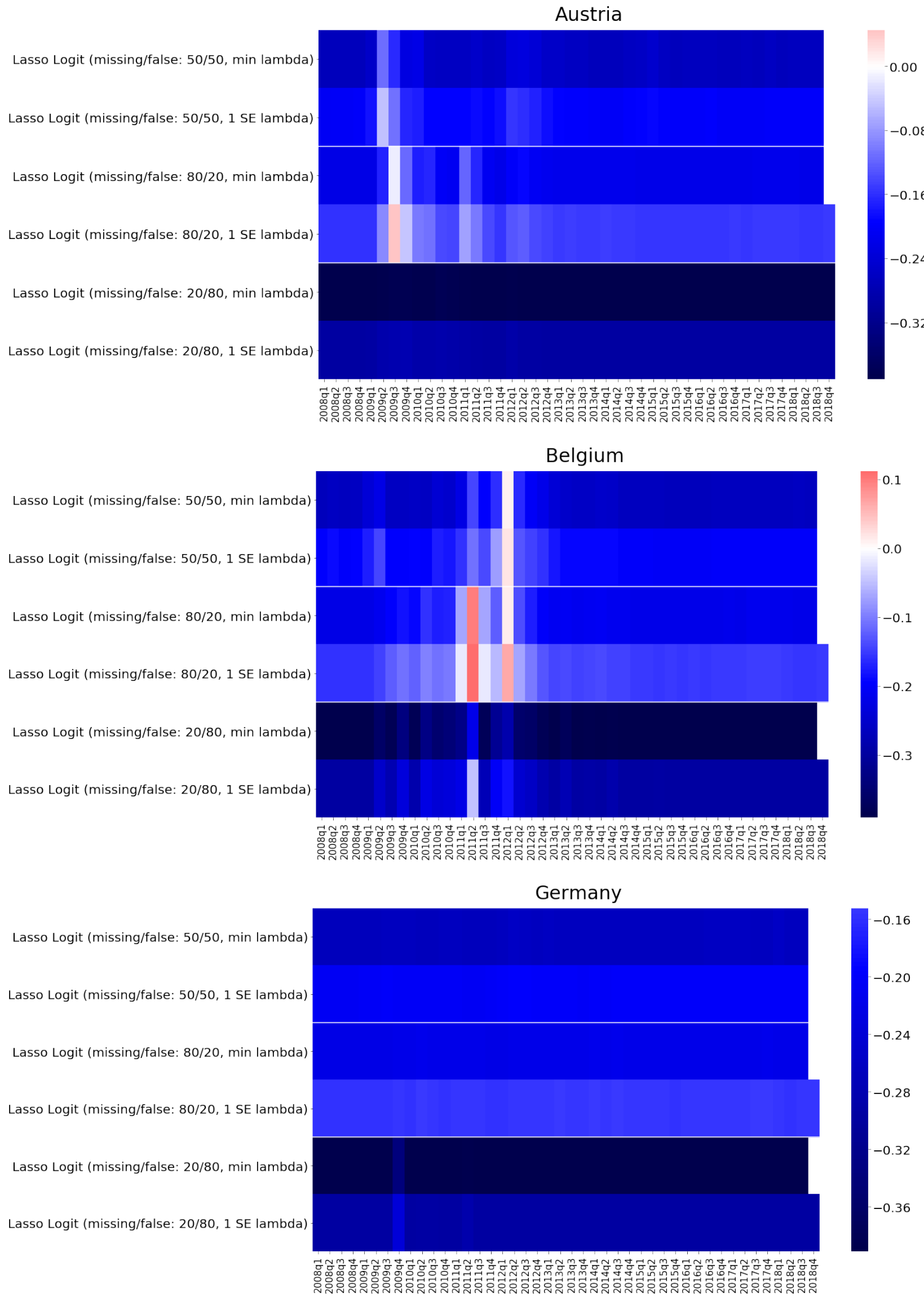




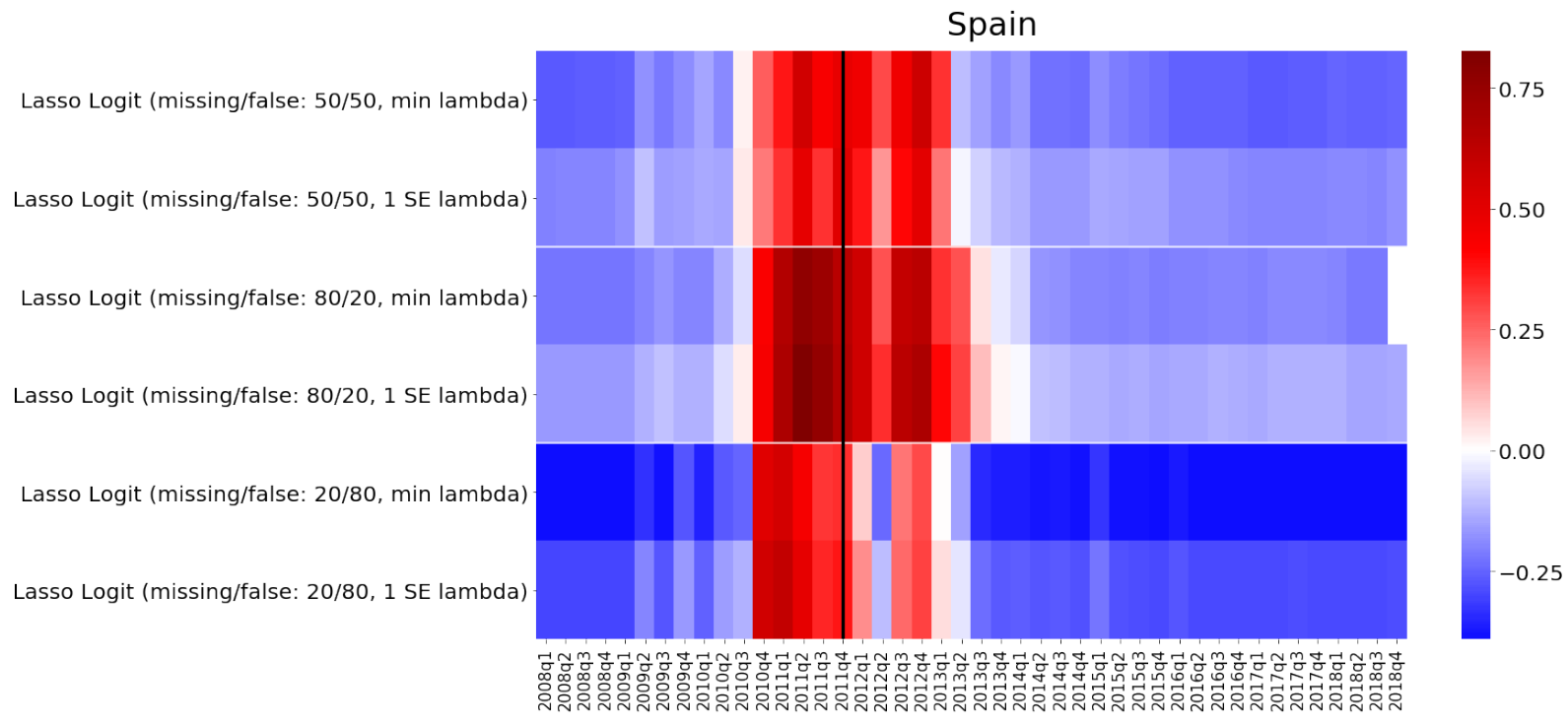

Finland

Lasso Logit (missing/false: 50/50, min lambda)

Lasso Logit (missing/false: 50/50, 1 SE lambda)

Lasso Logit (missing/false: 80/20, min lambda)

Lasso Logit (missing/false: 80/20, 1 SE lambda)

Lasso Logit (missing/false: 20/80, min lambda)

Lasso Logit (missing/false: 20/80, 1 SE lambda)
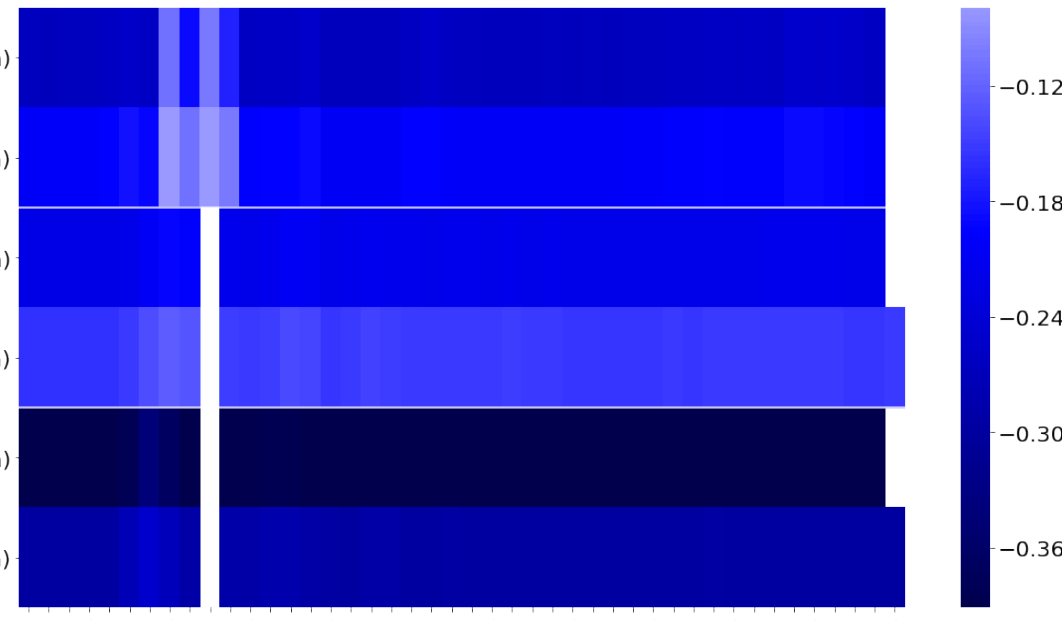

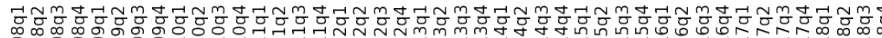

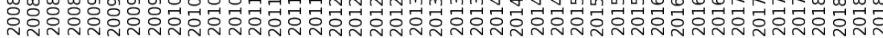

France

Lasso Logit (missing/false: 50/50, min lambda)

Lasso Logit (missing/false: 50/50, 1 SE lambda)

Lasso Logit (missing/false: 80/20, min lambda)

Lasso Logit (missing/false: 80/20, 1 SE lambda)

Lasso Logit (missing/false: 20/80, min lambda)

Lasso Logit (missing/false: 20/80, 1 SE lambda)

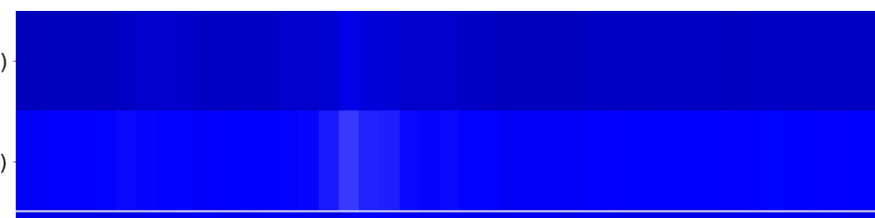

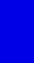




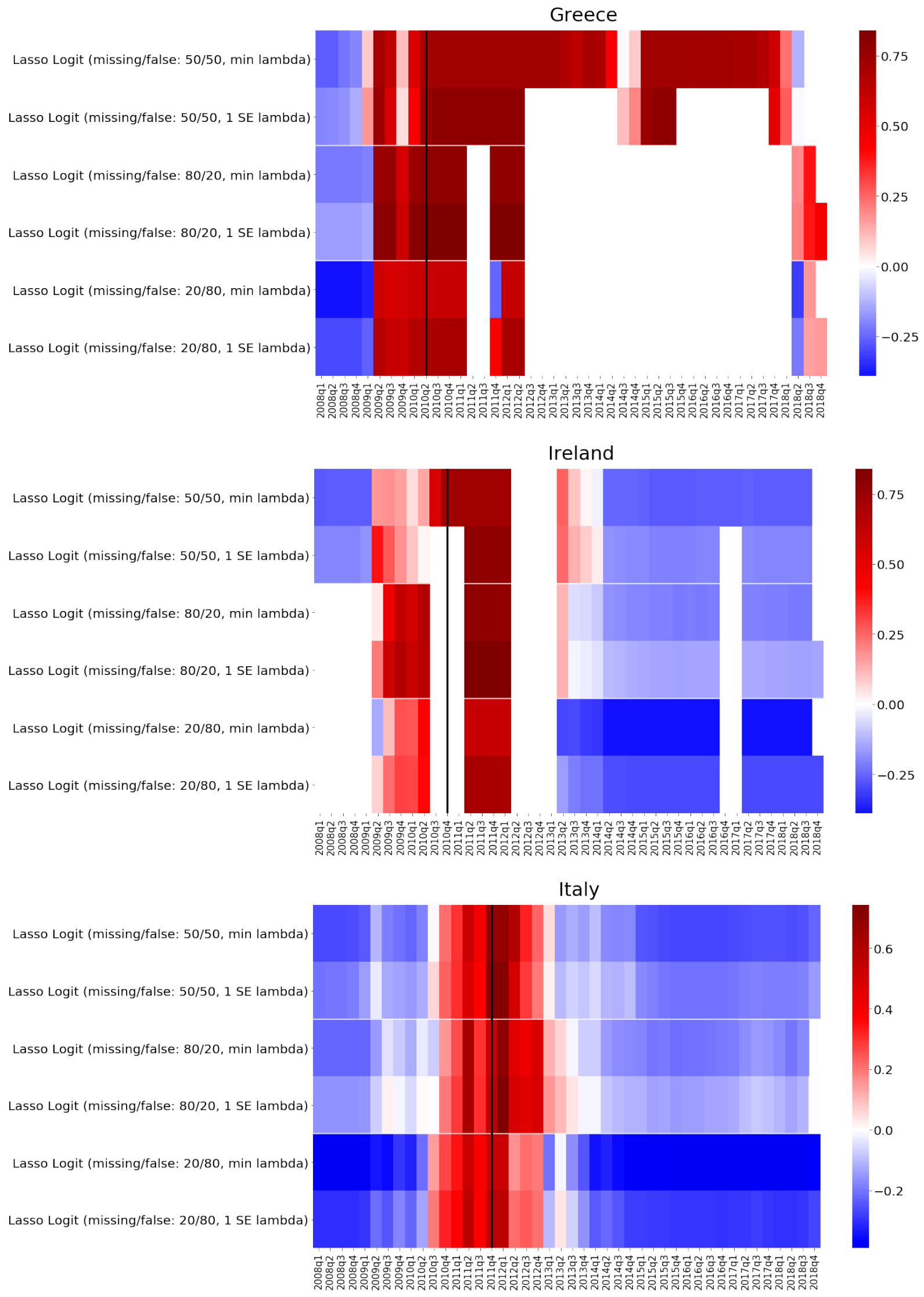


Latvia

Lasso Logit (missing/false: 50/50, min lambda)

Lasso Logit (missing/false: 50/50, 1 SE lambda)

Lasso Logit (missing/false: 80/20, min lambda)

Lasso Logit (missing/false: 80/20, 1 SE lambda)

Lasso Logit (missing/false: 20/80, min lambda)

Lasso Logit (missing/false: 20/80, 1 SE lambda)

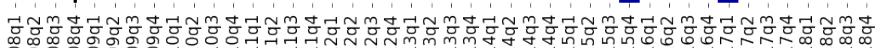

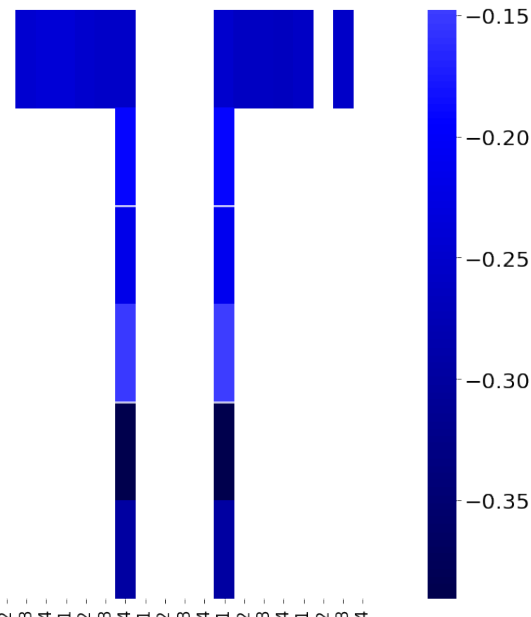

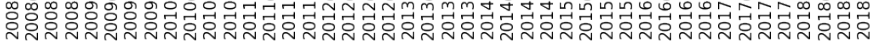

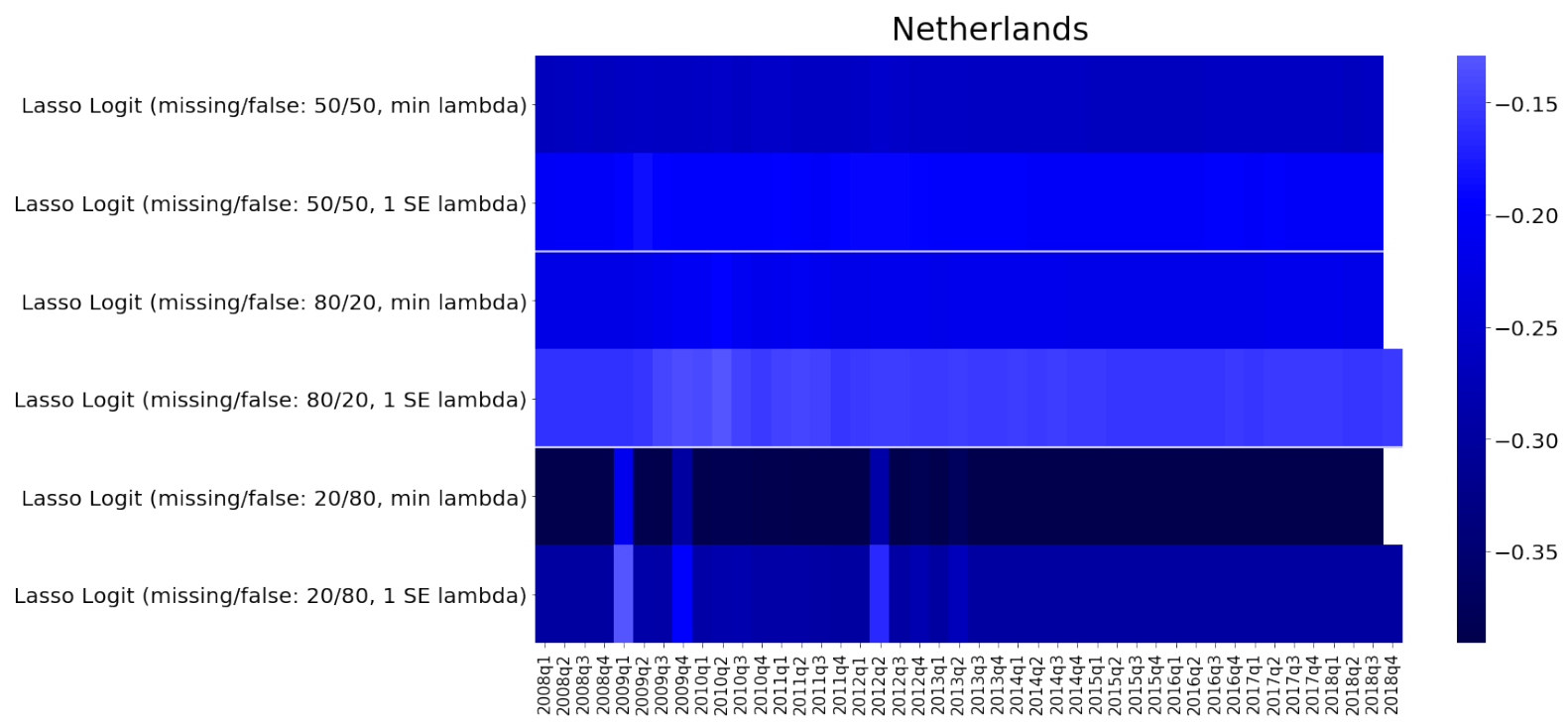

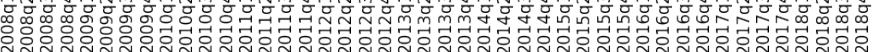

Portugal

Lasso Logit (missing/false: 50/50, min lambda)
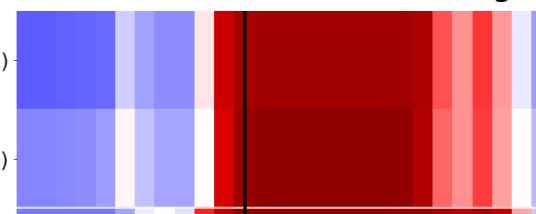

0.75

Lasso Logit (missing/false: 50/50, 1 SE lambda)

Lasso Logit (missing/false: 80/20, min lambda)

)

Lasso Logit (missing/false: 80/20, 1 SE lambda)

Lasso Logit (missing/false: 20/80, min lambda)

Lasso Logit (missing/false: 20/80, 1 SE lambda)
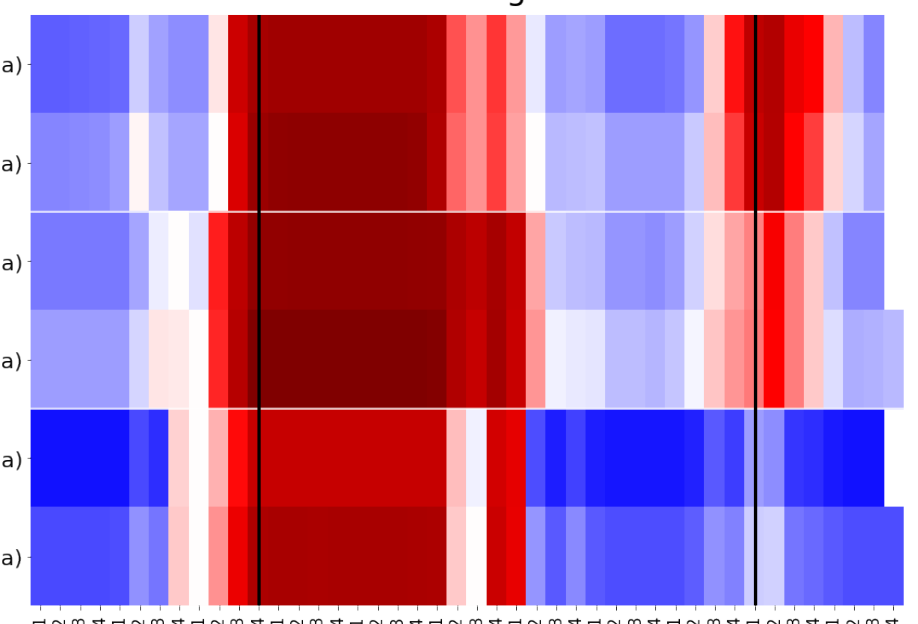

0.50 


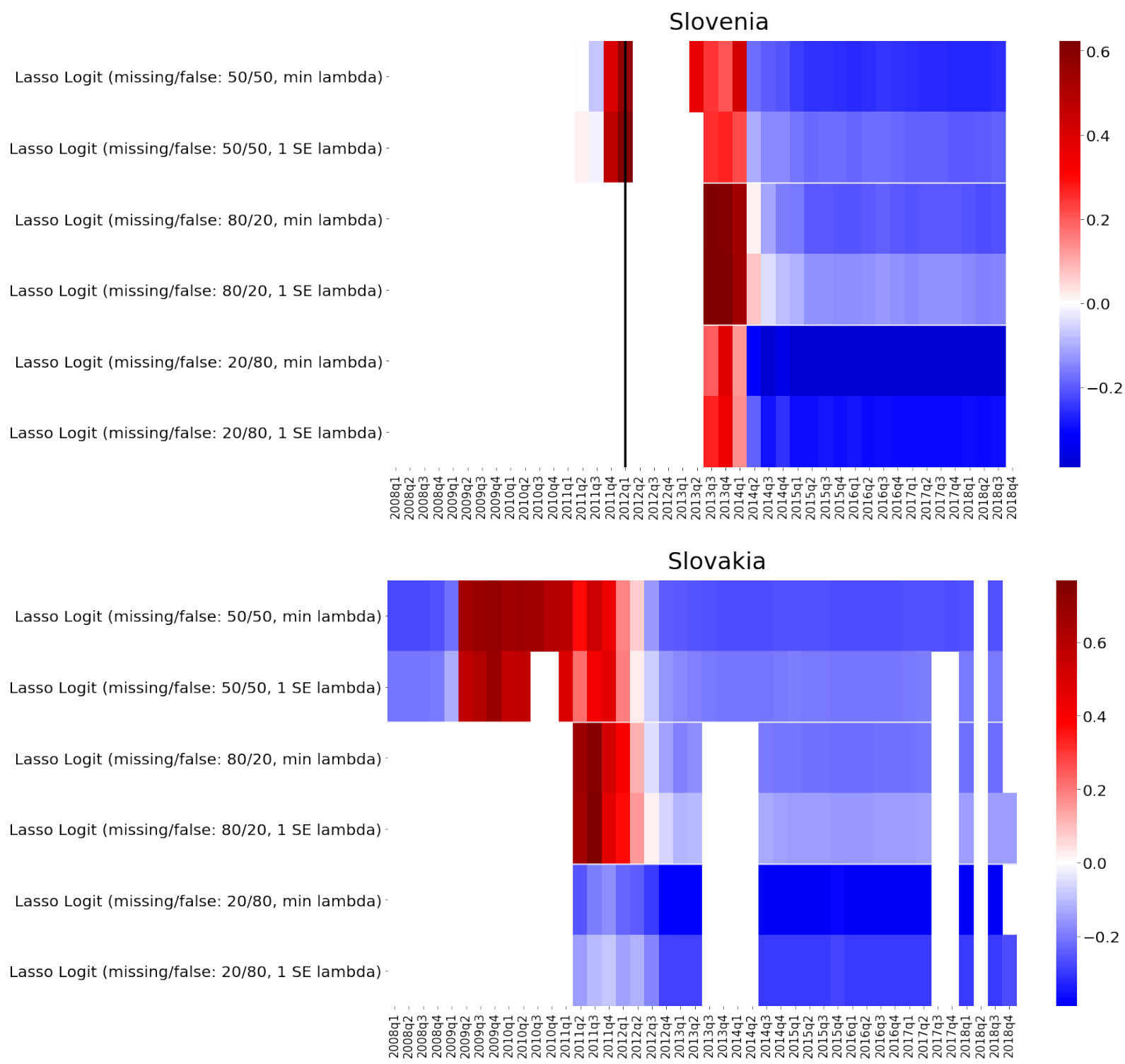

Notes: Lasso logit stands for penalized logistic regression. 


\section{Section B1 - Alternative loss of market access episodes definition}

Figure B1.1: Predicted probability from logistic regression using the smallest market tensions index
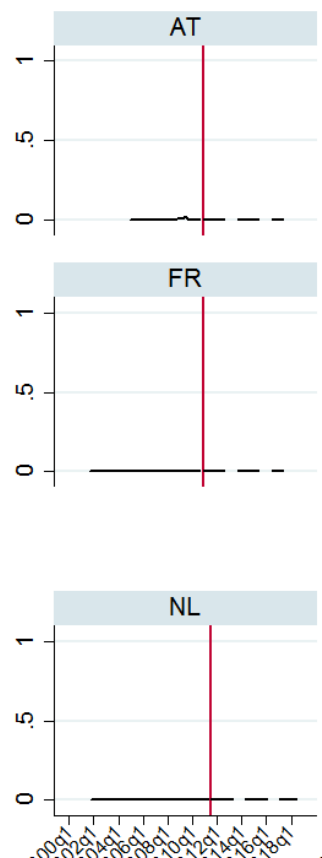

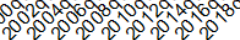
(⿻日禸
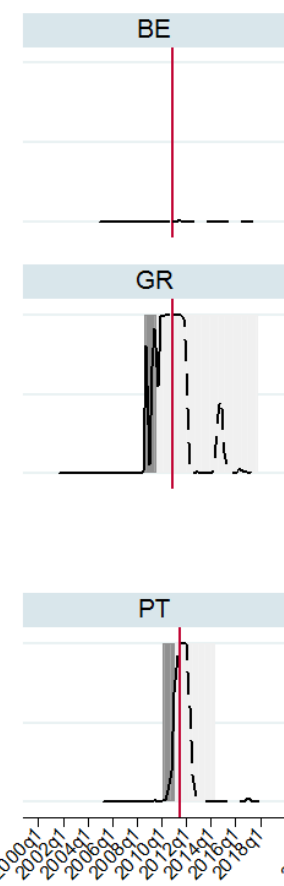

pre-LMA
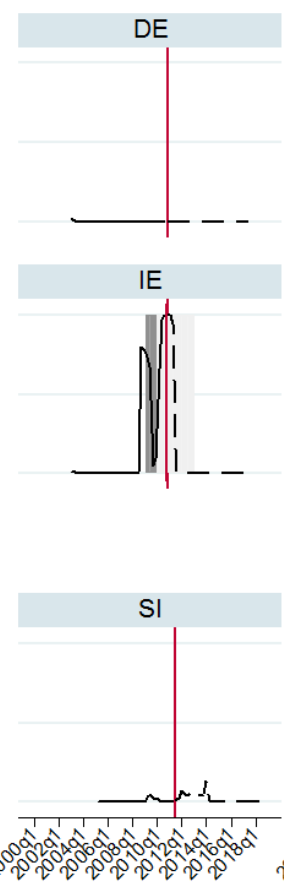

LMA
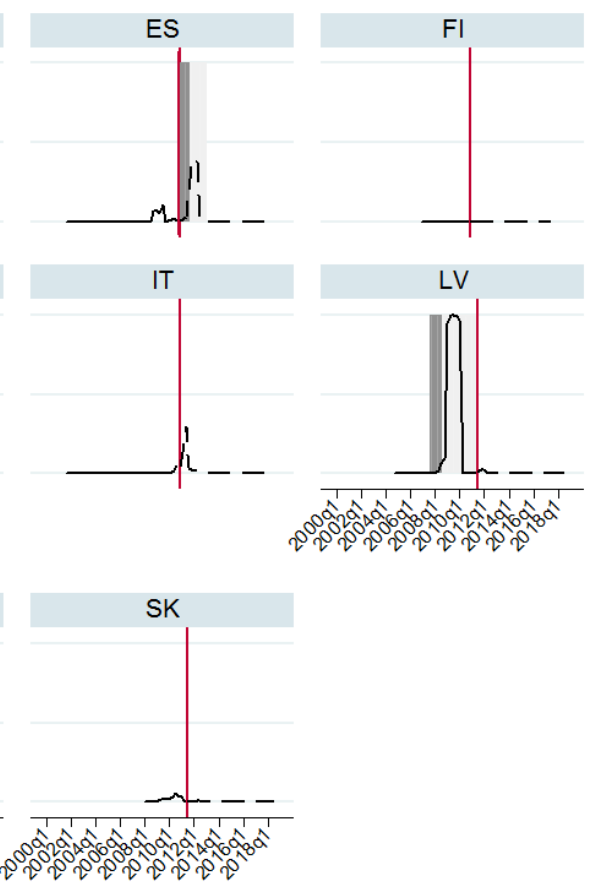

Probability (smallest MTI)

Notes: Probability of market access tensions from logistic regression using the smallest market tensions index. The vertical axis measures the probability of losing market access within up to 4 quarters. LMA shows periods of identified high market access tensions while pre-LMA identifies periods of up to 4 quarters prior to LMA. The red vertical line indicates start of out-of-sample forecast and the dashed line shows out-of-sample forecast probabilities of market access tensions. Country name abbreviations are as follows: $\mathrm{AT}=$ Austria, $\mathrm{BE}=\mathrm{Belgium}, \mathrm{DE}=$ Germany, $\mathrm{ES}=\mathrm{Sp}$ ain, $\mathrm{FI}=$ Finland, $\mathrm{FR}=\mathrm{France}, \mathrm{GR}=\mathrm{Greece}$, IE=Ireland, IT=Italy, LV=Latvia, NL=Netherlands, PT=Portugal, SI=Slovenia, SK=Slovakia. 
Table B1.1: Estimated coefficients from univariate logit with MTI

\begin{tabular}{c|ccc}
\hline & \multicolumn{3}{|c}{ Univariate logit } \\
Large MTI & $12.91^{*}$ & \\
Smaller MTI & $(6.844)$ & \\
& \multicolumn{3}{|c}{$(1.234)$} \\
Smallest MTI & \multicolumn{3}{|c}{$5.406^{* * *}$} \\
Constant & \multicolumn{3}{|c}{$(1.203)$} \\
& $-13.75^{* *}$ & $-6.405^{* * *}$ & $-7.027^{* * *}$ \\
Observations & $(5.677)$ & $(1.337)$ & $(1.604)$ \\
Number of countries & 295 & 328 & 399 \\
Standard errors are in parentheses. *** indicate $1 \%, * * 5 \%$ and * $10 \%$ significance level.
\end{tabular}

\section{Figure B1.2: Predicted probability from logistic regression with backward sequential variable selection}
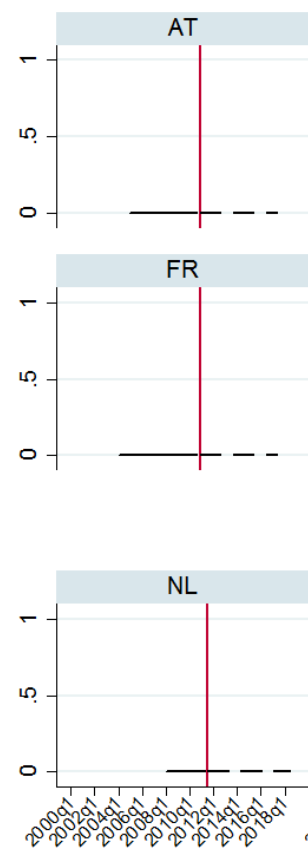
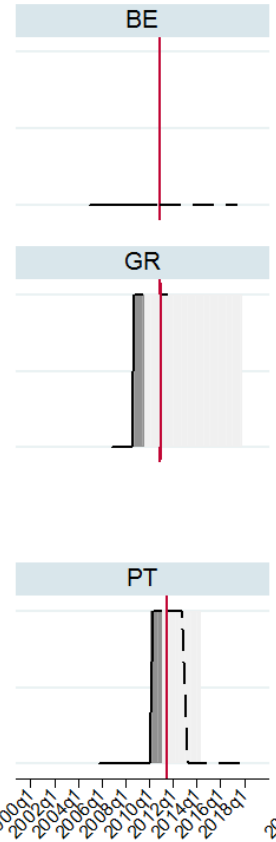

pre-LMA
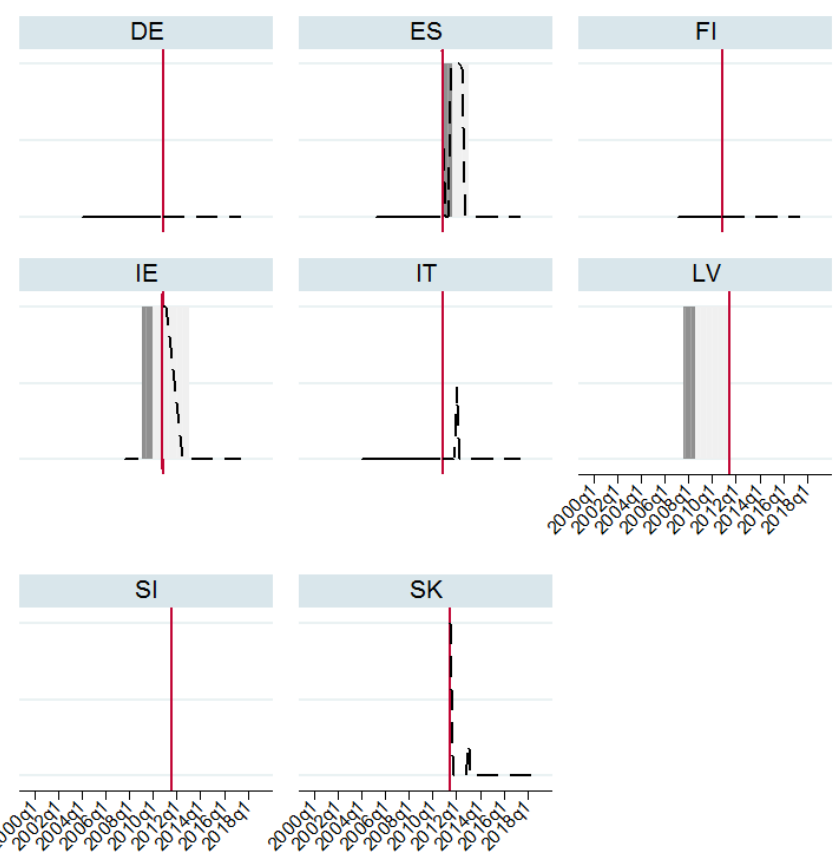

LMA

Notes: Probability of market access tensions from logistic regression with backward sequential variable selection. The vertical axis measures the probability of losing market access within up to 4 quarters. LMA shows periods of identified high market access tensions while pre-LMA identifies periods of up to 4 quarters prior to LMA. The red vertical line indicates start of outof-sample forecast and the dashed line shows out-of-sample forecast probabilities of market access tensions. Country name abbreviations are as follows: $\mathrm{AT}=\mathrm{Austria}, \mathrm{BE}=\mathrm{Belgium}, \mathrm{DE}=\mathrm{Germany}, \mathrm{ES}=\mathrm{Sp}$ ain, $\mathrm{FI}=\mathrm{Finland}, \mathrm{FR}=\mathrm{France}, \mathrm{GR}=\mathrm{Greece}, \mathrm{IE}=\mathrm{Ireland}$, IT=Italy, LV=Latvia, NL=Netherlands, PT=Portugal, SI=Slovenia, SK=Slovakia. 
Figure B1.3: Predicted probability from penalized logistic regression
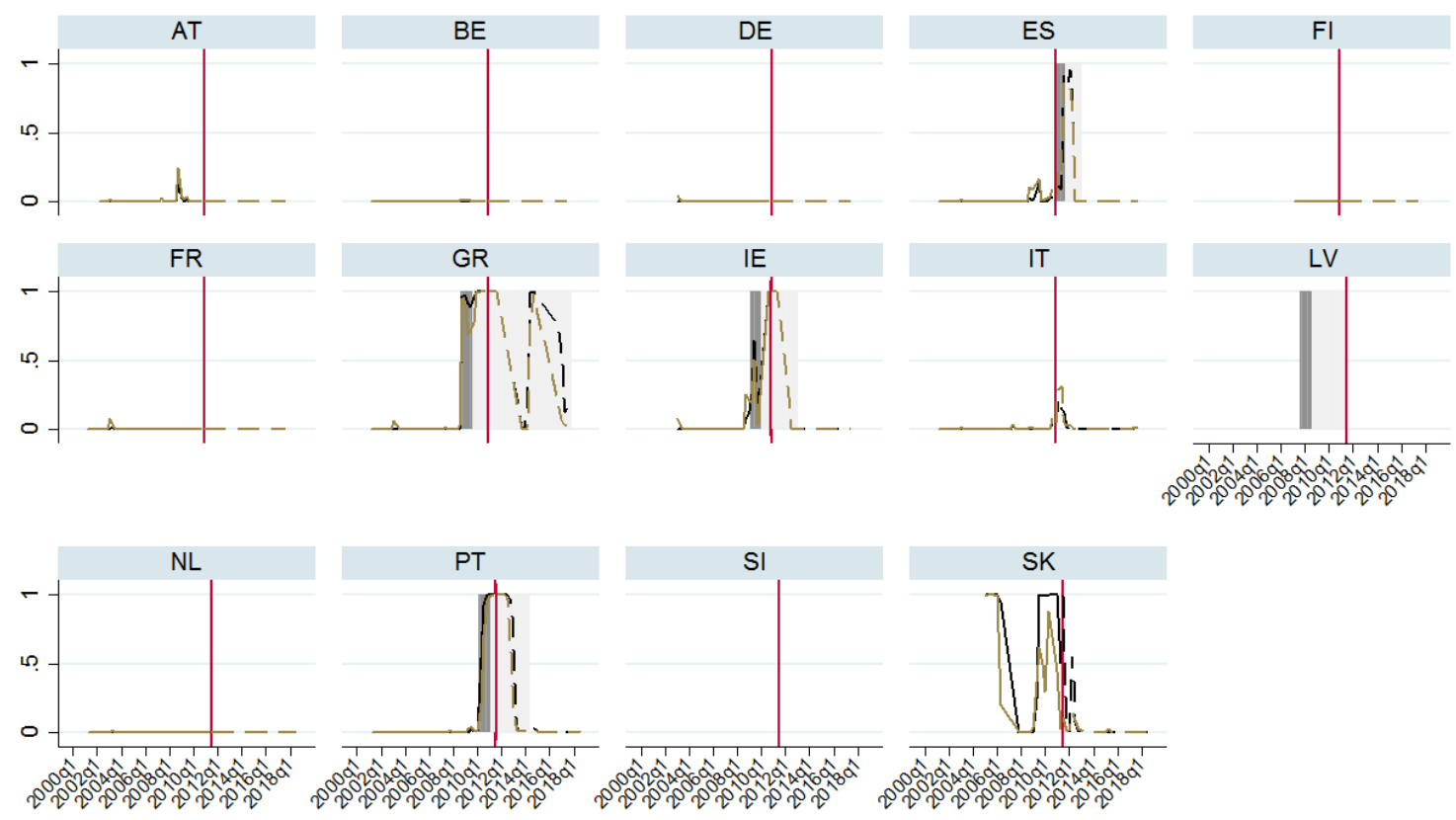

pre-LMA

LMA

Probability (optimal lambda)

Probability (1se lambda)

Notes: Probability of market access tensions from penalized logistic regression with loss-minimizing lambda (black line) and with lambda, for which model error is within one standard error of the minimum (brown line). The vertical axis measures the probability of losing market access within up to 4 quarters. LMA shows periods of identified high market access tensions while pre-LMA identifies periods of up to 4 quarters prior to LMA. The red vertical line indicates start of out-of-sample forecast and the dash line shows out-of-sample forecast probabilities of market access tensions. Country name abbreviations are as follows: $A T=$ Austria, $B E=$ Belgium, $D E=$ Germany, $E S=S p a i n, \quad F I=F i n l a n d, \quad F R=F r a n c e, \quad G R=G r e e c e, I E=I r e l a n d, \quad I T=I t a l y, \quad L V=L a t v i a$, NL=Netherlands, PT=Portugal, SI=Slovenia, SK=Slovakia. 
Figure B1.4: Predicted probability from boosted logistic regression
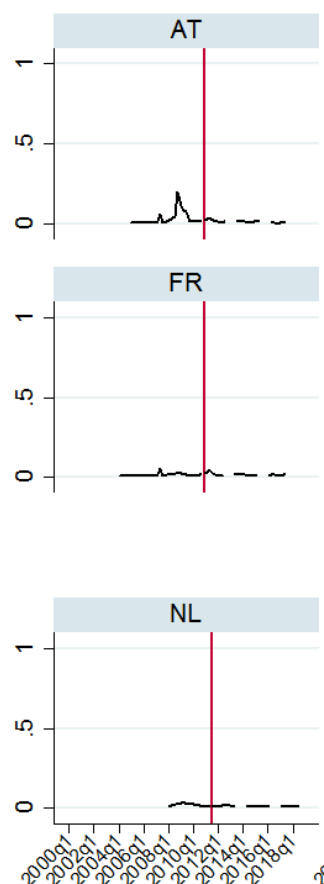
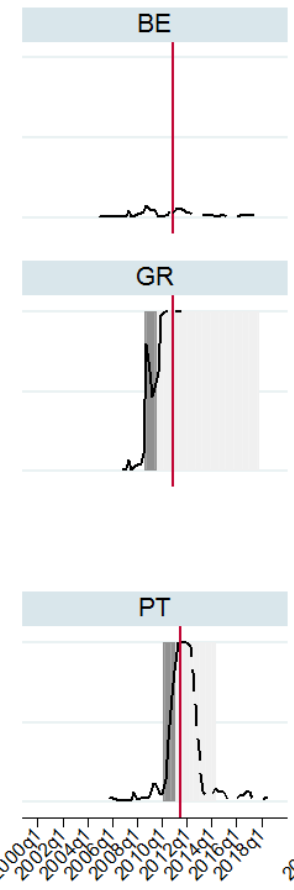

pre-LMA
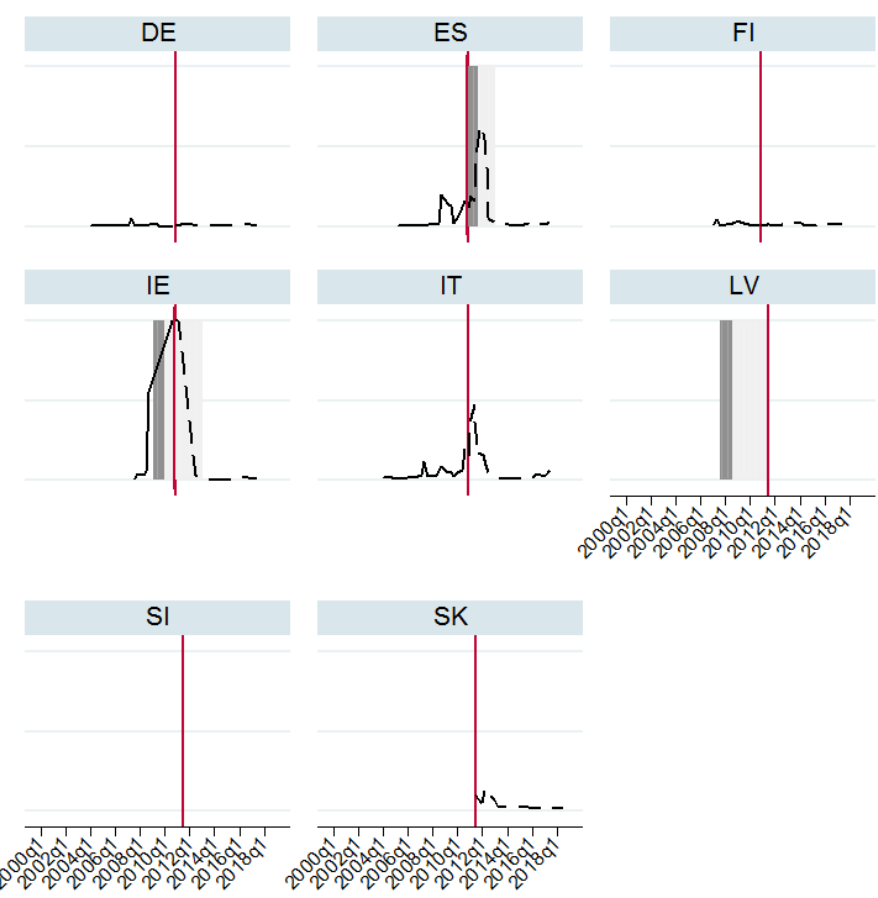

LMA
Probability

Notes: Probability of market access tensions from boosted logistic regression. The vertical axis measures the probability of losing market access within up to 4 quarters. LMA shows periods of identified high market access tensions while pre-LMA identifies periods of up to 4 quarters prior to LMA. The red vertical line indicates start of out-of-sample forecast and the dash line shows out-of-sample forecast probabilities of market access tensions. Country name abbreviations are as follows: $A T=$ Austria, $B E=$ Belgium, $D E=$ Germany, $E S=S p a i n, \quad F I=F i n l a n d, \quad F R=F r a n c e, \quad G R=$ Greece, $I E=I r e l a n d, \quad I T=\mid$ taly, $L V=L a t v i a$, $\mathrm{NL}=$ Netherlands, $\mathrm{PT}=$ Portugal, SI=Slovenia, SK=Slovakia. 
Table B1.1: Selected indicators and their coefficient estimates

\begin{tabular}{|c|c|c|c|c|c|c|c|c|}
\hline & \multicolumn{3}{|c|}{ Logit with Sequential Selection } & \multicolumn{2}{|c|}{ Penalized Logit } & \multicolumn{3}{|c|}{ Boosted Logit } \\
\hline Indicator & Coefficient & \multicolumn{2}{|c|}{ 95\% confidence interval } & Coefficient (lambda min) & Coefficient (lambda 1SE) & Coefficient & \multicolumn{2}{|c|}{$\begin{array}{c}\text { 95\% confidence } \\
\text { interval }\end{array}$} \\
\hline No. of issuances & - & - & - & - & - & _- & _- & - \\
\hline Bills issued & - & - & - & 0.92 & 0.30 & - & - & - \\
\hline Floating coupon issuance & - & - & - & 0.27 & - & - & - & - \\
\hline Syndicated issuance & -7.03 & -208.63 & 194.56 & -0.25 & -0.51 & -0.18 & -0.39 & 0.00 \\
\hline \multicolumn{9}{|l|}{ Secondary market } \\
\hline Bid-ask $2 Y$ & - & - & - & - & - & - & - & - \\
\hline Bid-ask $5 Y$ & -8.03 & -420.01 & 403.96 & -1.59 & -0.17 & - & - & - \\
\hline Bid-ask 10Y & 17.91 & -253.66 & 289.48 & 4.30 & 1.60 & 0.45 & 0.00 & 2.16 \\
\hline Foreign debt & - & - & - & - & - & - & - & - \\
\hline Forward rate & 10.16 & -456.25 & 476.57 & 2.99 & 2.15 & 1.24 & 0.10 & 1.63 \\
\hline Forward premium & - & - & - & - & - & - & - & - \\
\hline \multicolumn{9}{|l|}{$\begin{array}{c}\text { Global demand and } \\
\text { supply }\end{array}$} \\
\hline $\operatorname{CDS}$ & - & - & - & - & - & - & - & - \\
\hline Interest forecast & 19.36 & -1227.14 & 1265.85 & 3.39 & 2.77 & 1.36 & 0.00 & 1.86 \\
\hline $\begin{array}{c}\text { Economic policy } \\
\text { uncertainty }\end{array}$ & - & - & - & - & - & - & - & - \\
\hline US GDP & -7.50 & -596.08 & 581.08 & - & - & - & - & - \\
\hline$V 2 X$ & -10.12 & -926.90 & 906.66 & -1.04 & - & - & - & - \\
\hline Stock market & - & - & - & -0.17 & -0.13 & - & - & - \\
\hline GDP forecast & - & - & - & - & - & - & - & - \\
\hline Debt forecast & - & - & - & - & - & - & - & - \\
\hline Government expenditure & - & - & - & - & - & - & - & - \\
\hline Debt & 10.26 & -1029.40 & 1049.92 & - & - & - & - & - \\
\hline Interest payable & - & - & - & 0.06 & 0.00 & - & - & - \\
\hline Bank index & - & - & - & -3.25 & -2.94 & - & - & - \\
\hline Gross financing needs & - & - & - & - & - & - & - & - \\
\hline Bailouts & - & - & - & - & - & - & - & - \\
\hline Intercept & -11.91 & -563.07 & 539.25 & -4.71 & -4.81 & -3.03 & -3.70 & -2.53 \\
\hline
\end{tabular}

Notes: lambda min denotes loss-minimizing lambda and lambda $1 \mathrm{SE}$ indicates lambda, for which model error is within one standard error of the minimum. 
Figure B1.5: Predicted probability from Bayesian Model Averaging
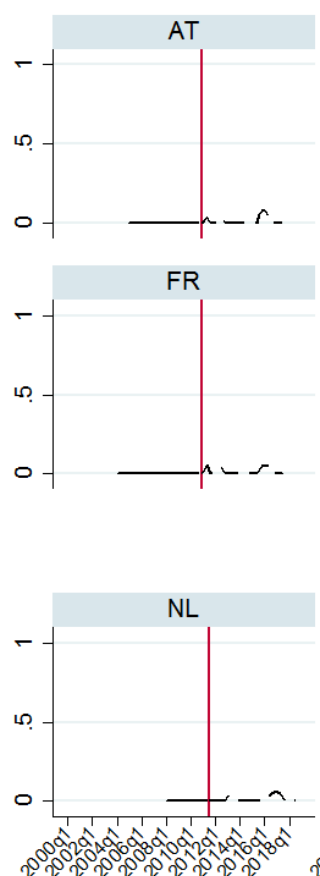
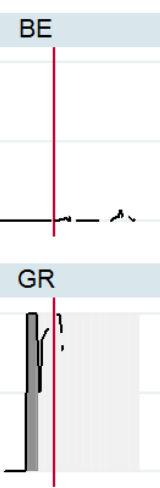

PT

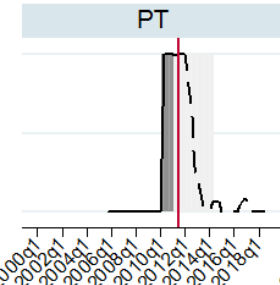

pre-LMA
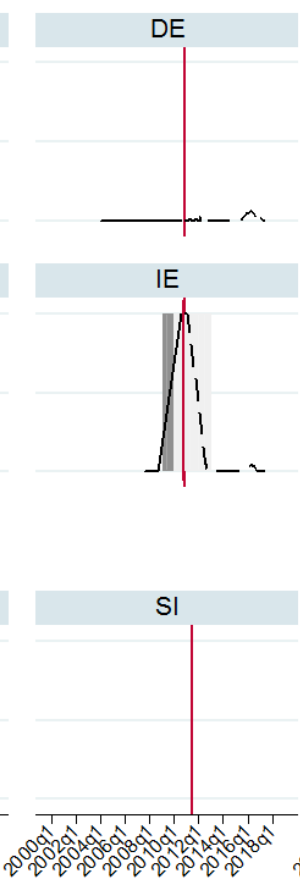

LMA
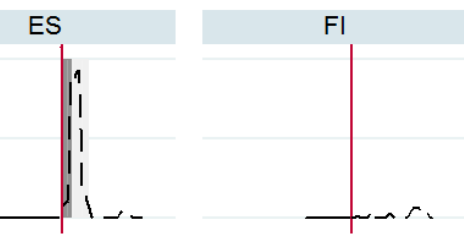

IT
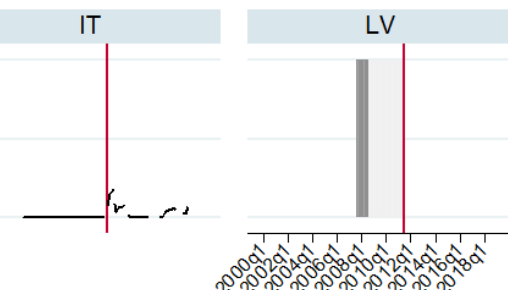

Notes: Probability of market access tensions from Bayesian Model Averaging with logistic regressions. The vertical axis measures the probability of losing market access within up to 4 quarters. LMA shows periods of identified high market access tensions while pre-LMA identifies periods of up to 4 quarters prior to LMA. The red vertical line indicates start of out-of-sample forecast and the dash line shows out-of-sample forecast probabilities of market access tensions. Country name abbreviations are as follows: $A T=$ Austria, $B E=$ Belgium, $D E=G$ ermany, $E S=S p a i n, F I=F i n l a n d, F R=F r a n c e, G R=G r e e c e, I E=|r e l a n d, I T=| t a l y$, $\mathrm{LV}=$ Latvia, $\mathrm{NL}=$ Netherlands, $\mathrm{PT}=$ Portugal, $\mathrm{SI}=$ Slovenia, $\mathrm{SK}=\mathrm{Slovakia}$. 


\section{Figure B1.6: Top 20 models from Bayesian Model Averaging}

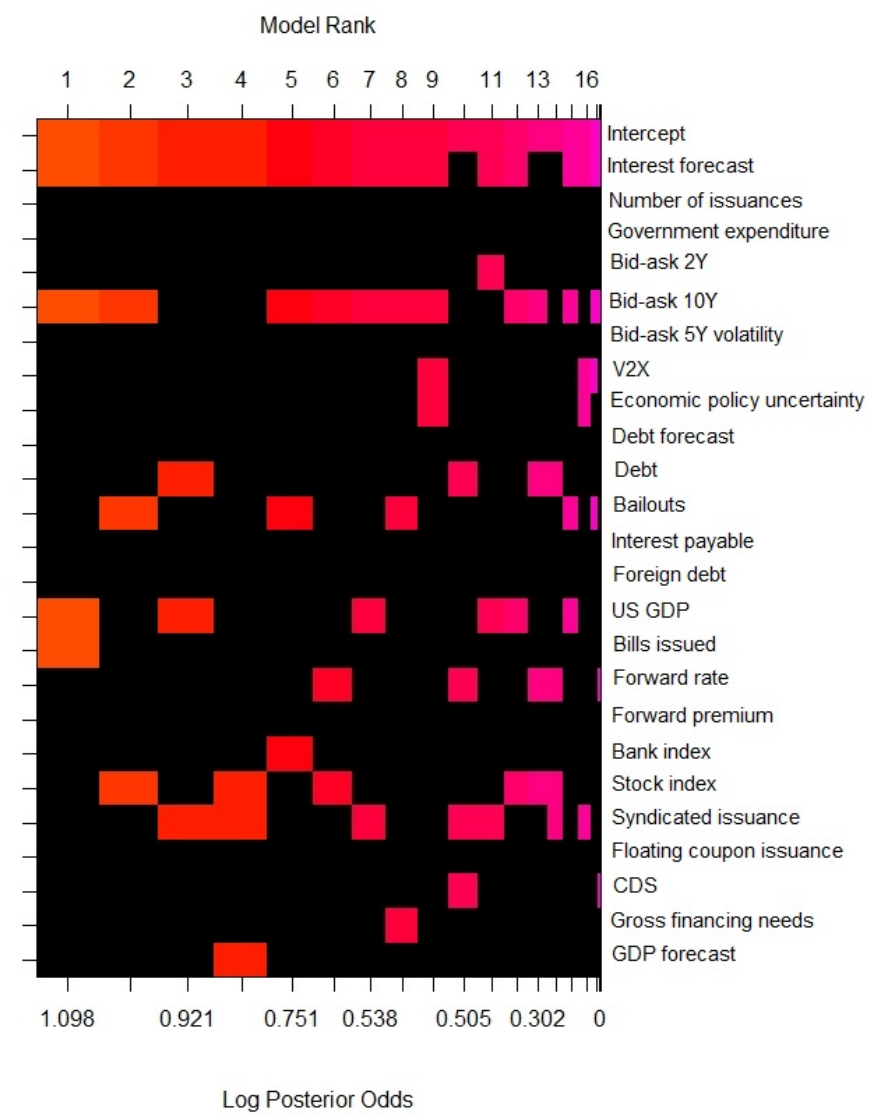

Notes: Top 20 models from Bayesian Model Averaging ranked (top x-axis) by their posterior model probability from the best (left) to worst (right). Rows correspond to top indicators while columns represent individual models. In each model, missing variables are in black, while included variables are coloured. The colour corresponds to the log of the posterior probability of that model. Posterior probabilities are scaled so that the worst model in the top 20 models is assigned 0 . Models with the same colours have similar log Bayes factors, i.e. the difference in their Bayes factors is not worth a mention. 
Table B1.2. Predicted probabilities in periods of up to 4 quarters

\begin{tabular}{|c|c|c|c|c|c|c|c|c|c|c|}
\hline & & & \multicolumn{3}{|c|}{ Logit w/Market tensions index } & \multicolumn{3}{|c|}{ Penalized logit } & \multirow[b]{2}{*}{$\begin{array}{c}\text { Boosted } \\
\text { logit }\end{array}$} & \multirow[b]{2}{*}{ BMA } \\
\hline & & & $\begin{array}{l}\text { Large } \\
\text { index }\end{array}$ & $\begin{array}{l}\text { Smaller } \\
\text { index }\end{array}$ & $\begin{array}{l}\text { Smallest } \\
\text { index }\end{array}$ & $\begin{array}{l}\text { Logit w/ } \\
\text { sequential } \\
\text { selection }\end{array}$ & $\begin{array}{l}\text { Optimal } \\
\text { lambda }\end{array}$ & $\begin{array}{c}1 \mathrm{SE} \\
\text { lambda }\end{array}$ & & \\
\hline \multirow{4}{*}{ Spain } & \multirow{12}{*}{$\begin{array}{l}\text { Quarters } \\
\text { before LMA } \\
\text { episodes }\end{array}$} & -4 & 0.000 & 0.018 & 0.011 & 0.664 & 0.109 & 0.049 & 0.119 & 0.081 \\
\hline & & -3 & 0.000 & 0.028 & 0.018 & 0.000 & 0.111 & 0.218 & 0.196 & 0.098 \\
\hline & & -2 & 0.000 & 0.048 & 0.030 & 0.000 & 0.086 & 0.183 & 0.156 & 0.110 \\
\hline & & -1 & 0.009 & 0.249 & 0.171 & 1.000 & 0.918 & 0.862 & 0.499 & 0.878 \\
\hline \multirow{4}{*}{ Greece } & & -4 & 0.653 & 0.845 & 0.803 & 1.000 & 0.970 & 0.955 & 0.798 & 1.000 \\
\hline & & -3 & 0.001 & 0.089 & 0.058 & 1.000 & 0.970 & 0.883 & 0.630 & 1.000 \\
\hline & & -2 & 0.654 & 0.769 & 0.671 & 1.000 & 0.915 & 0.689 & 0.462 & 1.000 \\
\hline & & -1 & 0.970 & 0.938 & 0.909 & 1.000 & 0.887 & 0.716 & 0.523 & 1.000 \\
\hline \multirow{4}{*}{ Ireland } & & -4 & & 0.811 & 0.734 & & 0.255 & 0.194 & & \\
\hline & & -3 & & 0.765 & 0.673 & & 0.643 & 0.510 & & \\
\hline & & -2 & & 0.084 & 0.051 & & 0.095 & 0.038 & & \\
\hline & & -1 & & 0.146 & 0.095 & & & & & \\
\hline \multirow{4}{*}{ Latvia } & & -4 & & & 0.003 & & & & & \\
\hline & & -3 & & & 0.000 & & & & & \\
\hline & & -2 & & & 0.017 & & & & & \\
\hline & & -1 & & & 0.063 & & & & & \\
\hline \multirow{4}{*}{ Portugal } & & -4 & 0.000 & 0.017 & 0.009 & 1.000 & 0.543 & 0.212 & 0.145 & 1.000 \\
\hline & & -3 & 0.002 & 0.104 & 0.070 & 1.000 & 0.926 & 0.706 & 0.391 & 1.000 \\
\hline & & -2 & 0.013 & 0.249 & 0.197 & 1.000 & 0.999 & 0.957 & 0.666 & 1.000 \\
\hline & & -1 & 0.312 & 0.732 & 0.692 & 1.000 & 1.000 & 0.985 & 0.817 & 1.000 \\
\hline
\end{tabular}




\section{Section B2 - Excluding forward rate, forward premium and CDS}

Figure B2.1: Predicted probability from logistic regression using the smallest market tensions index
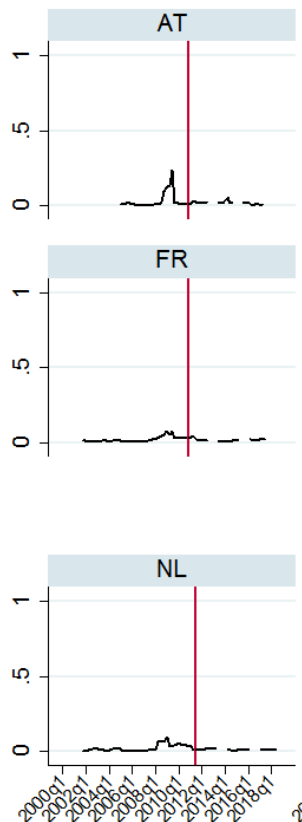
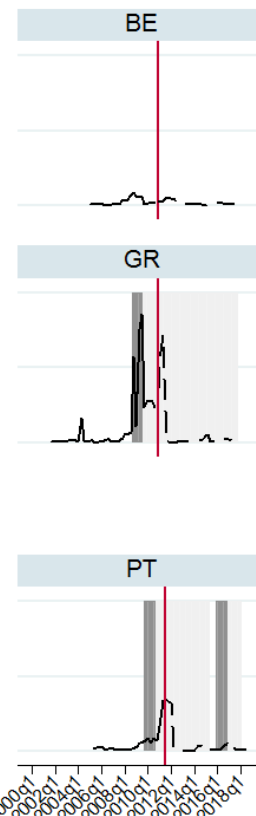

pre-LMA
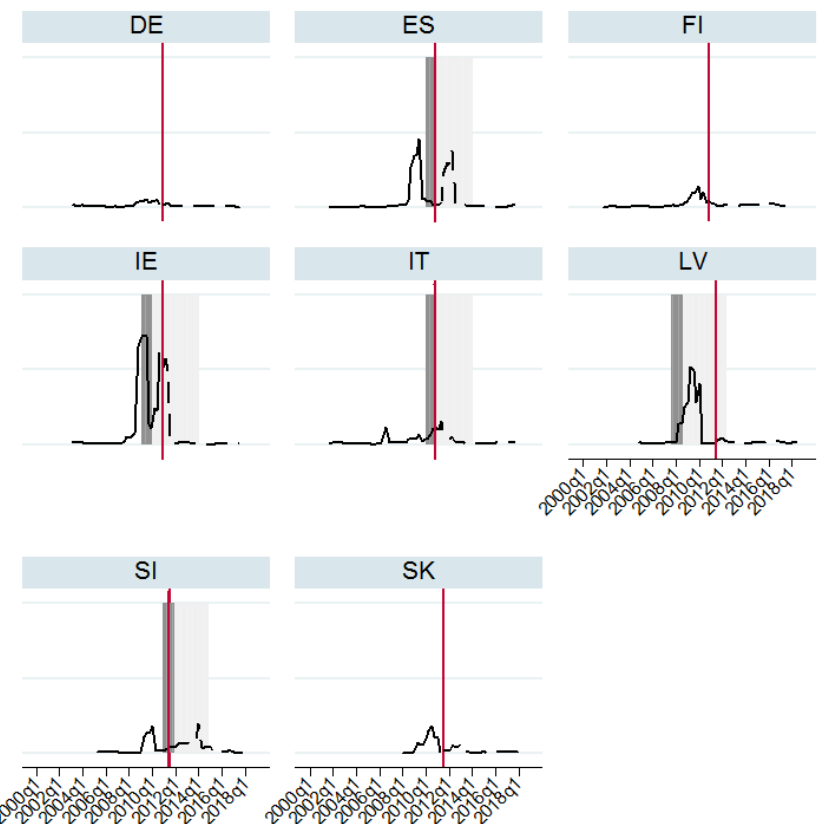

LMA

Notes: Probability of market access tensions from logistic regression using the small alternative market tensions index. The vertical axis measures the probability of losing market access within up to 4 quarters. LMA shows periods of identified high market access tensions while pre-LMA identifies periods of up to 4 quarters prior to LMA. The red vertical line indicates start of out-of-sample forecast and the dash line shows out-of-sample forecast probabilities of market access tension. Country name abbreviations are as follows: $A T=$ Austria, $B E=B e l g i u m, D E=G e r m a n y, E S=S p a i n, F I=F i n l a n d, F R=F r a n c e, G R=G r e e c e$, $\mathrm{IE}=$ Ireland, IT=Italy, LV=Latvia, NL=Netherlands, PT=Portugal, SI=Slovenia, SK=Slovakia. 
Table B2.1: Estimated coefficients from univariate logit with alternative MTI

\begin{tabular}{|c|c|c|}
\hline \multicolumn{3}{|l|}{ VARIABLES } \\
\hline \multirow{3}{*}{ Large alternative $\mathrm{MTI}$} & \multicolumn{2}{|c|}{ Univariate logit } \\
\hline & \multicolumn{2}{|l|}{$4.689 * * *$} \\
\hline & \multicolumn{2}{|l|}{$(1.036)$} \\
\hline \multirow[t]{2}{*}{ Smallest alternative $\mathrm{MTI}$} & & $2.519 * * *$ \\
\hline & & $(0.450)$ \\
\hline \multirow[t]{2}{*}{ Constant } & $-5.278 * * *$ & $-4.277 * * *$ \\
\hline & $(1.183)$ & $(0.675)$ \\
\hline Observations & 339 & 419 \\
\hline Number of countries & 12 & 14 \\
\hline
\end{tabular}

Figure B2.2: Predicted probability from logistic regression with backward sequential variable selection
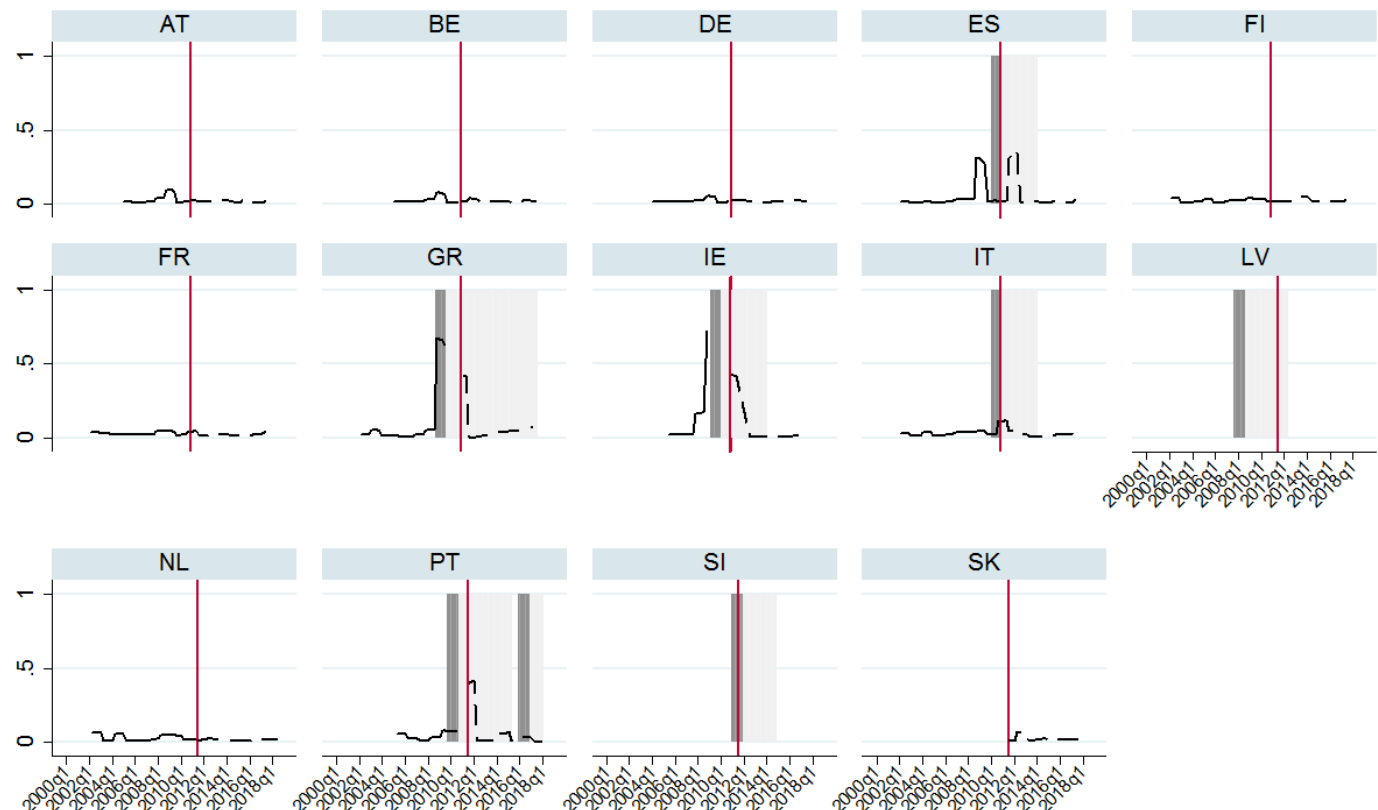

pre-LMA

LMA

Probability

Notes: Probability of market access tensions from logistic regression with backward sequential variable selection. The vertical axis measures the probability of losing market access within up to 4 quarters. LMA shows periods of identified high market access tensions while pre-LMA identifies periods of up to 4 quarters prior to LMA. The red vertical line indicates start of outof-sample forecast and the dash line shows out-of-sample forecast probabilities of market access tensions. Country name abbreviations are as follows: $\mathrm{AT}=$ Austria, $\mathrm{BE}=\mathrm{Belgium}, \mathrm{DE}=$ Germany, $\mathrm{ES}=\mathrm{Sp}$ ain, $\mathrm{FI}=$ Finland, $\mathrm{FR}=\mathrm{France}, \mathrm{GR}=\mathrm{Greece}$, IE=Ireland, IT=Italy, LV=Latvia, NL=Netherlands, PT=Portugal, SI=Slovenia, SK=Slovakia. 
Figure B2.3: Predicted probability from penalized logistic regression
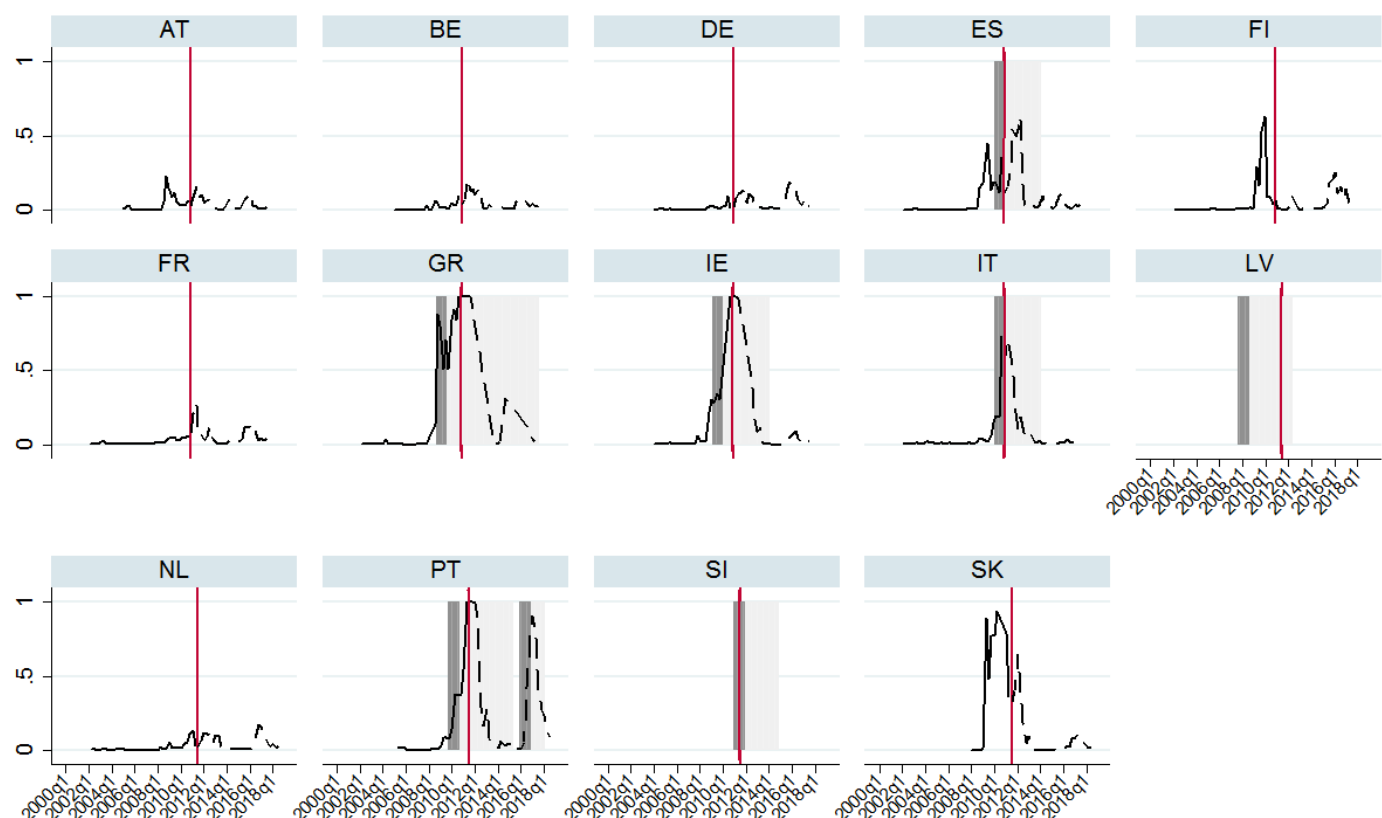

pre-LMA

LMA

Probability (min lambda)

Notes: Probability of market access tensions from penalized logistic regression with loss-minimizing lambda. The vertical axis measures the probability of losing market access within up to 4 quarters. LMA shows periods of identified high market access tensions while pre-LMA identifies periods of up to 4 quarters prior to LMA. The red vertical line indicates start of out-of-sample forecast and the dash line shows out-of-sample forecast probabilities of market access tensions. Country name abbreviations are as follows: $\mathrm{AT}=$ Austria, $\mathrm{BE}=$ Belgium, $\mathrm{DE}=$ Germany, $\mathrm{ES}=\mathrm{Spain}, \mathrm{FI}=$ Finland, $\mathrm{FR}=$ France, $\mathrm{GR}=$ Greece, $\mathrm{IE}=\mid \mathrm{rreland}, \mathrm{IT}=\mathrm{Italy}$, $\mathrm{LV}=$ Latvia, NL=Netherlands, $\mathrm{PT}=$ Portugal, $\mathrm{SI}=$ Slovenia, SK=Slovakia. 
Figure B2.4: Predicted probability from boosted logistic regression
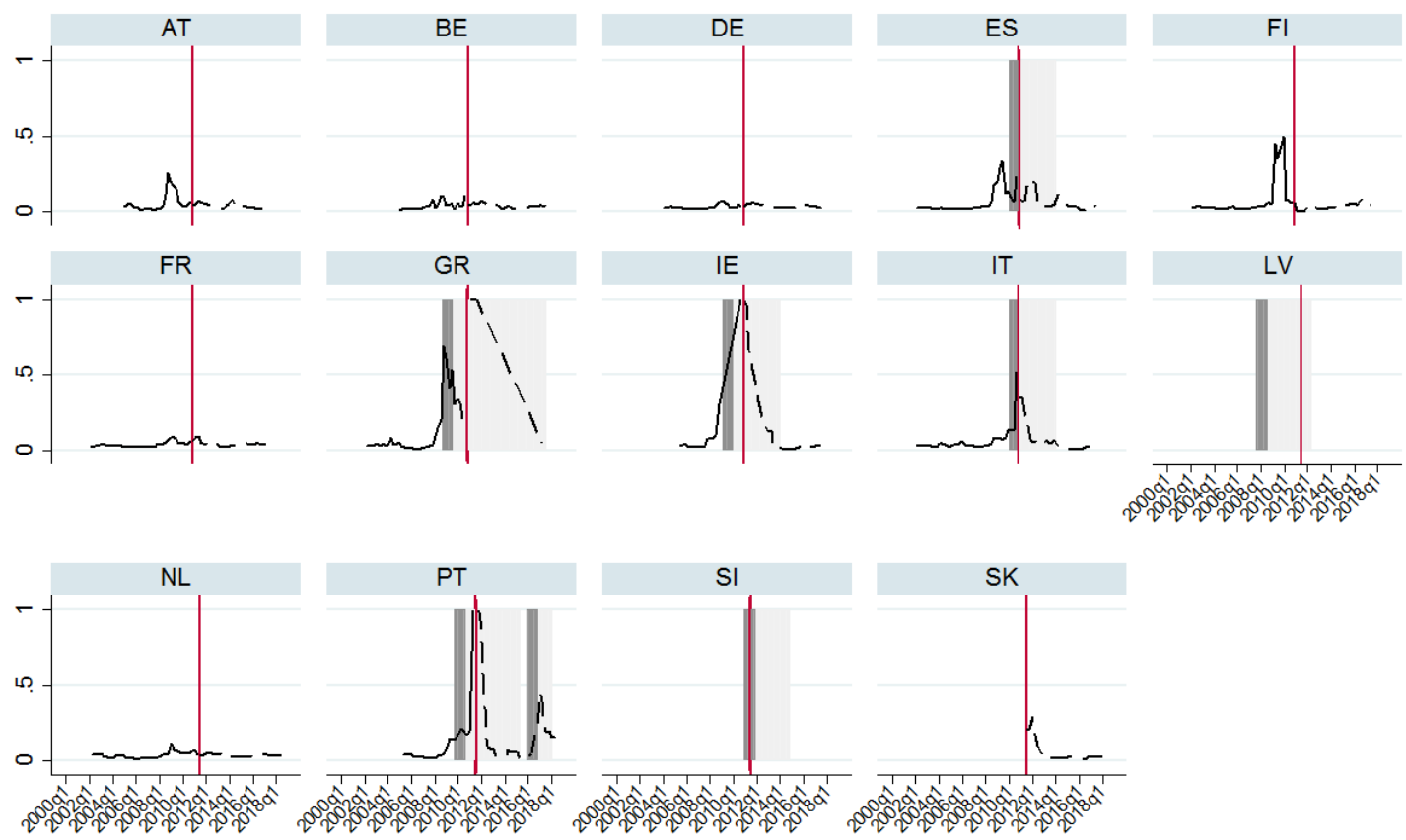

pre-LMA

LMA

Probability

Notes: Probability of market access tensions from boosted logistic regression. The vertical axis measures the probability of losing market access within up to 4 quarters. LMA shows periods of identified high market access tensions while pre-LMA identifies periods of up to 4 quarters prior to LMA. The red vertical line indicates start of out-of-sample forecast and the dash line shows out-of-sample forecast probabilities of market access tensions. Country name abbreviations are as follows: $A T=$ Austria, $B E=$ Belgium, $D E=$ Germany, $E S=S p a i n, \quad F I=F i n l a n d, F R=F r a n c e, ~ G R=G r e e c e, I E=I r e l a n d, I T=\mid$ taly, $L V=L a t v i a$, $\mathrm{NL}=$ Netherlands, $\mathrm{PT}=$ Portugal, SI=Slovenia, SK=Slovakia 
Table B2.1: Selected indicators and their coefficient estimates

\begin{tabular}{|c|c|c|c|c|c|c|c|c|}
\hline \multirow[b]{2}{*}{$\begin{array}{c}\text { Indicator } \\
\text { Primary market }\end{array}$} & \multicolumn{3}{|c|}{ Logit with Sequential Selection } & \multicolumn{2}{|c|}{ Penalized Logit } & \multicolumn{3}{|c|}{ Boosted Logit } \\
\hline & Coefficient & \multicolumn{2}{|c|}{ 95\% confidence interval } & Coefficient (lambda min) & Coefficient (lambda 1SE) & Coefficient & \multicolumn{2}{|c|}{ 95\% confidence interval } \\
\hline No. of issuances & - & - & - & - & - & - & - & - \\
\hline Bills issued & - & - & - & 0.35 & - & 0.07 & 0.00 & 0.20 \\
\hline Floating coupon issuance & - & - & - & 0.70 & - & 0.56 & 0.00 & 1.41 \\
\hline Syndicated issuance & - & - & - & - & - & - & - & - \\
\hline \multicolumn{9}{|l|}{ Secondary market } \\
\hline Bid-ask $2 Y$ & - & - & - & - & - & - & - & - \\
\hline Bid-ask $5 Y$ & - & - & - & 0.47 & - & 0.37 & 0.00 & 1.13 \\
\hline Bid-ask $10 Y$ & - & - & - & 0.79 & - & 0.43 & 0.00 & 2.33 \\
\hline Foreign debt & - & - & - & 0.59 & - & 0.21 & 0.00 & 0.46 \\
\hline Forward rate & - & - & - & - & - & - & - & - \\
\hline Forward premium & - & - & - & - & - & - & - & - \\
\hline \multicolumn{9}{|l|}{$\begin{array}{c}\text { Global demand and } \\
\text { supply }\end{array}$} \\
\hline CDS & - & - & - & - & - & - & - & - \\
\hline Interest forecast & 2.08 & 1.14 & 3.02 & 1.55 & - & 0.91 & 0.00 & 1.70 \\
\hline $\begin{array}{c}\text { Economic policy } \\
\text { uncertainty }\end{array}$ & - & - & - & 0.96 & - & 0.10 & 0.00 & 0.35 \\
\hline US GDP & - & - & - & - & - & - & - & - \\
\hline$V 2 X$ & - & - & - & -0.63 & - & - & - & - \\
\hline Stock market & - & - & - & - & - & - & - & - \\
\hline GDP forecast & - & - & - & - & - & - & - & - \\
\hline Debt forecast & - & - & - & - & - & - & - & - \\
\hline Government expenditure & - & - & - & - & - & - & - & - \\
\hline Debt & - & - & - & 0.22 & - & 0.14 & 0.00 & 0.39 \\
\hline Interest payable & - & - & - & 0.01 & - & - & - & - \\
\hline Bank index & 0.67 & -5.23 & 6.57 & 0.40 & & - & - & - \\
\hline Gross financing needs & - & - & - & 0.03 & - & 0.05 & 0.00 & 0.27 \\
\hline Bailouts & - & - & - & - & - & - & - & - \\
\hline Intercept & -2.74 & -3.35 & -2.13 & -2.58 & -3.09 & -2.35 & -3.77 & -1.88 \\
\hline
\end{tabular}

Notes: lambda min denotes loss-minimizing lambda and lambda 1 SE indicates lambda, for which model error is within one standard error of the minimum. 
Figure B2.5: Predicted probability from Bayesian Model Averaging
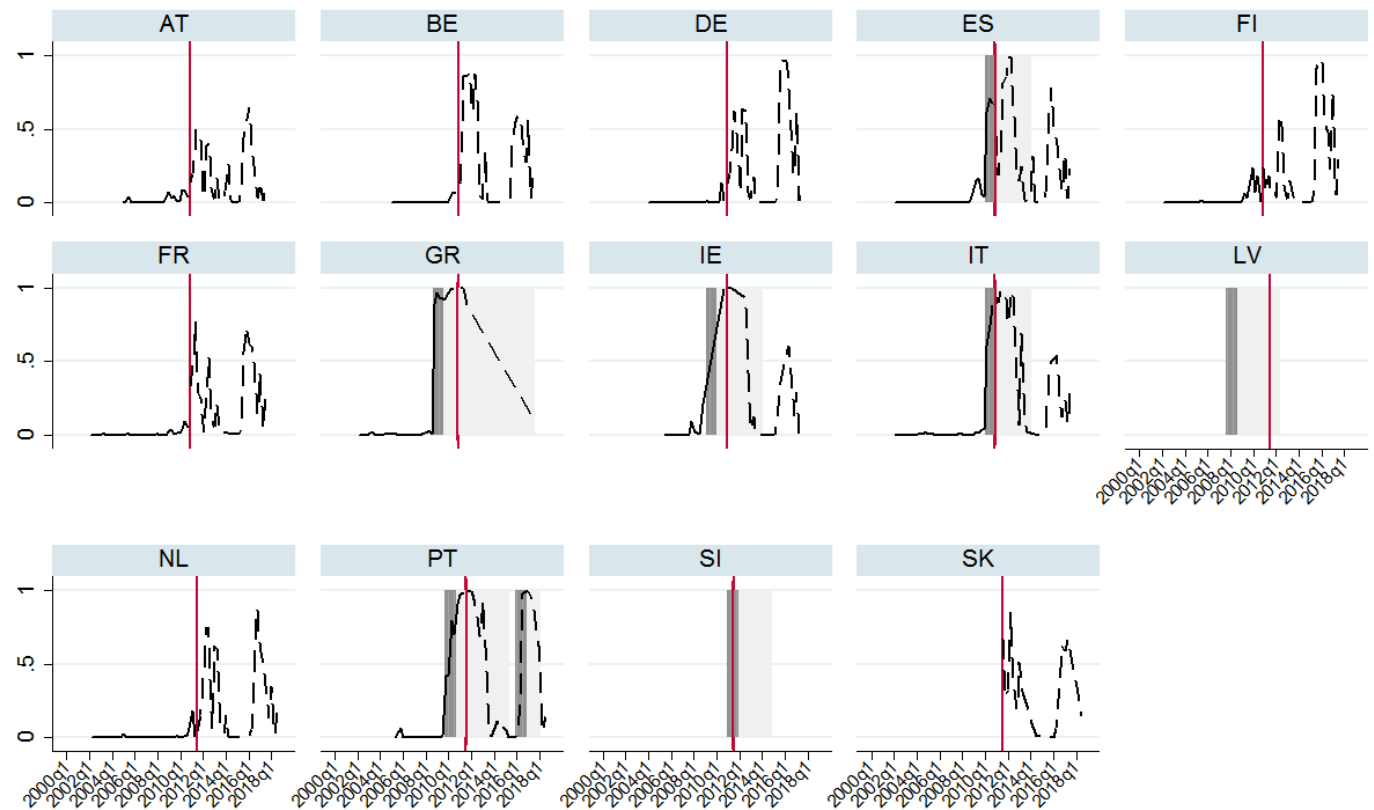

pre-LMA

LMA

Probability

Notes: Probability of market access tensions from Bayesian Model Averaging with logistic regressions. The vertical axis measures the probability of losing market access within up to 4 quarters. LMA shows periods of identified high market access tensions while pre-LMA identifies periods of up to 4 quarters prior to LMA. The red vertical line indicates start of out-of-sample forecast and the dash line shows out-of-sample forecast probabilities of market access tensions. Country name abbreviations are as follows: $\mathrm{AT}=$ Austria, $\mathrm{BE}=$ Belgium, $\mathrm{DE}=$ Germany, $\mathrm{ES}=$ Spain, $\mathrm{Fl}=$ Finland, $\mathrm{FR}=$ France, $\mathrm{GR}=$ Greece, $\mathrm{IE}=|\mathrm{rreland}, \mathrm{IT}=| \mathrm{Italy}$, $\mathrm{LV}=$ Latvia, NL=Netherlands, PT=Portugal, SI=Slovenia, SK=Slovakia. 


\section{Figure B2.6: Top 20 models from Bayesian Model Averaging}

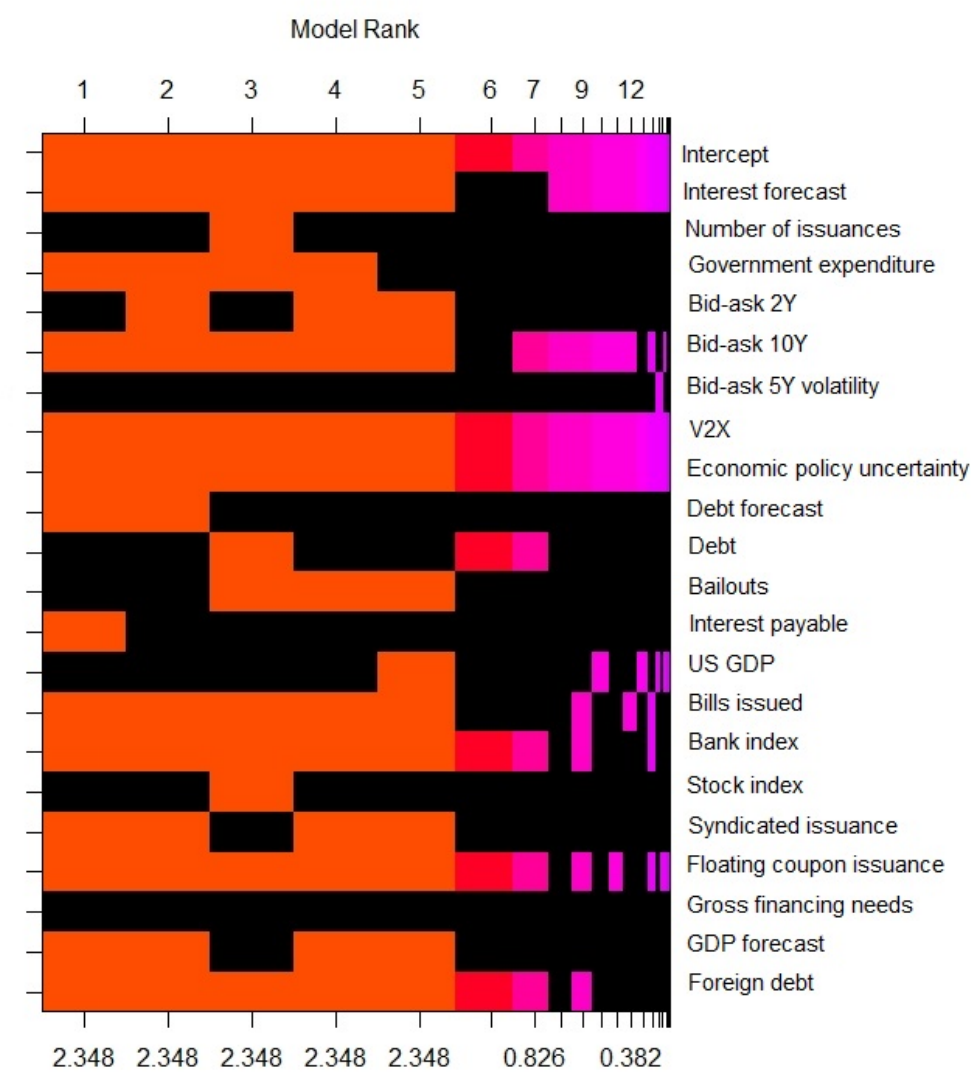

Log Posterior Odds

Notes: Top 20 models from Bayesian Model Averaging ranked (top x-axis) by their posterior model probability from the best (left) to worst (right). Rows correspond to top indicators while columns represent individual models. In each model, missing variables are in black, while included variables are coloured. The colour corresponds to the log of the posterior probability of that model. Posterior probabilities are scaled so that the worst model in the top 20 models is assigned 0 . Models with the same colours have similar log Bayes factors, i.e. the difference in their Bayes factors is not worth a mention. 
Table B2.2. Predicted probabilities in periods of up to 4 quarters

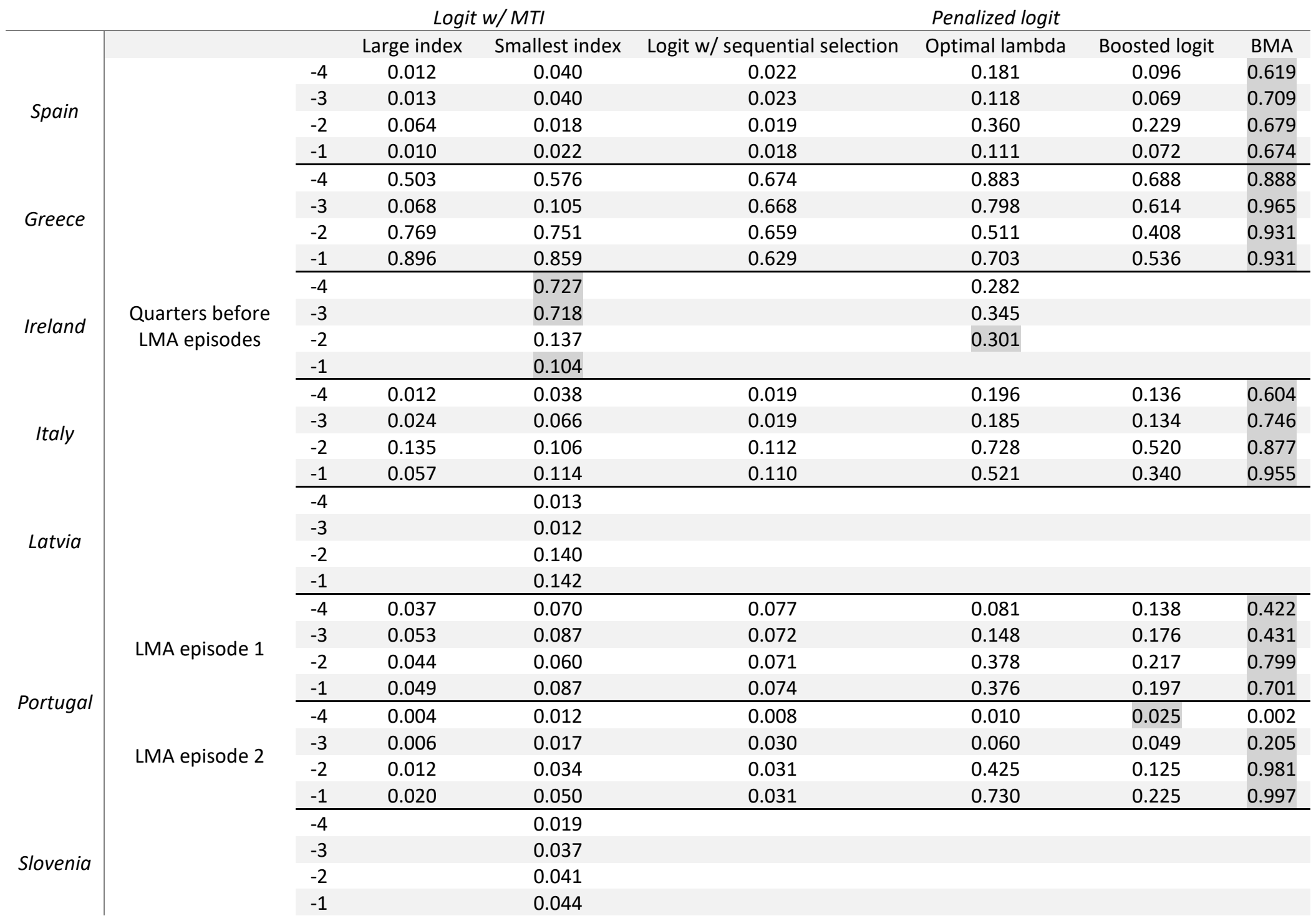


